\title{
EXPRESSION OF HOXB4 IN ENDOMETRIAL TISSUES FROM WOMEN WITH OR WITHOUT ENDOMETRIOSIS
}

\author{
by \\ Ghadeer M AlKusayer \\ MBBS, University of Sharjah, UAE, 2010 \\ A THESIS SUBMITTED IN PARTIAL FULFILLMENT OF \\ THE REQUIREMENTS FOR THE DEGREE OF
}

MASTER OF SCIENCE

in

THE FACULTY OF GRADUATE AND POSTDOCTORAL STUDIES

(REPRODUCTIVE AND DEVELOPMENTAL SCIENCES)

THE UNIVERSITY OF BRITISH COLUMBIA

(Vancouver)

November 2015

(C) Ghadeer M AlKusayer, 2015 


\section{Abstract}

Endometriosis is a benign gynecological disease that affects up to $10 \%$ of women of reproductive age; however, the pathogenesis of endometriosis remains poorly understood. HOX genes encode transcription factors that play roles in regulating cell proliferation, differentiation, angiogenesis, adhesion and motility in adult tissues - key features of endometrioid tissues. The aim of this study was to examine the localization of HOXB4, via immunohistochemistry (IHC), in both eutopic (EE) and ectopic endometrial tissues (deep infiltrating endometriosis (DIE) and endometriomas (Eoma)) from women with endometriosis and compare it to endometrial tissue from women with no history of endometriosis (EC). The localization of HOXB4 in these tissues was determined via immunohistochemistry (IHC) with a monoclonal HOXB4 antibody, where immunoreactivity was assessed by the Histoscore (H-Score) method.

HOXB4 protein was present in the endometrial glandular epithelial cells only. HOXB4 immunoreactivity in EC was significantly higher in the proliferative phase than in the secretory phase of the menstrual cycle; however, this difference was lost among the diseased groups (EE, Eoma and DIE). Interestingly, HOXB4 expression was significantly lower in the DIE lesions compared to matched eutopic endometrium and endometrioma /DIE lesions. After normalizing HOXB4 mRNA levels to endometrial epithelial cell content, HOXB4 mRNA levels were also significantly lower in the DIE groups when compared to EC and Eoma.

On the whole, HOXB4 expression is reduced in DIE, but not endometrioma endometriosis, and may be dysregulated in ectopic implants. During the menstrual cycle, the expression of HOXB4 in endometrial glandular epithelial cells is higher in the proliferative phase than the secretory phase in the normal eutopic endometrium. We here report for the first time the expression of HOXB4 localization and immunoreactivity not only in the normal eutopic endometrium but also in both eutopic and ectopic endometrial tissues in women with endometriosis. 


\section{Preface}

This thesis is submitted in partial fulfillment of the requirements for the Master of Science in Reproductive and Developmental Sciences degree. The development of the research project presented in this thesis and the experimental design were performed under the direction and input from Dr. Mohamed Bedaiwy and Dr. Christian Klausen. This thesis was revised by Dr. Mohamed Bedaiwy, Dr. Paul Yong, Dr. Christian Klausen, and Dr. Peter Leung.

This is a prospective study using archived formalin fixed paraffin embedded blocks collected by the Endo-Onc tissue bank group at the British Columbia Cancer Agency. I participated in the experimental design under the supervision of Dr. Bedaiwy and Dr. Klausen, and conducted all listed experiments, data collection and analysis. A manuscript will be prepared for a future publication based on results from Chapters 3 and 4. The manuscript will also include relevant sections of this thesis, including introduction, methods, results and discussions sections found in Chapters 1-5.

\section{Statement of research ethics approval and funding}

The ethics approval was obtained from the British Columbia Cancer Agency Research Ethics Board (H11-00536 and H14-03040), Case Western Reserve, Cleveland, Ohio, USA (IRB\# 12-10-28), and Sohaj University, Sohaj, Egypt, with samples transferred to Dr. Bedaiwy's lab in the Child and Family Research Institute (CFRI) according to the Material Transfer Agreement (MTA\# M15-00189). This project was covered by the Graduates Sponsorship Program at College of Medicine, Princess Nourah Bint AbdulRahman University, Riyadh, KSA and was internally funded by the Department of Obstetrics and Gynecology, University of British Columbia, Vancouver, BC, Canada. 


\section{Presentations}

American Society of Reproductive Medicine Annual Meeting in Baltimore, MD, USA in October $20^{\text {th }}, 2015$. Poster presentation. Expression Of HOXB4 In Endometrial Tissues From Women With Or Without Endometriosis. Ghadeer M. AlKusayer, Bo Peng, Christian Klausen, Sarka Lisonkova, Mary Kinloch, Paul Yong, Mohamed A. Bedaiwy. $15^{\text {th }}$ CFRI Trainee Research Forum Poster Presentation, CFRI, Vancouver, BC. June $18^{\text {th }}$,

2015. Poster presentation. HOXB4 Expression During the Menstrual Cycle in Eutopic and Ectopic Endometrium. Ghadeer M. AlKusayer, Bo Peng, Christian Klausen, Sarka Lisonkova, Mary Kinloch, Paul Yong, Mohamed A. Bedaiwy. 


\section{Table of Contents}

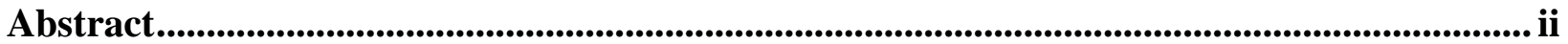

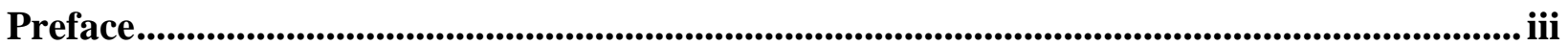

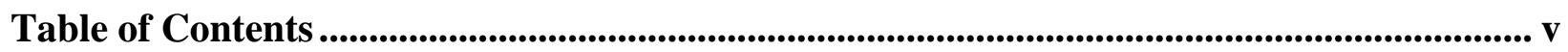

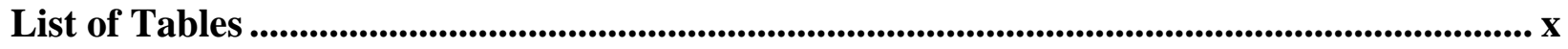

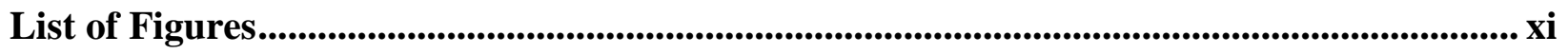

List of Abbreviations ........................................................................................................................ xiv

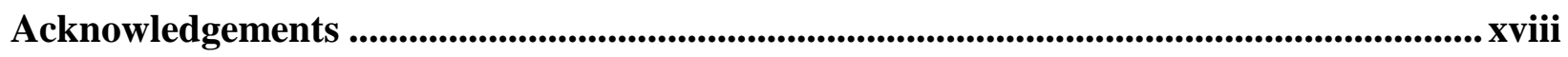

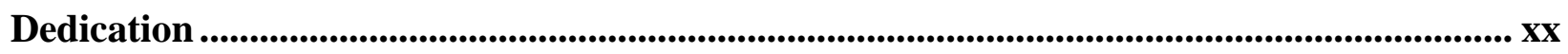

Chapter 1: Introduction .................................................................................................................. 1

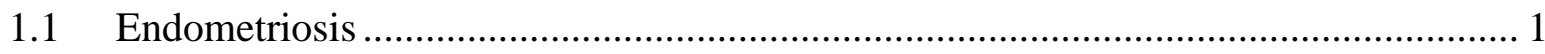

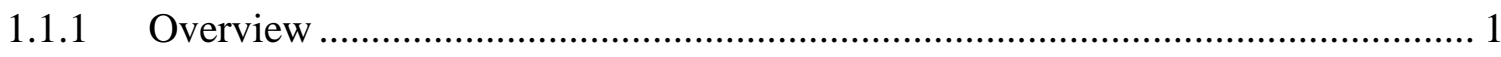

1.1.2 Pathophysiology of Endometriosis ..................................................... 3

1.1.2.1 Overview of Endometriosis Pathophysiology Theories .............................. 3

1.1.3 Anatomic Spread of Endometriosis........................................................ 13

1.1.3.1 Superficial Peritoneal Endometriosis ................................................... 14

1.1.3.2 Ovarian Endometriosis ............................................................... 15

1.1.3.3 Deep Infiltrating Endometriosis .......................................................... 15

1.1.4 The Physiological Changes in Endometriosis ............................................. 15 


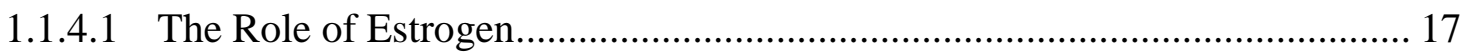

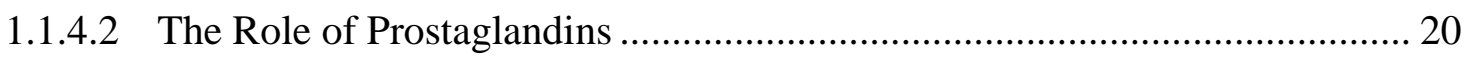

1.1.4.3 The Role of Progesterone ................................................................................ 21

1.1.5 Diagnosis and Management of Endometriosis................................................. 22

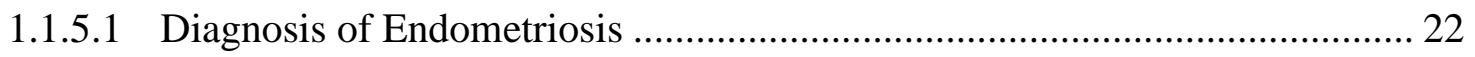

1.1.5.2 Management of Endometriosis.................................................................... 24

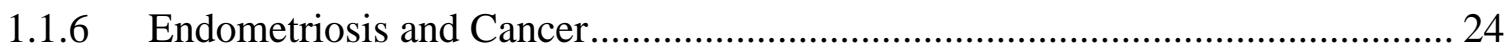

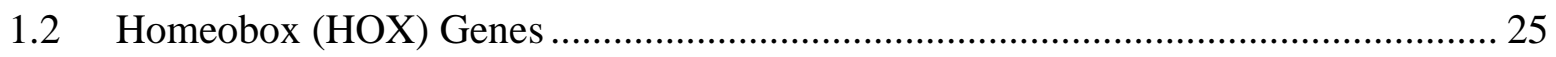

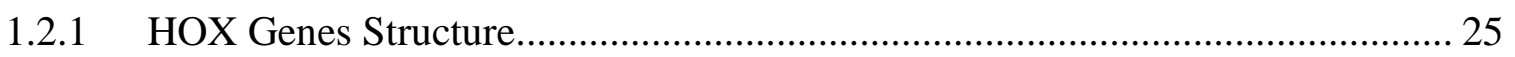

1.2.2 Regulation of HOX Genes Expression......................................................... 26

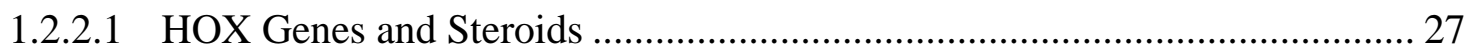

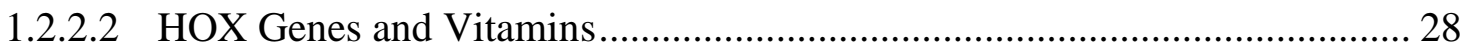

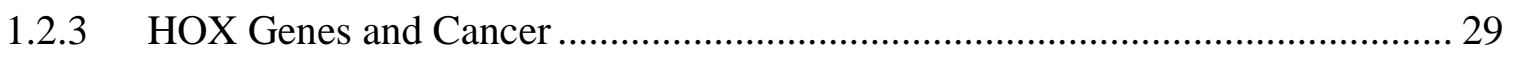

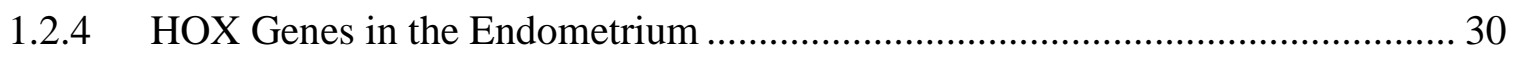

1.2.5 HOXB4

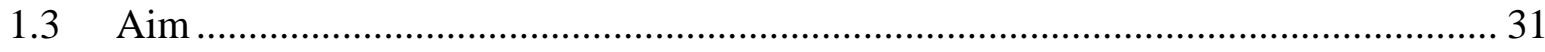

Chapter 2: Materials And Methods ...................................................................................................... 35

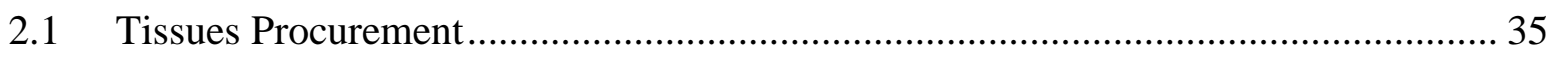

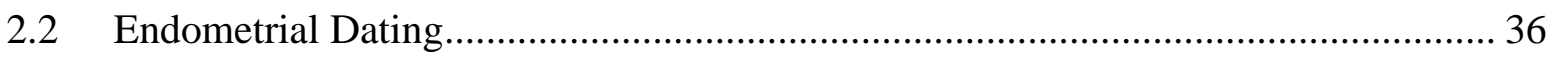




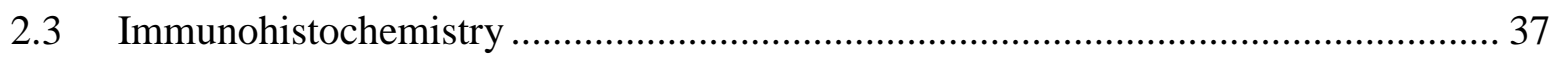

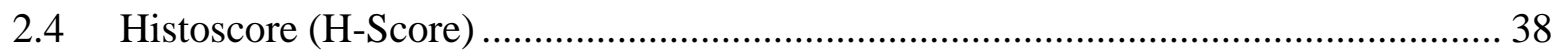

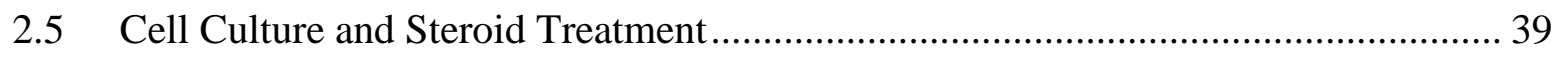

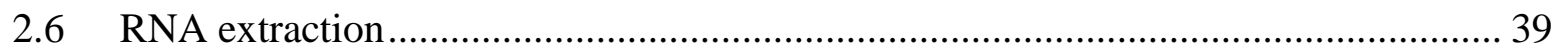

2.6.1 RNA Extraction from FFPE Blocks............................................................... 40

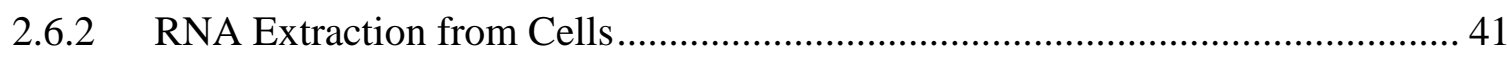

2.7 Reverse Transcription ........................................................................................ 42

2.8 Reverse Transcription Quantitative Real Time Polymerase Chain Reaction (RT-

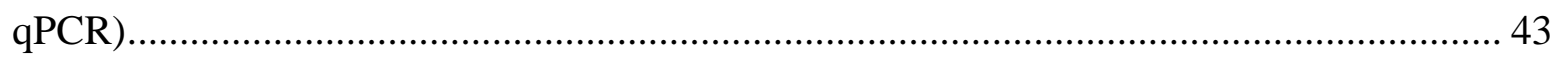

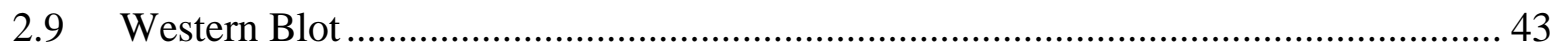

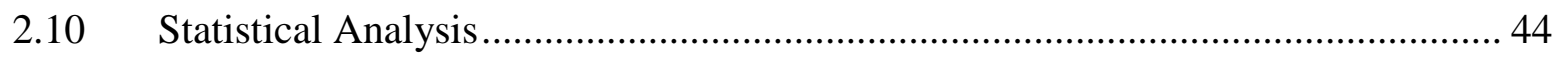

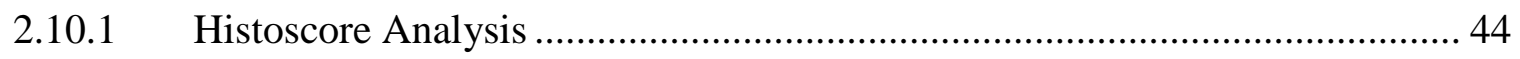

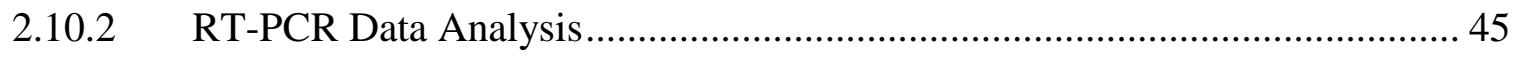

Chapter 3: Expression of HOXB4 in Endometrial Tissue ........................................................... 48

3.1 Rationale and Overall Hypothesis ....................................................................... 48

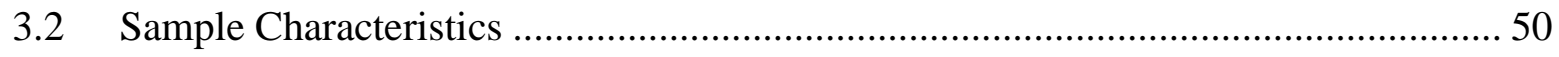

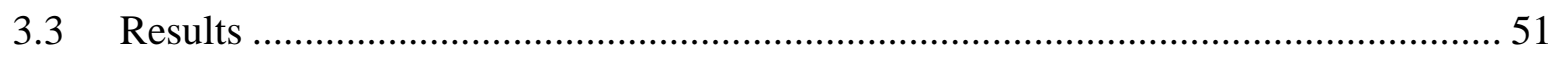

3.3.1 Localization of HOXB4 Expression in Patients without Endometriosis (EC) and Patients with Endometriosis (EE, Eoma, and DIE) ……………………………......... 51

3.3.2 HOXB4 Protein Expression during the Menstrual Cycle ................................... 53 
3.4 Discussion

\section{Chapter 4: The Expression of HOXB4 mRNA in Eutopic and Ectopic Endometrial}

Tissue from Women with or without Endometriosis.............................................................. 68

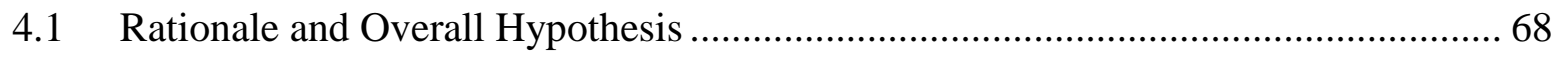

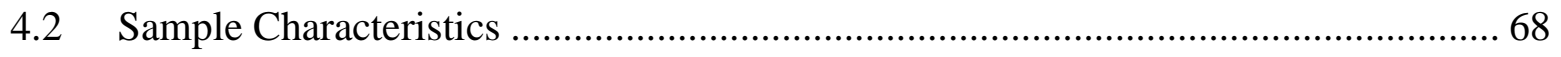

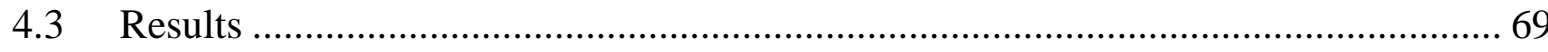

4.3.1 The Expression of HOXB4 mRNA in Eutopic and Ectopic Endometrial Tissue69

4.3.2 The Expression of HOXB4 mRNA in Different Pelvic Zones from Women with

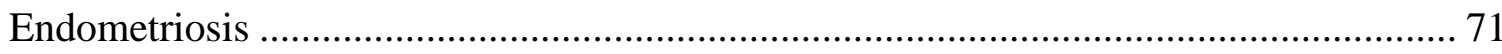

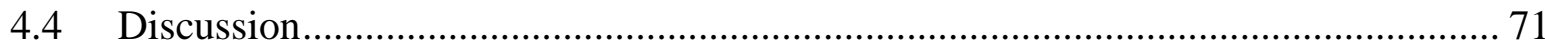

Chapter 5: Conclusion and Future Directions ............................................................ 82

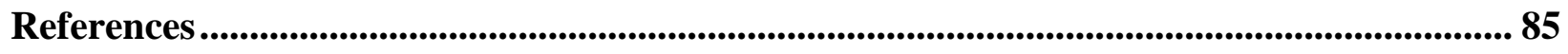

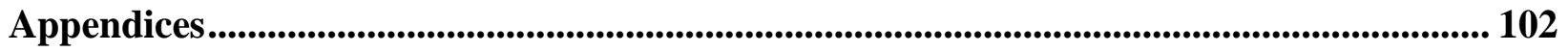

Appendix A: HOXB4 Expression and Function in Endometrial Cancer Cell Lines .......... 102

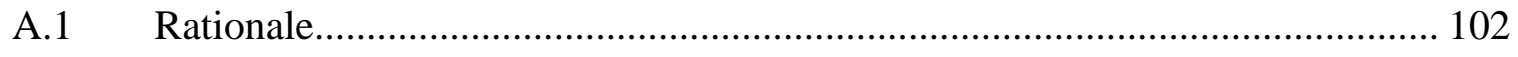

A.2 Expression of Hoxb4 in Endometrial Cancer Cells ..................................... 103

A.3 Effect of Estrogen Treatment on Hoxb4 Expression in Endometrial Cancer

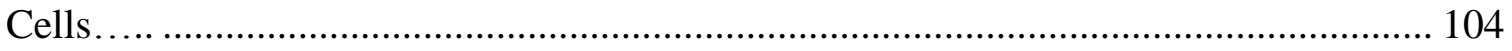

Appendix B: Hoxb4 Expression in Normal Endometrium and Endometrioma from the Gene Expression Omnibus (Geo) Microarray Database ..................................................... 109 
Appendix C: Hoxb4 Expression in Normal Endometrium and Endometriosis from the Gene Expression Omnibus (Geo) Microarray Database ... 110 


\section{List of Tables}

Table 1.1 Summary of Endometriosis etiology mechanisms................................................ 4

Table 2.1: RNA extraction procedure in the RecoverAll ${ }^{\mathrm{TM}}$ and AllPrep Kits.......................... 41 


\section{List of Figures}

Figure 1.1: Main molecular mechanisms accountable for the major symptoms of endometriosis.

Figure 1.2: Illustration of the anatomical boundaries and the contents of all pelvic zones ......... 33

Figure 1.3 Schematic illustration of HOX clusters in humans: ........................................ 34

Figure 2.1: Schematic presentation of the study population .............................................. 46

Figure 2.2: Schematic presentation of the blocks utilized in the study .................................. 47

Figure 3.1: Immunohistochemical localization of HOXB4 in the female genital tract ..............58

Figure 3.2: Immunohistochemical localization of HOXB4 in Normal Eutopic Endometrium

from women without endometriosis in the proliferative phase ......................................... 59

Figure 3.3: Immunohistochemical localization of HOXB4 in Normal Eutopic Endometrium

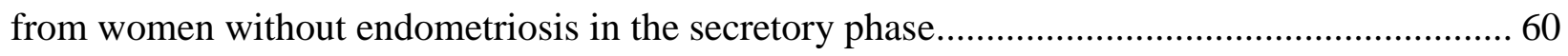

Figure 3.4: Immunohistochemical localization of HOXB4 in ovarian endometrioma............... 61

Figure 3.5: Immunohistochemical localization of HOXB4 in deep infiltrating endometriosis.... 62

Figure 3.6: Analysis of HOXB4 immunoreactivity in all available samples of lesions from patients without endometriosis (EC) and patients with endometriosis (EE, Eoma, and DIE) using

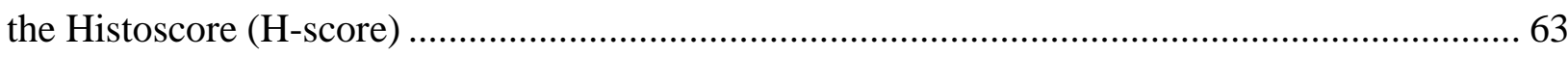

Figure 3.7: Matched sub-analysis of HOXB4 immunoreactivity in patients with endometriosis

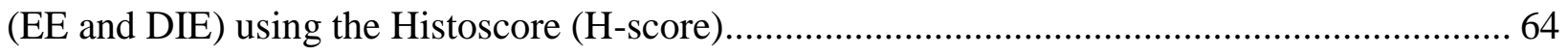

Figure 3.8: Matched sub-analysis of HOXB4 immunoreactivity in patients with endometriosis

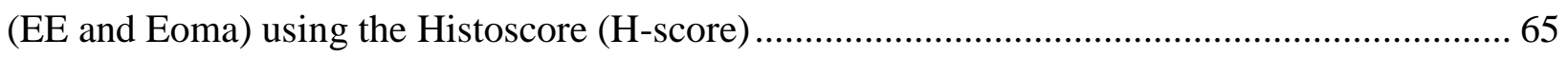


Figure 3.9: Analysis of HOXB4 immunoreactivity in all available samples of lesions from patients without endometriosis (EC) and patients with endometriosis (EE, Eoma, and DIE) during the menstrual phases using the Histoscore (H-score) 66

Figure 3.10: Analysis of the crude HOXB4 immunoreactivity in all available samples of lesions from patients without endometriosis (EC) and with endometriosis (EE, Eoma, and DIE) compared to inactive endometrium using the Histoscore (H-score). 67 Figure 4.1: HOXB4 mRNA levels normalised to the reference gene GAPDH in lesions from patients without endometriosis (EC) and patients with endometriosis (EE, Eoma, and DIE)..... 77 Figure 4.2: HOXB4 mRNA levels normalised to the epithelial marker Cytokeratin 7 in lesions from patients without endometriosis (EC) and patients with endometriosis (EE, Eoma, and DIE)

Figure 4.3: Correlation between the epithelial content and Cytokeratin7 79

Figure 4.4: HOXB4 mRNA levels normalised to the epithelial content in lesions from patients without endometriosis (EC) and patients with endometriosis (EE, Eoma, and DIE)..... 80 Figure 4.5: HOXB4 mRNA levels in deep infiltrating endometriosis lesions (DIE) in different pelvic zones 81

Figure A.1: The expression of HOXB4 in endometrial cancer cells 105 Figure A.2: E2 does not stimulate HOXB4 expression in HEC1A cells with different incubation periods 106

Figure A.3: E2 does not stimulate HOXB4 expression in HEC1B cells with different incubation periods 107

Figure A.4: E2 and its antagonist don't have an effect on HOXB4 expression in both HEC1A and HEC1B 108 
Figure B.1: HOXB4 expression in normal endometrium and endometrioma from the Gene Expression Omnibus (GEO) microarray database........................................................... 109

Figure C.1: HOXB4 expression in normal endometrium and endometriosis from the Gene Expression Omnibus (GEO) microarray database: ....................................................... 110 


\section{List of Abbreviations}

17BHD 17-beta-hydroxysteroid dehydrogenase

18S rRNA

18s ribosomal RNA

AA

Arachidonic acid

ACTB

Beta actin

ANTP

Antennapedia

BUS

B-upstream segment

$\mathrm{C} / \mathrm{EBP} \beta$

CCAAT/enhancer binding protein $\beta$

CK7

Cytokeratin 7

COX

Cyclooxygenase enzyme

CT

Cycle thresholds

$\mathrm{D}_{3}$

1,25-dihydroxyvitamin $\mathrm{D}_{3}$

DES

Diethylstilbestrol

DIE

Deep infiltrating masses

DNA

Deoxyribonucleic acid

E1

Estrone

E2

17ß-estradiol

E3

Estriol

EC

Normal eutopic endometrium

EC

Endometriosis

$\mathrm{EE}$

Eutopic endometrium

EFI

Endometriosis fertility index 


\begin{tabular}{ll} 
EGF & Epidermal growth factor \\
ENDO-ONC & Endometriosis determinants of oncogenesis tissue bank \\
Eoma & Endometrioma \\
EpCAM & Epithelial cell adhesion molecule \\
ER & Estrogen nuclear receptors \\
ER- $\alpha$ & Estrogen receptor-alpha \\
ER- $\beta$ & Estrogen receptor - beta \\
FFPE & Formalin fixed paraffin embedded \\
FSH & Follicle-stimulating hormone \\
GAPDH & Glyceraldehyde-3-phosphate dehydrogenase \\
GEO & Gene Expression Omnibus microarray database \\
GPER & G protein-coupled receptors \\
GTRH & Gonadotropin-releasing hormone \\
HDL & High-density lipoprotein \\
HOX & Homeobox gene \\
HPG & Hypothalamic-pituitary-gonadal axis \\
HS & Insulin-like growth factor 1 \\
H-score & Interleukin-1 \\
IGF-1 & HGFBepoietic stem cells \\
IL-1 & Intike growth factor binding protein 1 \\
\hline
\end{tabular}




\begin{tabular}{|c|c|}
\hline LDL & Low-density lipoprotein \\
\hline LH & Luteinizing hormone \\
\hline MCP-1 & Monocyte chemotactic protein- 1 \\
\hline mER & Membrane estrogen receptors \\
\hline MF & Molecular fixative \\
\hline MPA & Methylprogesterone acetate \\
\hline mRNA & Messenger RNA \\
\hline NK & Natural killer cell \\
\hline NSAID & Non-steroidal Anti-inflammatory drug \\
\hline P4 & Progesterone \\
\hline PG & Prostaglandin \\
\hline PGE2 & Prostaglandin $E_{2}$ \\
\hline $\mathrm{PGF}_{2 \alpha}$ & Prostaglandin $\mathrm{F}_{2 \alpha}$ \\
\hline PR & Progesterone receptor \\
\hline PR-B & Progesterone receptor B \\
\hline RA & Retinoic acid \\
\hline RANTES & Regulated on activation, normal $\mathrm{T}$ cell expressed and secreted \\
\hline RAR & Retinoic acid receptor \\
\hline RARE & Retinoic acid response element \\
\hline ROS & Reactive oxygen species \\
\hline RXR & Retinoid X receptor \\
\hline SF-1 & Steroidogenic factor 1 \\
\hline
\end{tabular}


StAR

STAR

TAF-1

TCDD

TGF- $\alpha$

$\mathrm{TNF} \alpha$

TNF- $\alpha$

VDR

VDRE

VEGF

WT1
Steroidogenic acute regulatory protein

Steroidogenic acute regulatory gene

Transcription initiation factor TFIID subunit 1

2,3,7,8-tetrachlorodibenzodioxin

Transforming growth factor alpha

Tumor necrosis factor- $\alpha$

Tumor necrosis factor- $\alpha$

Vitamin D receptor

Vitamin D response element

Vascular endothelial growth factor

Wilm's tumor 1 transcription factor 


\section{Acknowledgements}

First and foremost, I would like to express my gratitude to my thesis principle supervisor Dr. Mohamed Bedaiwy for his exceptional scientific guidance and patience as well as for providing me with the unique opportunity to explore this remarkable research project. I am also grateful to my supervisory committee members Dr. Peter Leung, Dr. Paul Yong, and Dr. Christian Klausen and committee chair Dr. Deborah Money and external examiner Dr. Timothy Rowe for their continuous support and constructive feeback.

A genuine heartfelt appreciation goes to all my colleagues in Dr. Bedaiwy's lab at the CFRI, especially to Dr. Bo Peng as he was my cornerstone, teaching me the necessary laboratory techniques, assisting with troubleshooting the problems encountered in my experiments, training me on how to maintain my data, and assisting in the writing of this thesis. His profound knowledge guided me since the day I joined the lab, making my graduate studies experience very enjoyable.

Further, I am grateful to Dr. Peter Leung and his lab members at the CFRI. I would like to sincerely thank Dr. Christian Klausen for his advice, insight, tremendous help, and endless hours spent in refining my study design, analysis and writing. He was always taking time out from his busy schedule to be there for me and I have no words to fully describe how I appreciate all his tireless guidance. To Dr. Ellen Zhu, Dr. Han Zhang, Dr. Hong Zhan, Drs Norihito and Maki Yoshioka, Luke Gooding, Dr. Maha Alsahan and Kayleigh Campbell, I am genuinely grateful for their care, assistance and emotional support. 
Appreciation also goes out to Dr. Blake Gilks and his team at the Department of Anatomical Pathology at VGH (Dr. Noorah AlMadani and Dr. Mehdi Agoumi, and Dr. Mary Kinloch), Dr. Huntsman's Lab and Dr. Michael Anglesio at the BC Cancer Agency, and Dr. Sarka Lisonkova at the Department of Obstetrics and Gynecology, BC Women's Hospital for their time and feedback. Many thanks to Ms Ariadna Fernandez, Ms Fontayne Wong, Ms, Margaret Luk and Ms Krystina Tran for their continuous support and help from the first day I started my thesis. Special thanks to Mrs. Roshni Nair for her whole-hearted guidance.

The completion of this thesis was made possible by the women participating in the EndoOnc study, Department of Pathology at Sohaj University, Sohaj, Egypt and Case Western Reserve, Cleveland, Ohio, USA. I would like also to acknowledge the studentship from the Graduates Sponsorship Program at Princess Nourah Bint AbdulRahman University, Riyadh, KSA, the Department of Obstetrics and Gynecology, University of British Columbia and CFRI.

Finally, I would like to extend my deepest gratefulness to my loving parents Dr. Majed Alkusayer and Yosra Alshamlan and my three caring sisters, Dr. Mishael, Abeer and Nouf for instilling in me the value of education and their never ending love and support every single day. They believed in me and I am extremely fortunate to have them as my family. 


\section{Dedication}

To my beloved grandmother, Aisha Saud AlBassam (1917-2005).

Since I was a little girl she believed in me and she will never be forgotten.

To all women who are suffering from Endometriosis and their families. 


\section{Chapter 1: Introduction}

\subsection{ENDOMETRIOSIS}

\subsubsection{Overview}

Endometriosis is a common, chronic and complex gynecological disease that affects 10-15 $\%$ of women in their reproductive age [1-4]. Approximately $70 \%$ of these women complain of pelvic pain and up to $40 \%$ suffer from infertility [5].

Endometriosis is characterized by the presence of uterine (endometrial) tissues in regions outside of the uterus. These outgrowing endometrial tissues growths, referred to as ectopic implants, are composed of uterine glands and stroma — resembling the inner endometrial lining of the uterus - and are most commonly found on the ovaries, peritoneum, bladder, or bowel. Ectopic implants also have an array of different appearances, ranging from fine superficial lesions to subtle infiltrating masses, deep infiltrating masses (DIE), and the thick walled, blood filled ovarian endometriomas or "chocolate cysts" $[6,7]$.

As endometrial ectopic implants are composed of uterine epithelial tissue, they respond to the cyclic dynamic hormonal changes of the menstrual cycle with growth and shedding phases. During the menstrual phase of the monthly cycle, ectopic implants will shed endometrial epithelial and stromal cells (resembling menstrual blood) that may then get trapped in the pelvis and adhere to the surrounding organs and tissues, depending on the location of the implants. With the repetition of each cycle, trapped blood can lead to irritation of surrounding organs and nerve endings. Furthermore, fibrous connective tissue development (fibrosis) between the implants and surrounding organs can lead to adhesion formations and distortion of the pelvic anatomy, resulting in symptoms of pelvic pain and/or infertility [8]. Indeed, symptoms of debilitating, enduring pelvic pain and/or subfertility/infertility help health care professionals diagnose endometriosis. The pain 
could be in the form of painful menstruation (dysmenorrhea), painful sexual intercourse (dyspareunia), painful bowel movement (dyschezia) or a chronic pelvic pain. Several epidemiology studies suggest that pelvic pain and infertility may affect up to $30 \%$ and $50 \%$, respectively, of women diagnosed with endometriosis [9-11]. These findings were estimated based on direct visualisation of the implants and/or histological confirmation of endometriosis. However, endometriosis in many women will often go undetected, as evidenced by incidental diagnoses of women during exploratory laparoscopies [12]. Nnoaham et al. reported in their multicentric study that the mean intermission of diagnosing endometriosis was a very poor 6.7 years [13]. It is important to better improve diagnosis of endometriosis in order to more fully understand the magnitude of this devastating disease [14].

Endometriosis is more common among Asians and Caucasians when compared to black and Hispanic women, with a mean age of diagnoses between 25 and 35 years old [15]. Other factors that have been associated with an increased risk of endometriosis include anatomical anomalies, low body mass index, nulliparity, short menstrual cycles, heavy menstruation, persistent menstruation, bleeding disorders, late menopause, a family history of the disease, alcohol consumption and smoking [16, 17]. Menarche after the age of 14, multiparity and a prolonged lactation period are associated with a decreased risk of endometriosis $[11,18]$.

In 2009, Ley et al. estimated the total annual cost, from a societal perspective, of endometriosis on the Canadian health care system to be $\$ 2.4$ billion, with a mean cost of $\$ 5200$ per patient [19]. In the United States, endometriosis is the third leading cause of gynecological hospitalization [20] with annual costs thought to exceed $\$ 49$ billion. In addition to the significant economic burden, this disease affects the patient's personal, social, and professional quality of life due to the severity of the symptoms [21]. 
Since the seventeenth century, the history of the many poorly understood pathogenesis theories proposed to explain endometriosis highlights the limitations in the classification of endometriosis. However, modern technology has enabled researchers to explore different molecular methods, the genetic and epigenetic changes featured in both eutopic and ectopic implants, giving hope to the future of diagnosing and treating endometriosis [15].

\subsubsection{Pathophysiology of Endometriosis}

\subsubsection{Overview of Endometriosis Pathophysiology Theories}

Although it is a very common disease with serious implications, no single theory has yet fully explained the pathogenesis of endometriosis. There are, however, many theories hypothesised $[15,22,23]$ as to how endometrial tissue in the uterus ("eutopic" endometrium) can become "ectopic" and implant/grow elsewhere in the body. The most widely accepted classical theories revolve around two different origins for the disease: endometrial tissue travelling and implanting in surrounding areas, or metaplasia of eutopic tissue into endometrial-like tissue. Combined these theories may explain most of the variations in appearance and location of endometriosis. Sampson's theory of retrograde menstruation (reflux) proposes that endometriosis is caused by menstruation that travels back up through the fallopian tubes into the pelvis (retrograde menstruation), carrying with it endometrial cells that may implant, spread, and grow $[6,24]$. A widely accepted alternate hypothesis, Meyer's Theory, proposes that ectopic endometrial tissue growths are caused by metaplasia (abnormal change in the nature of a tissue) of coelomic/peritoneal-derived cells, thereby explaining ectopic growths in regions where endometrial cells may not be able to travel to and implant. A further hypothesis, Halban's Theory, proposes that endometrial cells may travel in the pelvis and to remote locations via 
lymphatic/hematologic means, with subsequent implantation giving rise to ectopic growths [25].

However, none these classic theories have been unequivocally proven to explain the pathogenesis of endometriosis. Recently, increased understanding of the roles family history (genetics), the immune system, and oxidative stress play in its pathogenesis has broadened our view of the factors that contribute to the etiology of endometriosis (Table1.1). The classical theories, their interrelated literature, and some recent evidence of other factors contributing to the pathogenesis of endometriosis will be reviewed.

Table 1.1 Summary of Endometriosis etiology mechanisms

\begin{tabular}{|c|c|c|}
\hline Theory & Year & Summary \\
\hline $\begin{array}{l}\text { Embryonic Rest } \\
\text { (Von Recklinghausen } \\
\text { and Russell Theory) } \\
\end{array}$ & 1890 's & $\begin{array}{l}\text { - Endometriosis arises from the germinal Müllerian } \\
\text { remnants of the mullerian duct. }\end{array}$ \\
\hline $\begin{array}{l}\text { Metaplasia (Meyer's } \\
\text { Theory) }\end{array}$ & 1919 & $\begin{array}{l}\text { - Endometriosis caused by endogenous and/or } \\
\text { exogenous factors } \\
\text { - Coelomic epithelial cells may transform into } \\
\text { endometrial cells. }\end{array}$ \\
\hline $\begin{array}{l}\text { Retrograde } \\
\text { menstruation } \\
\text { (Sampson's Theory) }\end{array}$ & 1920 's & $\begin{array}{l}\text { - Migration, implantation, and proliferation of ectopic } \\
\text { endometrial tissue via retrograde menstruation } \\
\text { through mesosalpinx into the pelvis. }\end{array}$ \\
\hline $\begin{array}{l}\text { Lymphatic and } \\
\text { Hematologic Metastasis } \\
\text { (Halban's Theory) }\end{array}$ & 1920’s & $\begin{array}{l}\text { - Transportation of endometrial cells through the } \\
\text { lymphatic system to remote location outside the } \\
\text { pelvic cavity. }\end{array}$ \\
\hline Genetic & 1950 's & $\begin{array}{l}\text { - Genetic component increasing the ability for } \\
\text { attachment of endometrial cells and evasion of these } \\
\text { cells from immune clearance. }\end{array}$ \\
\hline Hormones & & $\begin{array}{l}\text { - Proliferation of ectopic implants via high } \\
\text { local/systemic estrogen levels and local } \\
\text { progesterone resistance. }\end{array}$ \\
\hline $\begin{array}{l}\text { Immunity and } \\
\text { Inflammation }\end{array}$ & & $\begin{array}{l}\text { - Decreased ability of immune cells to eliminate } \\
\text { ectopic endometrial tissue. } \\
\text { - Recruitment of pro-inflammatory cytokines by } \\
\text { immune cells promotes endometrial lesion growth. }\end{array}$ \\
\hline
\end{tabular}




\subsection{Theory of Embryonic Rest}

Interestingly, endometriosis has also been reported in male patients [26-29]. An acceptable explanation of endometrial like tissue being found in males was first proposed in the nineteenth century by both Von Recklinghausen and Russell: germinal embryonic mullerian cells in the male fetus may differentiate into endometrial cells under certain stimuli [30]. As both female and male gonads, ovaries and testis respectively, originate from a bi-potential gonad, alterations in development leading to endometrial cells in men is plausible [31]. However, many would debate that larger numbers of male patients with extra pelvic endometriosis should be observed if in situ developmental changes explain the etiology of endometriosis [32].

\subsection{Theory of Retrograde Menstruation and Implantation (Sampson's Theory)}

Although many reports had been published in the late 1800s to describe ectopic implants, John A Sampson is considered the first to surgically and histologically describe the classical ovarian endometriosis as "perforating hemorrhagic (chocolate) cysts of the ovary" in several case reports from 1921 to 1927 while observing a series of hysterectomies performed during different menstrual cycle phases [33]. Sampson was also the first to propose that peritoneal endometriosis may be derived from a perforated ovarian cyst; the subsequent dissemination of the contents leading to implantation and growth in the peritoneum. He also first proposed the theory that eutopic endometrial tissue travelling up the fallopian tube during menstruation could lead to ectopic implants, thereafter referred to as the Sampson's retrograde menstruation and implantation theory [15]. 
Sampson concluded that, during the menstrual cycle, both the eutopic and ectopic tissue will slough off its lining and disseminate into the circulation leading to implantation and possibly growth in favorable conditions (i.e. auto-transplantation) [6, 34].

In support of this theory, surgical induced menstrual canal obstruction in baboons stimulated retrograde menstruation resulting in up to $100 \%$ of these animals developing pelvic endometriotic implants $[35,36]$. Olive et al reported a higher prevalence of endometriosis in women suffering from obstructed menstrual outflow due to congenital mullerian anomalies like imperforated hymen or iatrogenic cervical stenosis [22, 37]. Moreover, the viability of the sloughed menstrual tissue to proliferate and grow has been confirmed in-vitro [38-40].

While the retrograde menstruation theory, to date, is the most supported theory for the pathophysiology of endometriosis, multiple reports show that only up to $10 \%$ of women in their reproductive years develop this disease despite the fact menstrual blood was visualised in the fallopian tubes and in the peritoneal cavity in up to $90 \%$ of menstruating women [41-43]. Moreover, this theory cannot explain cases of endometriosis in extra pelvic organs, pre-pubertal females, neonates, or male patients. This would suggest that other factors, besides retrograde menstruation and implantation, are contributing to the etiology of endometriosis.

\subsection{Theory of Coelomic Metaplasia (Mayer's Theory)}

The theory of coelomic metaplasia addresses the pathophysiology of pelvic and pleural (serous membrane lining the thorax and enveloping the lungs) endometriosis, proposing that transdifferentiation of ovarian germinal epithelial cells and peritoneal serosa into endometrial-like cells, via hormonal and/or immunological mechanisms, results in ectopic implants [44, 45]. In 1942, Peter Gruenwald hypothesized that extra-pelvic endometriosis is caused by embryologic 
metaplastic transformations in the mesothelial lining of the coelomic wall (which involves organs developing into the pelvic, plural cavities, and limb buds) into epithelial like tissue [46]. This metaplasia was due to the transformational capability of the precursor mesothelial cells that line the abdominal cavity and was thought to occur naturally or be induced via hormonal or immunological stimuli [22]. Matsuura et al tested this theory by examining the morphological and immunoreactivity differences between normal eutopic endometrium (EC), ectopic implants (superficial peritoneal and ovarian implants), normal peritoneum, and infoldings of the visceral peritoneum. They concluded that the immunoreactivity of ectopic implants and the infolding peritoneum were not different from eutopic endometrium; however, they were different from the adjacent peritoneal mesothelium. In addition, using human superficial ovarian glands, they were able to develop a human endometriosis model in vitro that showed the ability of the mesothelial cells to transform into endometrial like cells when subject to exogenous hormonal factors [47].

This theory explained endometriosis in cases of pre-pubertal girls as well as the presence of endometrial epithelial glands and stromal cells in unusual sites in females like the lung, bladder, thumb, thigh, or knee.

While this theory may be appealing as it explains the pathogenesis of endometriosis in organs that share the same coelomic precursor cells without relying on retrograde menstruation and implantation, some may argue that the rate of pleural endometriosis should be higher if this theory is correct and that this theory lacks the scientific evidence to support it [48]. However, studies that examine benign and malignant epithelial ovarian tumors and the similarities of these tumors to endometriosis may provide evidence to support this theory. 


\subsection{Theory of Lymphatic and Hematologic Metastasis}

Although Sampson's theory proposed lymphatic dissemination as an etiology for endometriosis, his theory was only proven in juxta-pelvic locations. In the 1920's, Dr. Josef Halban hypothesised that endometriosis is a result of hematologic and lymphatic metastasis of endometrial cells. He proposed that endometrial tissue is transported to remote locations by the lymphatic system. Indeed, this theory was supported by Javert in 1952 when he found the incidence of endometriosis in pelvic lymph nodes to be $6.5 \%$ in 153 women undergoing pelvic surgeries[30].

\subsection{The Role of Genetics and Epigenetic Changes}

In 1943, Goodall suggested that endometriosis may be familial. Several later reports documented that genetics may play a role and should be considered a risk factor for endometriosis $[49,50]$. Subsequent reports looked into the prevalence of endometriosis among first degree relatives and found a seven times higher likelihood of the disease being found among first degree relatives of an endometriosis patient than in the general population [15, 51]. Moreover, 14 out of 16 monozygotic twins were found to both develop endometriosis in their lifetime [52]. Some geneexpression profiling studies established a polygenic mode of phenotype inheritance with certain environmental risk factors; therefore, endometriosis seems to be hereditary through complex genetic and environmental traits [53].

With the advancement of technology and the ability to study epigenetic mechanisms, the importance of epigenetic changes in parallel to the genetic predisposition of this disease has been highlighted. Epigenetic changes play important roles in the proliferation, invasion and angiogenesis of the ectopic implants. These changes are stimulated by both hormonal and 
chemokine cues resulting in a complex cascade of interactions and changes locally or systemically and the eventual improved survival of ectopic endometrial cells [15].

\subsection{The Role of Steroid Hormones}

Endometriosis is not frequently seen in pre or postmenopausal women (not on hormonal treatment) indicating the role of steroid hormones. This role will be discussed in depth in section 1.1.4.

\subsection{The Role of Immune Cells}

Compromised cellular and humoral immunity was found to be linked to the pathogenesis of endometriosis [15]. Lymphocytes, natural killer (NK) cells, cytokines, macrophages, and mast cells play a critical role in promoting conditions suitable for angiogenesis and proliferation of endometrial cells in ectopic locations, supporting the growth and survival of ectopic implants. Even though the numbers of immune cells appears to be high in the peritoneal fluid of patients with endometriosis, the failure of ectopic implants to be eliminated by the immune system indicates an aberrant immune response resembling autoimmunity $[54,55]$. Indeed, reports have established an association between endometriosis and autoimmune diseases (e.g. systemic lupus erythematosus and rheumatoid arthritis) [15].

Normally, the innate immune response is facilitated by both macrophages and NK cells. They play the major protective role in eliminating abnormal cells in the peritoneal fluid. In patients with endometriosis, there is a higher concentration of macrophages and reduced concentration of NK cells in the peritoneal fluid. However, the cytotoxicity of macrophages is decreased, via 
production of chemokines and pro-inflammatory factors by the ectopic implants and macrophages themselves, enabling proliferation and invasion of the epithelial cells ectopically [23, 56, 57].

The role of the acquired immune response is mediated by B and T lymphocytes. Reports in the literature are contradictory when it comes to the abundancy and role of B lymphocytes in eutopic and ectopic endometrium in patients with endometriosis [58]. On the other hand, the number of total $\mathrm{T}$ lymphocytes is found to be higher in the peritoneal fluid and ectopic implants than in the eutopic endometrium in women with endometriosis $[15,58,59]$; however, decreased lymphocyte proliferation and reduction of $\mathrm{T}$ lymphocyte cytotoxic response to autologous endometrial cells in patients with endometriosis has been reported [60, 61].

Cytokines are proteins that are important in cell chemical signaling, and play a key role in initiating up and/or down regulation of the inflammatory response. In endometriosis, chemokines (family of cytokines involved in chemotaxis) such as Interleukin-1 (IL-1), IL-6, IL-8, tumor necrosis factor- $\alpha(\mathrm{TNF} \alpha)$, regulated on activation, normal $\mathrm{T}$ cell expressed and secreted (RANTES), and monocyte chemotactic protein-1 (MCP-1) are produced and activated by different immune cells. The function of these cytokines in endometriosis is concurrent and overlapping but they generally promote migration of endometrial cells, growth of endometrial cells ectopically, and stimulate adhesions between implants and organs (via fibrous connective tissue formation) in the pelvic cavity resulting in anatomical distortion and/or pain [15].

\subsection{Oxidative Stress and Inflammation}

Oxidation reactions are double-edged swords: they allow for the large amount of energy converted from food but also produce damaging reactive oxygen species (ROS). The mechanisms in place to mitigate oxidative cellular damage via ROS includes a systemic defence system of 
enzymatic (e.g. catalase, superoxide dismutase, and glutathione peroxidase) and non-enzymatic antioxidants (e.g. vitamins A, C, and E) that balance out the production of ROS [62]. An imbalance of antioxidants to ROS due to excess production of ROS and/or reduction in any of these antioxidants levels leads to ROS accumulation and subsequently oxidative stress [63]. This stress is toxic and damages cellular content by oxidizing nucleic acids, proteins, carbohydrates and lipids. In female reproduction, an imbalance of ROS to antioxidants was implicated in cases of endometriosis as DNA damage in the endometrial cells was due to oxidation of lipoproteins induced by ROS [64-67]. In endometriosis, the peritoneal cavity and its fluid are a major source of ROS. The increased water, electrolytes, and iron in the cavity (due to haemoglobin catabolism) leads to oxidation-reduction reactions and pro-inflammatory chemokine production resulting in the activation of oxidant enzymes and subsequent endothelial growth stimulation $[68,69]$. Verit et al reported that serum paraoxonase-1 level, a low-density lipoprotein (LDL) antioxidant enzyme associated with high-density lipoprotein (HDL), is lower in patients with endometriosis and may indicate a more advanced endometriosis [70]. On the other hand, the supplementation of vitamins $\mathrm{C}$ and $\mathrm{E}$ or a high antioxidant diet for three-four months in a relatively small population of patients with endometriosis lead to the reduction of peripheral oxidative stress markers (malondialdehyde and lipid hydroperoxides) when compared to the control group (women with endometriosis on a normal diet), highlighting the importance of exogenous antioxidant supplementation in endometrial patients [71]. 


\subsection{The Role of Diet and Environment}

Although there is not sufficient evidence to conclude dietary intake is a risk factor for endometriosis, environmental contaminants that enter the body through diet were found to be risk factors of endometriosis and may contribute to the etiology of this disease.

Endometriosis is an estrogen-dependant disease and some environmental toxins may affect ectopic implants via their effect on estrogen or estrogen receptors. Isoflavones (e.g. phytoestrogens) are polyphenolic complexes that have estrogen-like effects and are consumed via dietary intake (e.g. soybean has a high estrogenic action); however, these phytoestrogens have been reported to be present in lower levels than normal estrogen physiological levels. In animal studies, a couple of phytoestrogens have been found to reduce both the weight and surface of ectopic implants by reducing the concentration of estrogen in the circulation of the animals [72]. These results have yet to be replicated in humans.

2,3,7,8-Tetrachlorodibenzodioxin (TCDD) is a highly toxic and carcinogenic dioxin: two 6 member aromatic rings linked with two oxygens. It is synthesized chemically and can also be a product of metal production and waste/wood burning. Due to its high water solubility and relatively long half-life, TCDD may be stored in the body for years [73-75]. The toxicity of this dioxin can result in gene transcription and epigenetic aberrancies that has been found to play a key role in endocrine disruption in the context of the reproductive system. Endocrine disruption by TCDD occurs via steroidogenesis alterations, steroid receptivity alterations, immune function disorders, and as such TCDD can obstruct reproductive function [76]. For instance, TCDD was found to promote progesterone resistance, resulting in subsequent inflammation related molecular changes, by altering progesterone steroid synthesis and/or by altering progesterone receptor 
function [77]. Effects of TCDD on progesterone resistance were observed when isolated stromal cells stopped expressing progesterone receptor B (PR-B) when treated with TCDD in-vitro [78].

As presented above, and in addition to a recent literature review, the association between diet, environmental toxins exposure and endometriosis is disputable and better designed studies are crucial to examine the correlation [72].

\subsubsection{Anatomic Spread of Endometriosis}

Microscopically, endometriotic tissue is composed of endometrial epithelia and stroma in addition to fibrous tissue [79].

The ectopic implants are seen in the pelvis and anywhere in the body except the spleen [80, 81]; and are frequently found in the ovaries, anterior and posterior cul-de-sac, posterior broad ligament, uterosacral ligament, uterus, fallopian tube, sigmoid colon, appendix and round ligament [82-85]. Rarely, the ectopic implants can be seen in the bladder, ureter, surgical scars, pericardium and the pleura [86]. The complexity of endometriosis is best exemplified by the variation in disease form, appearance, and location. There are three common and unique pelvic forms: superficial peritoneal lesions (subtle or typical), ovarian endometriosis (endometrioma), and deep-infiltrating disease. Furthermore, the size, appearance and color of these implants may vary according to the lesion, patient age and the implant location [79]. A phenotypic classification has been proposed for these three forms according to lesion location and appearance and is currently being used. There has also been efforts to classify this disease on a genetic and molecular level; however, to date, none have proven more effective than gross phenotypic categorization [87-89].

In 1860, Von Rokitansky was the first to describe the histological description of endometriosis [90]. With the advancement of medical technology, surgeons were able to identify 
ectopic implants, based on anatomical location, even in cases of asymptomatic disease. In the twentieth century the definition of endometriosis was first given to the ovarian "chocolate cyst", see 1.1.3.2[6]. In the late 1960's the prevalence of endometriosis increased after the identification of pigmented lesions in the pelvis. The prevalence continued to increase with the identification of non-pigmented ectopic lesions in the mid-eighties [91]. Surgeons' experience with ectopic implants coupled with advances in surgical and histopathological approaches led to the discovery of "subtle lesions", the definition of which is controversial in the literature [92].

Nisolle and Donnez debated that the anatomical location of the ectopic implants could be a key factor in the histogenesis of this disease [93].

\subsubsection{Superficial Peritoneal Endometriosis}

The difficulty in diagnosing microscopic endometriotic lesions makes reporting an accurate prevalence of endometriosis difficult. The superficial peritoneal category of endometriosis includes subtle and typical lesions that are rarely diagnosed without direct visualization. The definition of subtle lesions is debated in the literature but generally they are described as superficial, small (< than $3 \mathrm{~mm}$ ), fluid filled sacs (vesicles) that can be white, red, or flame-like in colouration. Typical lesions are larger at up to $4 \mathrm{~cm}$ in diameter and are usually dark (powder-burn or gunshot lesions) and sclerotic with angiogenic activity [92].

The biological activity varies between the different superficial peritoneal types as evidenced by observations of a lower mitotic index (indicating lower activity) in the white lesions, due to lack of vascularization, when compared to typical lesions [94]. Patients with superficial endometriosis tend to have minor symptoms and usually less structural changes in the pelvis. 


\subsubsection{Ovarian Endometriosis}

Endometriomas (chocolate cysts) develop when the surface (cortex) epithelium of the ovary, which has metaplastic potential under the influence of growth factors, is invaginated [95]. Endometriomas present as complex cystic masses that can grow as large as $15 \mathrm{~cm}$ in diameter, are thick-walled, can occur unilaterally or bilaterally, and contain a thick homogeneous dark red/brown liquid — hence the name "chocolate cyst" [96]. As with the other types of endometriosis, patients with endometriomas usually will present with pelvic pain and/or infertility. However, Fauconnier et al reported that chronic pelvic pain is correlated with deep infiltrating endometriosis more than with endometriomas [97].

\subsubsection{Deep Infiltrating Endometriosis}

Deep infiltrating endometriosis is defined as lesions penetrating more than $5 \mathrm{~mm}$ beneath the peritoneum [98]. They account for the more severe pain, depending on the localization and depth of the lesion. They can be found anywhere in the pelvis (cul-de-sac is the most common site of pelvic lesions), the abdominal wall, or localized in many unusual sites outside the pelvis, including the chest [99].

As in endometrioma, DIE also is frequently complicated by adhesion development. Adhesion development can lead to pelvic organs displacement and may be the cause of infertility in these patients.

\subsubsection{The Physiological Changes in Endometriosis}

The uterus is composed of two anatomical parts: the uterine body and cervix. The uterine body consist of a functional surface that is formed of single-layered surface epithelium, basal 
lamina, glands, connective tissue called stroma, and blood vessels. This functional surface epithelium will respond to hormonal changes during the menstrual cycle, resulting in reepithelialisation after each cycle and menstrual shedding. The basal lamina, however, does not respond to hormonal changes and thus it does not go through menstrual shedding.

The hypothalamic-pituitary-gonadal axis (HPG) regulates the changes in physiological concentration of the gonadal steroids in circulation. Gonadotropin-releasing hormone $(\mathrm{GnRH})$ is released in a pulsatile fashion from the arcuate nuclei of the hypothalamus and positively regulates the synergistic action of follicle-stimulating hormone (FSH) and luteinizing hormone (LH) being released into circulation. FSH and LH regulate the ovary to produce the gonadal steroids: estrogen and progesterone [100]. This regulation occurs in a cyclic manner that manifests in a uterine cycle and an ovarian cycle occurring in tandem. A cycle usually lasts between 28-32 days but may vary from woman to woman. The uterine cycle has three phases: the menstrual phase (from menstruation day up to day 7), the proliferative phase (from day 7 to 13), and secretory phase (from day 14 to menstruation) [101].

Proliferation of the uterine lining is caused by cumulative amounts of estrogen in circulation and occurs in parallel to the follicular changes in the ovary caused by circulating FSH. The secretory phase of the uterus occurs in parallel to the luteal phase in the ovary: the remnant of the dominant follicle is transformed into the corpus luteum which produces progesterone under the influence of LH. If no pregnancy occurs, progesterone levels will decrease leading to menstruation, sloughing off of the uterine epithelium, and the commencement of a new cycle [102]. It is common that the menstrual phase may be painful in some women (especially teenagers and young women) with some abdominal cramps or back pain [103]. 
The classical symptoms of endometriosis are dysmenorrhea (pain with menstruation), dyspareunia (pain with vaginal intercourse), and infertility. The key pathological features contributing to these symptoms are growth of the ectopic endometrial implants and inflammation. During the proliferative phase, as in the eutopic endometrium, the ectopic implants grow in response to high estrogen levels. When this tissue subsequently sheds in the menstrual phase, the trapped blood can lead to inflammation of the surrounding tissue and adhesion formation, potentially resulting in distortion of the anatomy of the pelvis. An alteration in the anatomy of the pelvis is thought to cause the main symptoms of endometriosis, pelvic pain and/or infertility. Proliferation and growth of the implants is mainly promoted by estradiol and estrogen, whereas inflammation is promoted by prostaglandin, estrogen and cytokines [15].

\subsubsection{The Role of Estrogen}

Estrogen is the primary female steroid hormone and plays a major role in development and

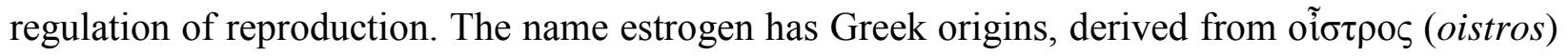
which means "producer of female desire" [104]. Estrogen has three natural endogenous bioactive forms: estrone (E1), 17 $\beta$-estradiol (E2), and estriol (E3). E1 is the least profuse estrogenic hormone and it is usually produced by peripheral aromatization of androstenedione. E2, on the contrary, is the most bioactive form of the three forms and is produced mainly in the ovaries via aromatization of androgens [105]. E3 is biologically potent during early pregnancy.

During the first two weeks of the menstrual cycle, the majority of circulating E2 is produced by the dominant follicle and plays essential roles in the endometrium revascularisation and proliferation of the functionalis layer [106]. The main mechanism of action of estrogen, as any other steroid hormone, is genomic, producing alterations in gene transcription via a cytosolic 
estrogen receptor. This hormone-receptor mechanism is dependent on the binding of the lipophilic estrogen hormone to specific estrogen nuclear receptors (ERs) (at the hormone binding domain) in the cytosol after the hormone has crossed the lipophilic cell membrane. Binding of estrogen to its receptor results in the activation of the hormone-receptor complex that enables the complex to bind to corresponding, specific DNA sites via a DNA binding domain. The protein complex can then be translocated to the nucleus of the cell, where DNA binding dimerization and subsequent regulation of messenger RNA (mRNA) transcription takes place. Proteins are synthesised by ribosomes as the end products of mRNA translation. In this process E2 receptors are just as important as E2 (the hormone) as E2 receptors are necessary to convert the hormonal signals into changes in gene transcription and cell function. There are multiple clinical factors of importance with regards to the action of the hormone-receptor complex, perhaps the most important being the duration and dose of hormone exposure $[15,107,108]$. In addition to the ERs, there are other hormone-receptor mechanisms that provide rapid cellular responses at the level of the cell membrane (membrane estrogen receptors (mERs)) and at the level of the endoplasmic reticulum (G protein-coupled receptors (GPER), e.g. GPR30) [109, 110].

Estrogen nuclear receptors have two isoforms: ER-alpha (ER- $\alpha$ ) and ER-beta (ER- $\beta$ ), encoded by chromosomes 6 and 14 respectively. Both receptors are five domain proteins named $\mathrm{A} / \mathrm{B}, \mathrm{C}, \mathrm{D}, \mathrm{E}$, and $\mathrm{F}$ domains. In ERs, the $\mathrm{N}$-terminal $\mathrm{A} / \mathrm{B}$ domain is a regulatory domain that activates gene transcription and is significantly different between the ERs. ER- $\alpha$ contains a transcription initiation factor TFIID subunit 1 (TAF-1) which will activate gene transcription, even in the absence of estrogen, via binding with epidermal growth factor (EGF), Insulin-like growth factor 1 (IGF-1), and Transforming growth factor alpha (TGF- $\alpha$ ). ER- $\beta$ however, does not have TAF-1 and can only regulate gene transcription when bound by estrogen. Next to the regulatory 
domain is the DNA-binding domain ( $\mathrm{C}$ domain) which promotes the dimerization of estrogen receptor response elements onto DNA. The D domain (the hinge), which is a region connecting domain $\mathrm{C}$ and $\mathrm{E}$, acts as a rotation site during the conformational change process and plays a role in the nuclear localization of the estrogen receptors. The $\mathrm{E}$ domain is responsible for gene transcription activation and it contains both estrogen hormone and coactivator /corepressor protein binding sites. The C-terminal F domain plays a role in the estrogen-bound receptor activity [15].

In patients with endometriosis, estrogen is produced locally from the ovary, peripherally via conversion of circulating androgens to estrogens by adipose tissue (as in normal women), and, in addition, a significant amount of estrogen is produced in the endometriotic implants through local aromatisation and/or other steroidogenic enzymes [111]. Moreover, ectopic implants express lower levels of $17 \beta$-hydroxysteroid enzymes, resulting in a reduction in the potency of E2 conversion to E1, effectively increasing the more bioactive E2 form of estrogen [22]. Another suggested mechanism resulting in high E2 bioavailability in patients with endometriosis is linked to prostaglandins (PGs). Local utilization of systemic cholesterol in the ectopic implants facilitates the local production of the $\mathrm{E} 2$ precursor androstenedione by steroidogenic acute regulatory protein (StAR; encoded by STAR gene) and aromatase (encoded by CYP19A1 gene), which results in elevated $\mathrm{E} 2$ [112]. Interestingly, prostaglandin $\mathrm{E}_{2}\left(\mathrm{PGE}_{2}\right)$, which is produced locally in the ectopic implants, promotes the expression of both STAR and CYP19A1 genes either directly or by binding to its receptor which in turn leads to an increase in the intracellular level of cyclic adenosine monophosphate (cAMP) and consequently increases STAR and CYP19A1 genes expression in the endometriotic stromal cells [112]. This mechanism is only observed in ectopic implants and not in disease free eutopic endometrium due to the absence of steroidogenic factor 1 (SF-1), as there are 
high levels of transcriptional repressors like Wilm's tumor 1 transcription factor (WT1) and CCAAT/enhancer binding protein $\beta(\mathrm{C} / \mathrm{EBP} \beta)$, in the latter [15].

\subsubsection{The Role of Prostaglandins}

Prostaglandins (PGs) are a subclass of eicosanoids derived from free arachidonic acid (AA) metabolism and are expressed in almost all the body's tissues. The chemical skeleton of PGs consists of 20 carbon atoms in a 5-carbon ring structure, with subsequent structural changes on the base skeleton determining the biological activity of the different PGs. The AA precursor to prostaglandins is freed from plasma membrane phospholipids by the phospholipase A2, cyclized/oxygenated/reduced by the cyclooxygenase (COX) enzyme isoforms COX-1 or COX-2 forming $\mathrm{PGH}_{2}$, and finally converted in the uterus to prostaglandin $\mathrm{E}_{2}\left(\mathrm{PGE}_{2}\right)$ and prostaglandin $\mathrm{F}_{2 \alpha}\left(\mathrm{PGF}_{2} \alpha\right)$. They have wide range functions such as vasoconstriction, vasodilation, smooth muscle contractility, blood pressure control, and inflammation attenuation.

Each prostaglandin has a specific receptor (a seven transmembrane G protein coupled receptor) that initiates signal cascades after being bound by the prostaglandin [113].

Higher levels of $\mathrm{PGE}_{2}$ are found in eutopic endometrium and ectopic implants of women with endometriosis when compared to disease free endometrium, and are thought to contribute to the pelvic pain and inflammation symptoms of endometriosis. The higher levels of $\mathrm{PGE}_{2}$ in endometrial stroma of patients with endometriosis is caused by the stimulation of cyclooxyganse (COX-2) by multiple cytokines (tumor necrosis factor- $\alpha$ (TNF- $\alpha$ ), IL-1 $\beta$, IL-6) and growth factors (vascular endothelial growth factor (VEGF)) that in turn promotes $\mathrm{PGE}_{2}$ production (Figure 1.1)[15]. Accordingly, the symptoms of pelvic pain and inflammation in endometriosis are a result of a continuous positive feedback loop that drives formation of estrogen and $\mathrm{PGE}_{2}$ via classical 
inflammatory responses that in turn results in further ectopic endometrial proliferation and inflammation. In conclusion, aromatase and $\mathrm{COX} 2$ actions are increased in the eutopic endometrium and ectopic implants of women with endometriosis leading to high local estrogen and $\mathrm{PGE}_{2}$ levels, respectively [114].

\subsubsection{The Role of Progesterone}

Another endocrine-related feature of endometriosis is the potential for resistance to progesterone. Progesterone (P4) is also an endogenous ovarian steroid hormone that is secreted by the corpus luteum during the luteal phase of the menstrual cycle and plays a major role in embryogenesis during pregnancy. The name of this hormone originated in the 1930's when progestin (pro- + gestation) was blended with the German word Luteosteron (corpus luteum and sterol) $[115,116]$. Many of the physiological effects of progesterone are amplified by estrogens, as estrogen signaling can up-regulate progesterone receptor (PR) levels [117].

There are two isoforms of the progesterone receptor - PR-A and PR-B - which are encoded by a single gene on chromosome 11q22, via two distinct promoter regions, and function as ligand-activated transcription factors mediating progesterone's regulation of cellular activities in tissues where they are expressed[15, 118, 119]. The two PR isoforms are structurally similar; however, PR-A is truncated compared to PR-B, missing an additional 164 amino acids that is found at the N-terminus of PR-B — termed the B-upstream segment (BUS) [15]. PR-A contains two activation factors (TAF-1 and TAF-2) located in the regulatory and hormonal binding domains respectively, whereas PR-B contains three activation factors (TAF-1, TAF-2, and TAF-3) allowing for PR-B to initiate transcription regulation even in the absence of the ligand (i.e. progesterone) [15]. PR-B activates progesterone-responsive genes; whereas, at the transcriptional level, PR-A 
does not activate progesterone-response genes. PR-A, on the other hand, plays a dominant repressor role of both PR-B and ER transcriptional activity in the presence of the ligand [120]. There are other cytoplasmic isoforms for PRs (PR-C, PR-S, and PR-T) reported in the literature; however, they demonstrate lower tendencies to initiate functional transcriptional changes [121].

In the normal secretory endometrium, progesterone stimulates stromal cell proliferation. The receptiveness of the endometrium to this progesterone signal depends upon the type, amount, and ratio of PR isoforms. For instance, the amount of PR-A, transcriptionally inactive and a repressor of PR-B transcriptional activity, in a cell plays an important role in progesterone resistance and repressing the anti-inflammatory action of PR-B. Therefore, the cellular ratio of PRA to PR-B is thought to play a role in many pathologies, including endometriosis $[120,122]$. In the normal endometrium, production of progesterone receptor isoforms is stimulated by E2. However, in ectopic implants, the level of PR-A is reduced and PR-B is undetectable when compared to normal eutopic endometrium, even though these ectopic implants produce viable quantities of progesterone and estrogen (Figure1.1) $[15,23,114]$. The resistance to progesterone in ectopic implants, via very low levels of PRs, is thought to contribute to elevated E2 levels and proliferation promotion as progesterone-mediated retinoic acid production is reduced which then leads to lower 17-beta-hydroxysteroid dehydrogenase (17BHD) levels, promoting high levels of E2 and high local aromatase activity [15].

\subsubsection{Diagnosis and Management of Endometriosis}

\subsubsection{Diagnosis of Endometriosis}

Clinical symptoms, a physical exam, and imaging modalities are not enough to make a final diagnosis of endometriosis. Only by laparoscopic findings which are (if possible) confirmed 
histologically, by the presence of endometrial glands and stroma, can a diagnosis of endometriosis be established [15].

Recently, a standardized system to report pelvic structures and/or anomalies during a diagnostic pelvic laparoscopy has been proposed [123]. Briefly, the pelvis was divided into four zones paired into two midline and two lateral zones that are demarcated by major anatomical structures in the pelvis (Figure 1.2).

Unfortunately, there are no available biomarkers to help screening for this overwhelming disease and definitive diagnosis can only be achieved by histopathological confirmation performed after a laparoscopy — the standard surgical management for endometriosis used to restore normal anatomy, relieve pain, and prevent adhesion formation [124, 125].

Due to the variety of endometriosis anatomical distribution, attempts at classifying this disease have been made and revised repetitively. The first classification system was the American Fertility Society classification in 1979, which was revised in 1985 and again in 1996. The American Fertility Society classification and staging system classifies endometriosis as either minimal, mild, moderate, or severe based on the severity of size, depth, and location of ectopic implants in addition to the general prognosis prediction of pain and infertility [126]. Although it is the most widely used classification system among gynecologists, it has many limitations, such as it poorly addresses deep infiltrating endometriosis and it lacks predicting both post-surgical pregnancy rates and outcome [15]. Therefore, other classifications were introduced. The ENZIAN score introduced in 2005 provides better classification for DIE involvement on other organs but does not classify the severity of the disease better than American Fertility Society classification [127, 128]. The Endometriosis Fertility Index (EFI) was introduced in 2010 to address demographical and morphological data as a predictor of post-surgical pregnancy rates in women 
with endometriosis [129]. This index included the factors that can predict unassisted pregnancy over 3 years after the surgery

\subsubsection{Management of Endometriosis}

Usually women who are seeking treatment are the ones who present with the clinical symptoms of endometriosis: pelvic pain and/or infertility. Treatment approaches can be conservative, medicinal and/or surgical depending on the severity of the symptoms and whether fertility is a concern.

Medicinal treatments for women with mild to severe pain include non-steroidal Antiinflammatory drugs (NSAIDs) in combination with estrogen-progesterone contraceptive pills and/or gonadotropin-releasing hormone agonist, depending on the levels of pain [15]. Another approach is to disrupt the positive feedback loop of continuous E2 and $\mathrm{PGE}_{2}$ production by administering exogenous aromatase inhibitors, subsequently restricting tissue growth (E2 levels) and the resulting inflammation and pain $\left(\mathrm{PGE}_{2}\right)[112]$.

Surgical treatment aims to delay or eliminate recurrence and to restore normal anatomy. Instrumental and technical advancement in treating endometriosis with the evolution of a minimal invasive approaches permit better short and long term surgical outcomes. Based on the severity and the type of endometriosis, different surgical approaches have been established [15].

\subsubsection{Endometriosis and Cancer}

Endometriosis shares many biological features with cancer: invasion of the surrounding tissue, migration to different locations, proliferation, and quick recurrences after treatment [130134]. In epithelial ovarian cancer, it is well known that the tumors are derived from germinal 
epithelium; therefore, the presence of ovarian surface epithelium could be accounted for by coelomic metaplasia [135].

According to the 2014 statistics from the Canadian Cancer Society, ovarian cancer is the fifth leading cause of cancer-related death in Canadian women and the most lethal gynaecological malignancy. The majority of epithelial ovarian cancer consists of high-grade serous cancers, which are now thought to be driven from the fallopian tube. Another one-quarter of ovarian cancer consists of low-grade serous, endometrioid, and clear cell cancers that are thought to derive from endometriosis. Indeed, an elevated risk of epithelial ovarian cancer is associated with endometriosis as shown by a meta-analysis reporting a $27-80 \%$ risk of ovarian cancer in women with endometriosis when compared to women from the general population without endometriosis [136].

\subsection{Homeobox (HOX) Genes}

\subsubsection{HOX Genes Structure}

In 1921, Dr. Calvin Blackman Bridges discovered the dominant regulatory genes in the fruit fly Drosophila melanogaster that explained the segmental replacement of the legs in the antennae location. These regulatory genes are the Homeobox superfamily (HOX) [137-139]. To date, in humans, the HOX family is composed of 39 regulatory HOX genes coding for nuclear proteins which are identified on four clusters (A-D) located on different chromosomes, at 7p15, 17p21, 12q13, and 2q31, respectively (Figure 1.3) [138]. In 1984, cloning these genes expanded our understanding about their function at the molecular level [140-142]. Each gene has a distinctive 181 base pair region encoding a 61 amino-acid long DNA-binding domain that is folded into a helix-turn-helix motif. 
The HOX genes preserve a relationship known as collinearity; each HOX cluster contains up to 11 genes organized in a linear fashion that is parallel to their expression along the anteriorposterior body axis [143]. In humans, HOX genes function as transcription factors regulating a series of downstream gene pathways. These pathways control structural embryogenesis and organogenesis by specifying the positional identity of the embryo's organ development along anterior-posterior axis, known as embryonic segmentation. The order of structures in this segmentation relates to the order of the HOX genes controlling the development of that structure along the chromosomes or in the cluster.

In addition, HOX genes play an important role during adult life with regards to functional differentiation, regulating hematopoietic stem cell differentiation [144], endothelial cells angiogenesis [145], adhesion, and motility [139, 146, 147]. Recently, an important link was established between HOX genes and oncogenesis as well as tumor suppression [148]. HOX genes, together with co-activators, bind to DNA and consequently regulate expression of genes involved in oncogenesis.

\subsubsection{Regulation of HOX Genes Expression}

Mechanisms of regulating HOX gene expression is guided by the 3' to 5' location of the HOX gene in the cluster, which resembles their expression along the A-P axis. All 3' genes are expressed in the anterior tissues and are recessive to the more dominant phenotype of the 5 ' genes that are expressed posteriorly. Not only in the developing tissue, but also in the adult tissue, HOX genes are considered the morphological identity regulators. Mechanisms regulating adult tissue cellular balance were linked to HOX transcriptional mechanisms. Understanding these principles of HOX gene location helped in identifying HOX gene dysregulation and the critical role this 
dysregulation plays in carcinogenesis [148]. As a general rule, when a HOX gene is highly expressed during embryogenesis, the same gene is increased in cancer. However, if the HOX gene is highly expressed in the adult tissues, the expression of that HOX gene is decreased in cancer [149]. Moreover, HOX genes may have opposing functions in different tissues when regulated by specific pathways that either contribute to normal organogenesis or the disruption that happens during tumor genesis in the same organ or in a different one [139]. An example would be HOXB13; this gene is essential in the normal development of the prostate [150] and supresses prostate cancer formation [151], meanwhile it promotes the invasiveness of breast cancer [152].

HOX genes regulate tissue identity during development and in adult tissues; however, they are in turn regulated by the interaction of many hormones and their receptors, including sex steroids and vitamins [153].

\subsubsection{HOX Genes and Steroids}

HOX genes during female reproductive tract embryogenesis are regulated by estrogen. In humans, during the development of the Müllerian duct, the collinearity of HOX genes (as mentioned earlier) is uniquely preserved. This is evident in the linear expression of the HOXA cluster genes during female reproductive organogenesis. HOXA9 is expressed in the rostral portion of the paramesonephric duct that differentiate into the oviducts, followed by HOXA10 expression in the regions that develop into the uterus, and HOXA11 expression in the regions that develop into the uterus and the cervix. Finally, the 5' HOXA13 is expressed in the dorsal portion, which differentiates into the vagina [154]. There is enough evidence to prove that these genes continue to maintain the adult functional characteristics of the female reproductive tract such as plasticity [155]. Diethylstilbestrol (DES), a nonsteroidal estrogen used to treat pregnant mice to improve 
pregnancy outcomes, treated mice demonstrated posterior shifts of HOXA9, 10 and 11 gene expression from the normal pattern, leading to multiple reproductive anomalies [156]. Moreover, this posterior shift was demonstrated by Block et al in human endometrial cancer cells treated with DES. This resulted in two fold increase in HOXA9 expression posterior to its normal expression domain (i.e. oviduct) [156]. Knocking out Er $\alpha$ in mice resulted in sterility while mice that lacked $\operatorname{Er} \beta$ were either sub fertile or infertile [157]. Moreover, in vitro human primary cultured endometrial cells treated with $17 \beta$ estradiol resulted in concentration-dependent elevation in HOXA10 and HOXA11 mRNA levels [158]. Progesterone also plays a role in regulating HOX genes in the adult tissue. It regulates the expression of both HOXA10 and HOXA11 in the endometrial tissue. This is evident in its role in mediating endometrial receptivity by endocrineHOX signalling pathways [153]. Taylor et al treated primary endometrial cell cultures with medroxyprogesterone acetate (MPA). They found that the expression levels of both HOXA10 and HOXA11 are increased in a linear fashion temporally coincident with the level of the steroids hormones during the menstrual cycle [158].

\subsubsection{HOX Genes and Vitamins}

Vitamin A has many active forms, one of relevance is retinoic acid (RA). It functions as a hormonal metabolite that is essential for the growth and development of epithelial cells. This role is clear during embryonic development as RA serves as an intercellular signalling molecule regulating the developmental direction along the AP axis [159]. RAs mechanism of action is mediated by binding to its nuclear receptor, retinoic acid receptor (RAR), at the retinoic acid response element (RARE) region along with the heterodimer retinoid X receptor (RXR). This will result in conformational changes of RAR that allows for up or down transcriptional regulation of 
HOX genes and other target genes [160]. Indeed, HOX genes developmental functions are regulated by RA as determined in mouse deletion analysis studies. In a cluster, 3'HOX genes were found to be more sensitive to transcriptional changes induced by RA when compared to genes around the 5' [161]. Moreover, RAREs, when bound by RA, where found to regulate HOXA1 in humans and mice $[161,162]$. Furthermore, early expression patterns of HOXB1 in mice and chicken are established by enhancers that, in conjunction with RAREs, regulate the expression of this gene [163]. During murine embryogenesis, ectopic exposure to RA resulted in increased anterior expression of the $3^{\prime} \mathrm{HOXB}$ genes but not the 5' genes [164]. Overall, RA is an important regulator during embryogenesis and organogenesis.

Vitamin $\mathrm{D}$ is metabolised in vivo to the active form calcitriol or 1,25-dihydroxyvitamin $\mathrm{D}_{3}$. Upon binding of $\mathrm{D}_{3}$ to vitamin $\mathrm{D}$ receptor (VDR), a cascade of reactions are triggered that results in the binding of the $\mathrm{D}_{3}$-VDR complex to specific vitamin $\mathrm{D}$ response elements (VDREs) in the enhancers of target genes allowing for regulation of these genes. Indeed, in primary human endometrial stromal cells, HOXA10 was upregulated after exogenous $\mathrm{D}_{3}$ treatment [165].

\subsubsection{HOX Genes and Cancer}

Little is known about how endometriosis undergoes malignant transformation to endometrioid and clear cell ovarian cancers $[166,167]$. However, the Müllerian ducts are originated from the embryonic coelomic cavity epithelium, where differentiation of the primitive uterine tube to oviducts, fallopian tubes, uterine corpus and cervix is regulated by many transcriptional factors including HoxA9, A10 and A11 [168, 169]. Although normal ovarian epithelia don't express any of these genes, the morphological resemblance of the epithelial ovarian cancer and the Müllerian duct derived epithelium suggest that they share the same cellular origins, 
which is regulated by HOXA9,A10 and A11. This conclusion was supported when differentiation of the Müllerian duct, resulting in cells with morphological resemblance to epithelial ovarian cancers cells, occurred via inducing the collinear expression patterns of these HOX genes in the ovarian surface epithelium of tumorigenic mice [168-172]. The HOXB family was further identified in a high susceptibility region for ovarian cancer (locus 17q21) [173]. Moreover, HOXA4 was found to regulate some of the biological features of ovarian cancer cells. Ota T. and colleagues demonstrated that HOXA4 regulates the migratory capacity of ovarian cancer cells, but it has no effect on invasiveness $[174,175]$. Interestingly, a recent study has shown that HOXB4 suppresses ovarian cancer cell invasion, but not migration, by modulating the cell adhesion molecule CD44 [176].

\subsubsection{HOX Genes in the Endometrium}

Some of the first HOX clusters studied in the endometrium were HOXA10 and HOXA11. Taylor et al in 1999 looked into the role of these clusters in the development of the uterus [177, 178]. Although the HOX superfamily does regulate developmental and functional differentiations of the tissues, there are many hormonal factors that play important roles in regulating the expression of the superfamily. For instance, HOXA10, expressed in the glands and the stroma of the eutopic endometrium, is up regulated in a stage-dependent manner, reaching the highest expression magnitude in the late secretory phase. Moreover, treatment of endometrial cell cultures with $17 \beta$ estradiol and medroxyprogesterone acetate increase the expression of HOXA10 [158].

The HOXA10 cluster also plays a key role in embryo implantation [179]. In endometriosis, the expression of HOXA10 does not exhibit this mid-luteal rise seen in the normal endometrium, which might contribute to the infertility in women with endometriosis [179]. 


\subsubsection{HOXB4}

HOXB4 is one of four HOX group 4 paralogs of the Antennapedia (ANTP) homeobox superfamily genes. It is located on chromosome 17 and encodes a nuclear protein that functions as a transcription factor implicated in cellular differentiation and development. In mice, HOXB4 is expressed during embryogenesis in two germ layers (neural tube epithelium and mesoderm). In the adult mice however, HOXB4 is expressed in the kidneys, lungs and testes [180]. In humans, HOXB4 has been studied extensively in the hematopoietic stem (HS) and progenitor cells in vivo and in vitro. In vitro, all these genes were found to stimulate proliferation and inhibit differentiation in hematopoietic precursors [181]. HOXB4 overexpression in HS cells enhance the differentiation and expansion of these embryonic stem cells, yet this effect is lost in the adult cells $[182,183]$. In the female reproductive tract, a genome-wide association study demonstrated a likely predisposition mutation to serous ovarian cancer at locus (17q21) [173]. New evidence suggest that HOXB4 inhibits invasion of high-grade serous ovarian carcinoma cells [176]. In the endometrium, HOXB4 was found to be expressed in the human primary glandular epithelial cells and this expression is steroid dependent [184].

\subsection{Aim}

The aim of our study was to examine the expression and localization of HOXB4 in normal human endometrial tissues as well as eutopic endometrium and ectopic implants from women with endometriosis throughout the menstrual cycle. We hypothesized that the expression of HOXB4 is reduced in eutopic and ectopic endometrial tissues of patients with endometriosis. 


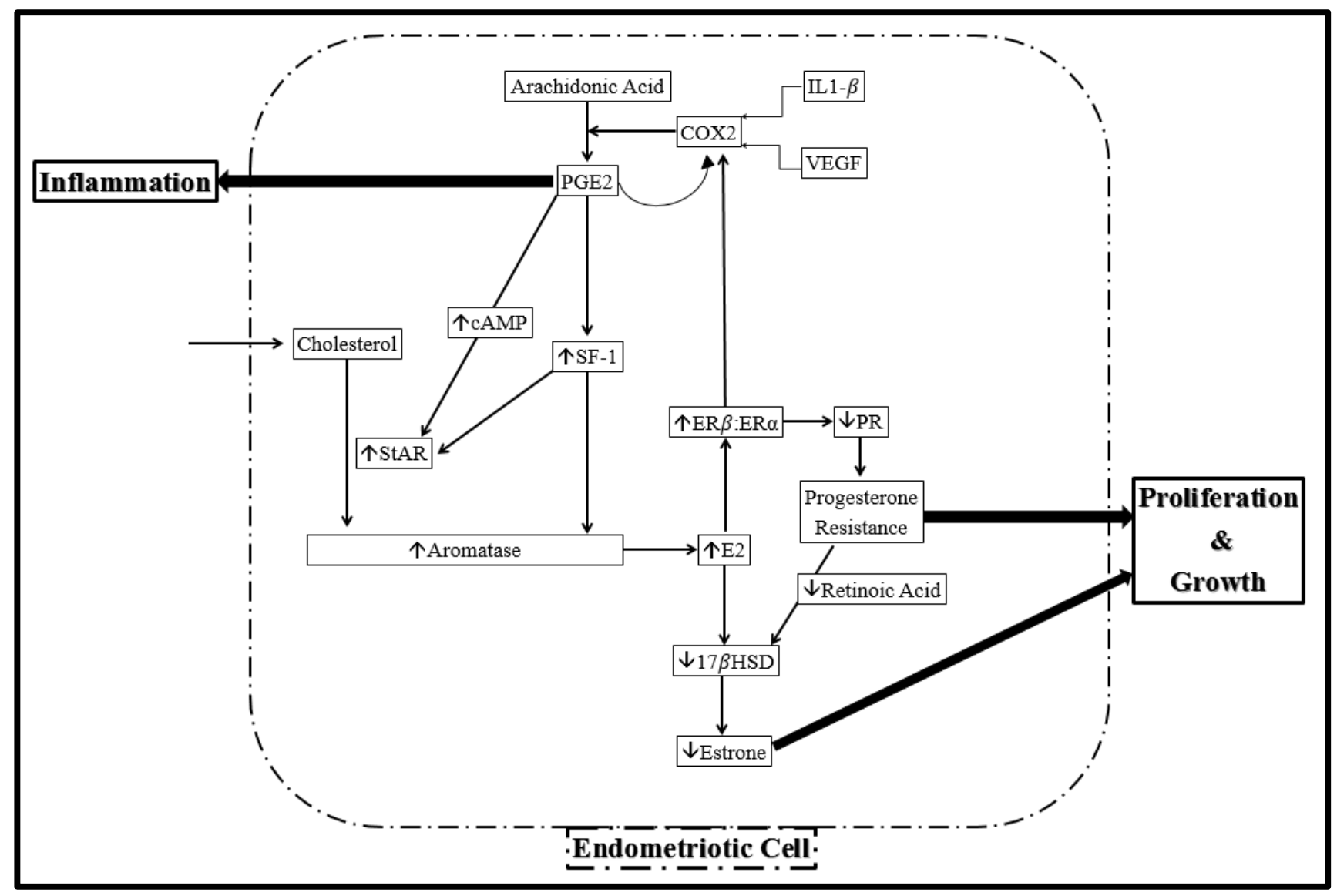

Figure 1.1: Main molecular mechanisms accountable for the major symptoms of endometriosis. Adapted from [15, 112] 


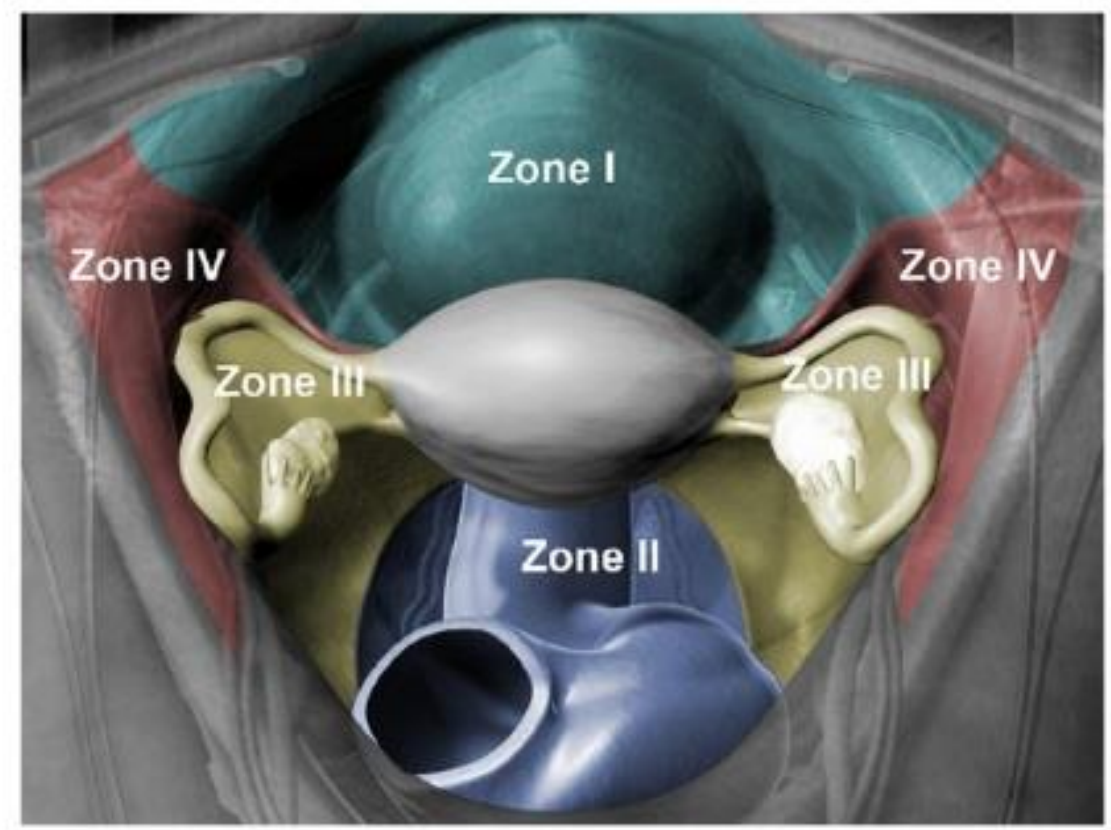

Figure 1.2: Illustration of the anatomical boundaries and the contents of all pelvic zones [185]. 


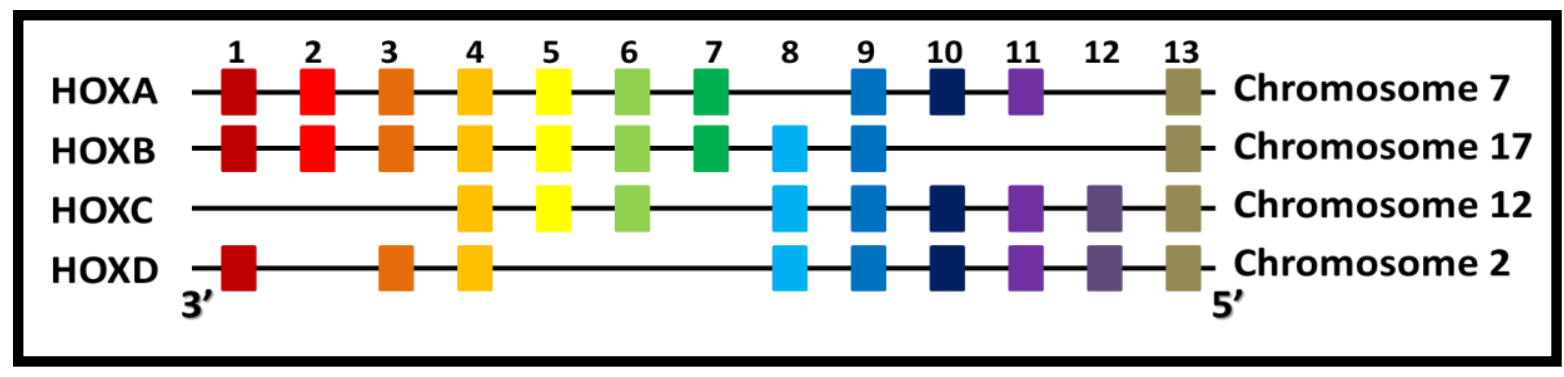

Figure 1.3 Schematic illustration of HOX clusters in humans:

Thirteen paralogous groups of the HOX genes in a linear order (the numbered columns). HOX 4 group is found on all the four clusters (A, B, C and D). In humans, HOXB4, as all the 3' HOX genes, is expressed in the anterior tissues earlier in life and have less phenotypical dominance (red to yellow) in comparison to the posterior tissues (all 5' genes in green to brown). Adapted from $[139,153]$ 


\section{Chapter 2: Materials And Methods}

\subsection{TISSUES PROCUREMENT}

Control eutopic endometrial biopsies or curettage, from forty four fertile women without endometriosis, were obtained from Case Western Reserve, Cleveland, Ohio, USA - approved by the institutional review board (IRB\# 12-10-28) - and Sohaj University, Sohaj, Egypt, with samples transferred to Dr. Bedaiwy's lab according to the Material Transfer Agreement (MTA\# M1500189 ). These control women underwent laparoscopy for benign gynecological conditions other than endometriosis (e.g. tubal ligation and re-anastomosis) (Figure 2.1).

In the disease group, eutopic and ectopic endometrial tissues were obtained from forty seven women who underwent laparoscopy to diagnose or manage endometriosis and were obtained from the Endometriosis Determinants Of Oncogenesis (ENDO-ONC) Tissue Bank, Vancouver General Hospital (VGH) pathology and British Columbia Cancer Agency (BCCA). This tissue bank was approved by the Clinical Research Ethics Board at the University of British Columbia (REB number: H05-60119) and patients were recruited prospectively at BC Women's Centre for Pelvic Pain \& Endometriosis, Vancouver, BC, Canada (REB number: H14-03040).

None of the patients received any hormonal therapy for at least 3 months before the laparoscopy. Although the histopathological diagnosis of cases and controls was given in accordance to the standardized procedures in the hospital of origin, all the haematoxylin and eosin stained sections for eutopic and ectopic tissues were histologically reviewed by a pathologist in order to identify samples with uterine glands. Additionally, the cycle phase in the eutopic endometrium in both cases and controls was confirmed by histologic dating according to the Noyes criteria described below [186]. 


\subsection{ENDOMETRIAL DATING}

The assessment and categorization of endometrial dating described by Noyes remains one of the most challenging areas in gynecologic pathology [186]. Briefly, based on haematoxylin and eosin morphology, the endometrium cycles are divided into several phases: 1) menstrual phase, 2) early proliferative phase, 3) mid- to late proliferative phase, 4) 16-day endometrium, 5) vacuole phase of early secretory endometrium, 6) the secretory exhausted phase, and 7) the predecidua phase. These criteria are used to assess whether the ovulation has occurred, evaluate possible luteal phase defects, investigate irregular maturation in endometrial glands and stroma, determine the hormonal status, examine the causes of endometrial bleeding and infertility, and estimate the luteal maturation for potential recipients of egg donation or frozen embryos [186, 187]. However, its reliability has been challenged given the wide range of alterations and changes seen in the endometrium during the reproductive and menopausal years [187].

Due to the limitation of accessing patients' menstrual history, endometrial dating was determined by histological examination only using the criteria of Noyes; however, endometrial dating was only divided into proliferative or secretory phases due to the limited number of eutopic endometrium slides included in the control and the cases of this study. In the proliferative group, the glands and stroma had increased mitotic activity. Furthermore, the glands were tubular, elongated and more tortuous with an even and wide distribution. Stromal cells appeared separated from each other due to a small cytoplasmic volume in the cells. The secretory phase was also characterised by sub-nuclear vacuoles glands with predecidual changes in the stroma (eosinophilic cytoplasm).

A group of eutopic endometrial slides $(n=9)$ were found to be lacking mitotic changes. These slides were marked as inactive and were not included in the general analysis. 


\subsection{IMMUNOHISTOCHEMISTRY}

Formalin Fixed Paraffin Embedded (FFPE) and preserved in Molecular Fixative (MF) eutopic and ectopic endometrium, containing endometrial glands, were sectioned at $4 \mu \mathrm{m}$ slices. The monoclonal rabbit HOXB4 antibody (\#2096-1, Epitomics) used in IHC was validated [176]. Briefly, variable concentration of HOXB4 monoclonal antibody was used in OVCAR-8, A2780, OVCAR-5 and CaOV-3 cells in order to analyzed the expression of HOXB4 via immunocytochemistry. OVCAR-8 and A2780 cells highly expressed HOXB4. Moderate expression was observed in CaOV-3 cells and no HOXB4 expression was observed in OVCAR-5 cells. Moreover, treating OVCAR-8 cells with HOXB4 siRNA diminished the expression of HOXB4 in all the cells. The subsequent slides were stained using previously published protocols $[176,188]$. Briefly, after de-paraffinization and rehydration, antigen retrieval was done with a preheated antigen retrieval reagent in a steamer (Preheat Dako retrieval solution modified citrate buffer pH 9, (Cat \# S2367). Endogenous peroxidase activity was quenched (Dual Endogenous Enzyme block for autostainer, Cat\# S2003) and the sections were incubated with HOXB4 antibody (1:800) at $4{ }^{\circ} \mathrm{C}$ overnight. To detect primary antibody, EnVision+ Dual Link System-HRP (Dako, Cat\# K4061) was used. The sections were then exposed to a chromogen reaction for 10 minutes (Liquid DAB Chromogen System (Dako, Cat\# K3468) and counterstained with Harris haematoxylin for 30 seconds (Sigma). Finally, the slides were rehydrated through 3-minute ethanol and xylene washes and mounted. The signals were observed under a light microscope (Leica). All slides were analyzed using an Olympus BX 41 Microscope (Olympus Corporation).

Some of the tissues were preserved in a molecular fixative (mixture of methanol and polyethylene glycol). While this is a novel technique in tissue preservation that has been proven to be preferable in downstream molecular diagnostic assays [189], the staining level was found to be significantly 
reduced or absent in all the MF blocks. Due to the time and resources limitations we had to exclude these cases or slides from this study until the immunoblotting protocol is modified and validated to assure the accuracy of the results.

\subsection{HISTOSCORE (H-SCORE)}

We compared the variable intensities of HOXB4 expression in the glands of both eutopic and ectopic endometrium using the Histoscore method (H-Score). Three different reviewers who were blinded to the phase and the diagnosis scored the slides on a multi-headed microscope (UMDO10B3, Olympus BX51, Olympus America, Melville, NY, USA). The process was as follows: (i) the slide was scanned at low power first (either $\mathrm{x} 2.5$ or 10) to select the area most representative of the total staining intensity (ii) the highest intensity stained glands were analyzed with a magnification of $\mathrm{x} 40$ (HPF) to evaluate the staining intensity of the epithelial nuclear expression in that fixed area (iii) the proportion of the staining was then assessed. The immuno-reactivity of HOXB4 was independently determined by all the observers via interpretation of the stain intensity (in our case epithelial nuclear expression) using an intensity strength (I) score of 0, 1, 2, 3 (no stain, weak, moderate, or strong respectively). A proportion score $(\mathrm{P}=0-100 \%)$ was also determined for each slide followed by an $\mathrm{H}$-score calculated with the following formula: $\mathrm{H}$-score $=\Sigma \mathrm{P}(\mathrm{I}+1)[190,191]$.

The mean score from all three observers was calculated. In cases where there was more than one slide to represent a specimen in the same patient, all the slides were scored and the highest one among them was entered in the final analysis. 


\subsection{CELL CULTURE AND STEROID TREATMENT}

cDNA from HEC1A, HEC1B, HEC50, KLE, RL952 and AN3CA endometrial cancer cells were kindly provided by Dr. Peter Leung's Lab at the Child and Family Research Institute Vancouver, BC, Canada. Only HEC1A and HEC1B cells (also provided generously by Dr. Leung's Lab) were cultured for experiments examining the regulation of HOXB4 expression.

HEC1A and HEC1B cells were maintained in DMEM/F12 (Sigma-Aldrich, Oakville, Ontario, Canada) media supplemented with 10\% fetal bovine serum (FBS) (HyClone) and 1\% penicillin/streptomycin (Invitrogen). Cells were routinely split at 80\% confluence using trypsinEDTA and routinely sub-cultured at 1:10, and the medium was routinely changed every $48 \mathrm{~h}$.

Prior to estrogen treatment, the cell lines were grown to $80 \%$ confluency, washed twice with PBS, trypsinised and re-suspended in fresh DMEM containing 10\% charcoal-dextran stripped FBS (Hyclone) for 24h. The cell suspension was further diluted such that a $200 \mathrm{~mL}$ aliquoted dish produced approximately $50-60 \%$ confluency after $24 \mathrm{~h}$ of incubation at $37 \mathrm{C}$. At this stage, the DMEM was replaced with DMEM containing 0.5\% stripped FBS. After $48 \mathrm{~h}$, incubations with the sex steroids $17 \beta$-estradiol (E2) (Sigma-Aldrich, Helsinki, Finland) was started for $48 \mathrm{~h}$ to a final concentration of $10^{-8} \mathrm{M}$ E2 $[192,193]$. Hormone treatment was for $1 \mathrm{~h}, 3 \mathrm{~h}, 6 \mathrm{~h}, 12 \mathrm{~h}, 24 \mathrm{~h}$, and $48 \mathrm{~h}$ for mRNA experiments. All cells were cultured and sub-cultured at $37^{\circ} \mathrm{C}$ in a humidified incubator with 5\% $\mathrm{CO}_{2}$. After treatment, they were kept in TRIzol® Reagent (Ambion, Cat\# 15596-026) for less than $72 \mathrm{~h}$ in preparation for RNA extraction.

\subsection{RNA EXTRACTION}

Total RNA was extracted from both archived FFPE blocks and cultured cell lines. 


\subsubsection{RNA Extraction from FFPE Blocks}

We examined HOXB4 mRNA levels in normal human endometrium (EC), eutopic endometrium (EE), and ectopic endometrial implants (Eoma and DIE) in patents with endometriosis. EC $(n=24), E E(n=25)$, Eoma $(n=21)$, and DIE $(n=20)$ blocks were not older than 3 years (Figure 2.2). The extraction process was initiated using the RecoverAll ${ }^{\mathrm{TM}}$ Total Nucleic Acid Isolation Kit for FFPE (Ambion, AM1975); however, due to company supply issues and low recoverable RNA concentration ( $\geq 10.6 \mathrm{ng} / \mu \mathrm{L}$, ranging from 10.6 to up to $296.3 \mathrm{ng} / \mu \mathrm{L}$ ), with a success rate (>77 ng/uL) of 51.7\% (15/29 samples), we used another kit - AllPrep DNA/RNA FFPE Kit (Qiagen Inc., Mississauga, ON, Cat\#80234). This kit had a recovered measurable RNA ( $\geq 10.3 \mathrm{ng} / \mu \mathrm{L}$, with concentrations ranging from 10.6 to over $400 \mathrm{ng} / \mu \mathrm{L})$ success rate $(>77 \mathrm{ng} / \mu \mathrm{L})$ of $72.6 \%$ (48/66 samples). The concentration of RNA in samples was assessed by NanoDrop-1000 spectrophotometer.

The extraction procedure was slightly modified in both of the kits, the procedures are compared in Table 2.1. 
Table 2.1: RNA extraction procedure in the RecoverAll ${ }^{\mathrm{TM}}$ and AllPrep Kits

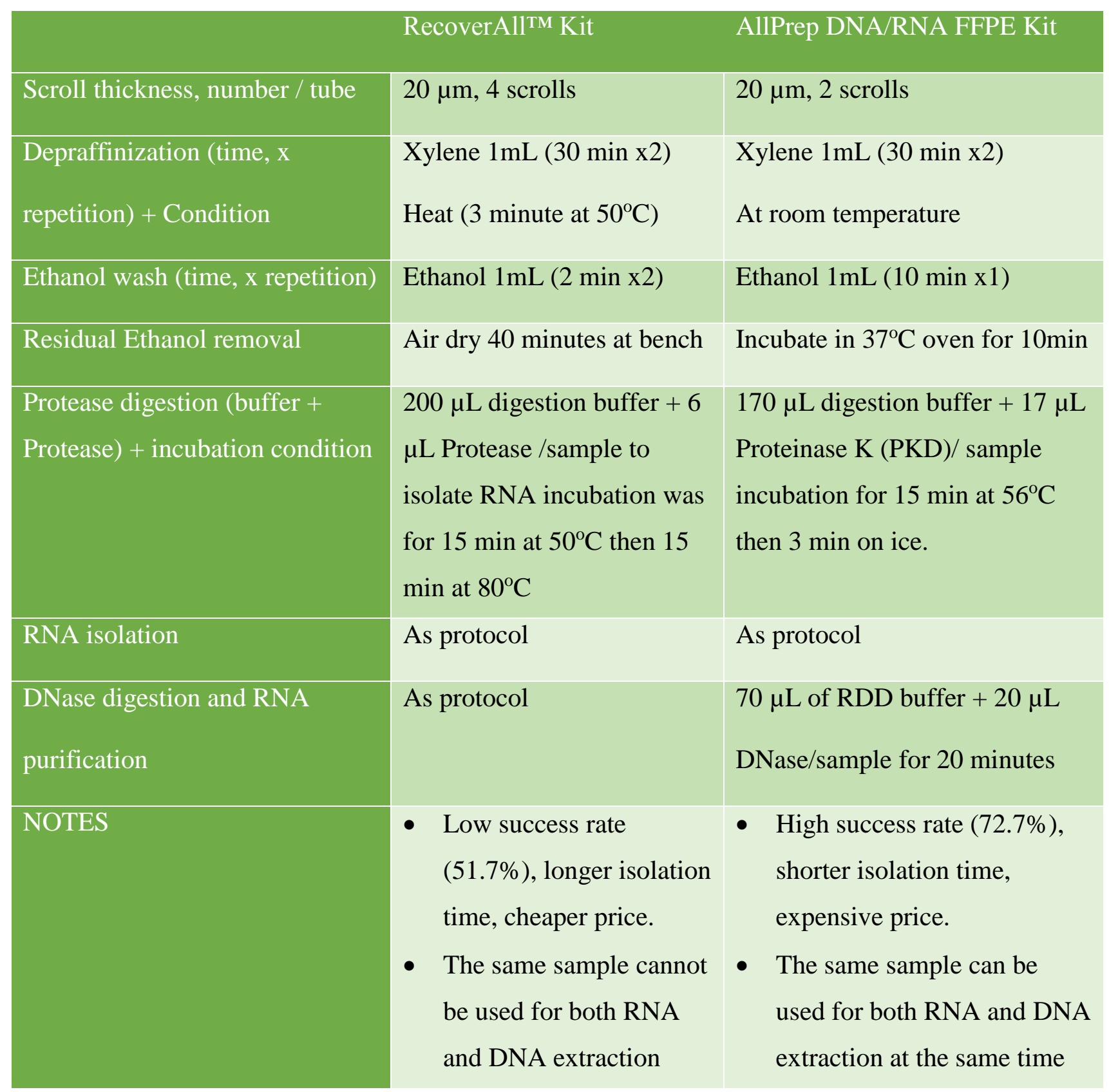

\subsubsection{RNA Extraction from Cells}

RNA was extracted from cultured cells with the TRIzol Reagent (Ambion, Cat\#15596026). Briefly, after treating the cells, the samples were homogenized with $1 \mathrm{~mL}$ of TRIzol and kept 
in $-80^{\circ} \mathrm{C}$. On the day of extraction, the samples were incubated at room temperature until they thawed. The separation phase was then initiated by incubating them at room temperature with 200 $\mu \mathrm{L}$ of Chloroform for 15 minutes followed by a centrifugation at $4^{\circ} \mathrm{C}$. RNA was then precipitated by adding $500 \mu \mathrm{L}$ of isopropanol and washed with $75 \%$ ethanol. Finally, RNA was re-suspended in $20 \mu \mathrm{L}$ buffer ATE elution solution (Qiagen, Germany). The concentration and purity of total RNA was measured by a NanoDrop-1000 spectrophotometer (NanoDrop Technologies, Inc., Wilmington, DE). All samples with a RNA concentration more than $85 \mathrm{ng} / \mathrm{mL}$ and a $260 / 280$ ratio of more than 1.85 were processed to the reverse transcription step.

\subsection{REVERSE TRANSCRIPTION}

Complementary DNA (cDNA) synthesis was performed with the High Capacity cDNA RT kit (Applied Bio systems, Cat\# 4368814, Luithaunia). All samples with RNA concentration of $\geq 80$ $\mathrm{ng} / \mu \mathrm{L}$ were included in the RT step. Briefly, using aliquots of 1 ug RNA in $10 \mathrm{~mL}$, RNA was converted to cDNA. The samples of RNA were diluted to $20 \mathrm{ng} / \mathrm{Ll}$. The next step was to prepare the master mix by adding to each sample $2 \mu \mathrm{L}$ of $10 \mathrm{xRT}$ buffer, $2 \mu \mathrm{L}$ of $10 \mathrm{x}$ random primer, $0.8 \mu \mathrm{L}$ of $25 \mathrm{xdNTP}, 4.2 \mu \mathrm{L}$ DNAse/RNAse free water and $1 \mu \mathrm{L}$ of Reverse Transcriptase. The mixture of the diluted RNA and master mix was then processed in Eppendorf Mastercycler Gradient (Eppendorf, Hamburg, Germany) according to the following cycles: 10 minutes at $25^{\circ} \mathrm{C}, 120$ minutes at $37^{\circ} \mathrm{C}, 5$ minutes at $85^{\circ} \mathrm{C}$ and finally 60 minutes at $4{ }^{\circ} \mathrm{C}$. The mixture was then stored at $-20^{\circ} \mathrm{C}$ until RT-PCR. 


\subsection{REVERSE TRANSCRIPTION QUANTITATIVE REAL TIME POLYMERASE CHAIN REACTION (RT-QPCR)}

For the FFPE samples, quantitative real-time PCR (qPCR) was conducted using TaqMan Gene expression Assay kits consisting of HOXB4 (Hs00256884_m1HOXB4) primer and GAPDH (Hs02758991_g1GAPDH) primer. In addition, Cytokeratin 7 (CK7; Hs00559840_m1KRT7) which is an epithelial cells marker was used to further validate our downstream target expression. Both GAPDH and CK7 were amplified as the reference gene in each reaction. Together, the diluted cDNA of each sample, the TaqMan assay, and the TaqMan Gene Expression Mastermix were loaded in duplicates in a 96-well plate. Each $20 \mu \mathrm{l}$ TaqMan reaction contained 5 ng cDNA, $1 \times$ TaqMan gene expression master mix (Applied Biosystems) and 1×TaqMan gene expression assay. The reaction was conducted at $50^{\circ} \mathrm{C}$ for 2 minutes, $95^{\circ} \mathrm{C}$ for 10 minutes, and 40 cycles of $95^{\circ} \mathrm{C}$ for 15 seconds and $60^{\circ} \mathrm{C}$ for 1 minute. The signal was detected using the ABI Prism 7300 Sequence Detector System (Applied Biosystems, Foster City, CA). The amplification signals were detected by the FAM dye detecting system. A mean value was used for the determination of mRNA levels by the comparative $\mathrm{CT}(2-\Delta \Delta \mathrm{CT})$ method with GAPDH or CK7 as the reference gene.

For the cell cultures, PCR was repeated in three different cultures and only HOXB4 and GAPDH assays were used in duplicates.

\subsection{WESTERN BLOT}

Cells were washed once with iced-cold PBS and cell lysis was accomplished using the proteinase inhibitor cocktail (Sigma) added to ice-cold lysis buffer (Cell Signaling Technology). The culture dish was placed on ice for $5 \mathrm{~min}$. Tissue lysates were then centrifuged at $\geq 13000 \mathrm{Xg}$ for $30 \mathrm{~min}$ at $4^{\circ} \mathrm{C}$. A DC protein assay (Bio-Rad Laboratories, Richmond, CA) was used to measure protein 
concentration in both cell lysates and tissue lysates. The protein lysates were diluted to equal concentrations and boiled for 5 mins with loading buffer $(2.5 \% \mathrm{w} / \mathrm{v}$ sodium dodecyl sulphate (SDS), 10\% v/v glycerol, $50 \mathrm{mM} \mathrm{HCl,} \mathrm{pH} \mathrm{6.8,} 0.5 \mathrm{M} \beta$-mercaptoethanol and $0.01 \% \mathrm{w} / \mathrm{v}$ bromophenol blue). $20 \mu \mathrm{g}$ of protein was separated by $8 \%$ or $10 \%$ SDS-polyacrylamide gel electrophoresis at $120 \mathrm{~V}$ for 2 hours. Proteins were transferred to polyvinylidene difluoride (PVDF) membranes at $100 \mathrm{~V}$ for 2 hours. The membranes were blocked with $5 \%$ skim milk in $0.05 \%$ Tween-20 Tris-buffered saline (TBS: $10 \mathrm{mM}$ Tris-HCl, pH7.4, $150 \mathrm{mM} \mathrm{NaCl}$ ) for 1 hour at room temperature. The primary antibody of HOXB4 in a 1:1000 dilution was incubated overnight at 4 ${ }^{\circ} \mathrm{C}$. To visualize bound antibodies, peroxidase-conjugated secondary antibodies (1:20000; Bio-Rad Lab), SuperSignal West Pico and Femto chemiluminescent substrates (Pierce, Nepean, ON), and X-ray film (Kodak) were used.

\subsection{STATISTICAL ANALYSIS}

\subsubsection{Histoscore Analysis}

All the age values were expressed as mean \pm SD. Mann-Whitney rank sum test was used to compare scores from examination of ectopic and eutopic endometrium. Kruskal-Wallis nonparametric test was used to compare multiple categories. Mann-Whitney test was used for unpaired comparisons. Wilcoxon test was used for pair-wise comparisons. A $P$ value of $<0.05$ was considered statistically significant. All the tests were done using GraphPad Prism 6 (GraphPad InStat program; GraphPad Software, Inc., San Diego, CA, USA) with the consultation of Dr. Sarka Lisonkova. 


\subsubsection{RT-PCR Data Analysis}

Quantitative qPCR results were analysed using GraphPad Prism 6 (GraphPad InStat program; GraphPad Software, Inc., San Diego, CA, USA). Outliers were excluded automatically using the ROUT method in Prism software which detects outliers while fitting a curve with nonlinear regression. This method is better than the commonly used Grubbs' method as it can identify one or more outliers by detecting outliers from a stack of values in a column data table.

Expression values for HOXB4 were normalized to the endogenous control of GAPDH, Cytokeratin 7 (CK7), and ratios relative to an endometrial control (sample 9) were generated. Relative gene expression ratios were calculated according to $\Delta \Delta \mathrm{CT}$ protocol [194] using the average efficiency of HOXB4 and CK7 and the CT of each duplicate. To analyze the differences between groups, Kruskal-Wallis non-parametric test was used to compare multiple categories. Mann-Whitney test was used for unpaired comparisons. A $P$ value of $<0.05$ was considered statistically significant. All values are expressed as mean \pm SD. All the tests were done using GraphPad Prism 6 (GraphPad InStat program; GraphPad Software, Inc., San Diego, CA, USA) with the consultation of Dr. Sarka Lisonkova. 


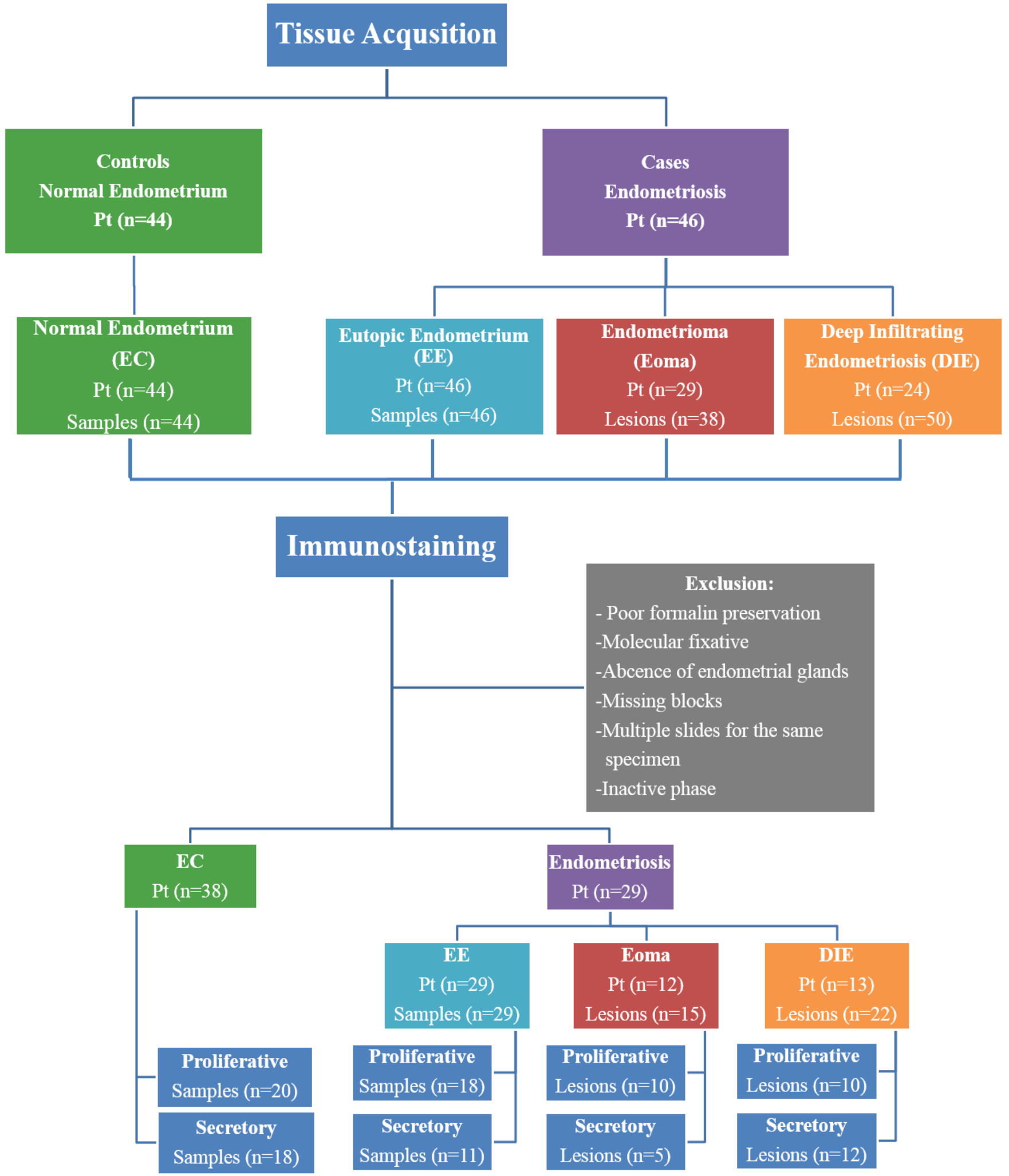

Figure 2.1: Schematic presentation of the study population. Pt: the total number of patients. 


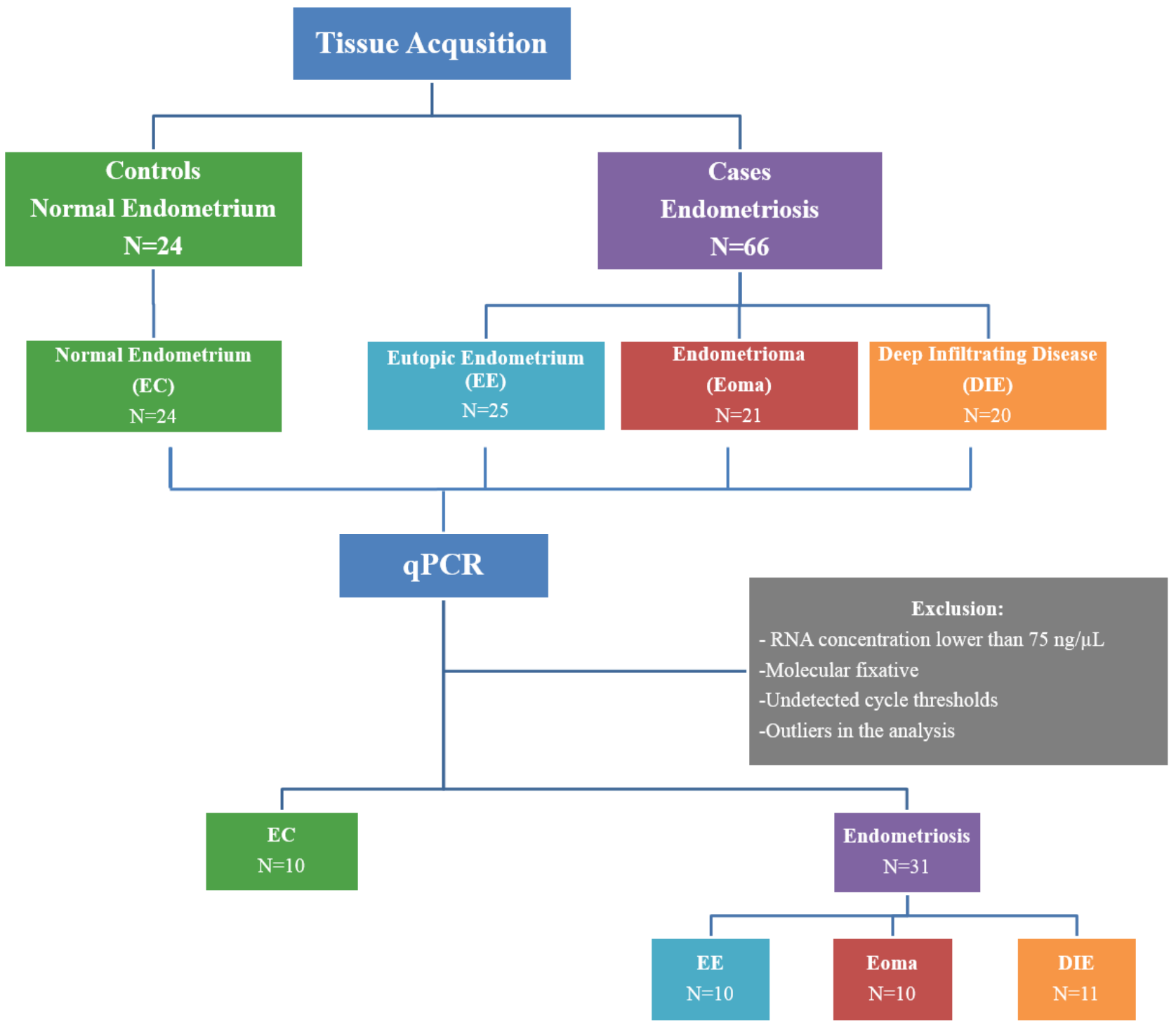

Figure 2.2: Schematic presentation of the blocks utilized in the study: N: the total number of blocks. 


\section{Chapter 3: Expression of HOXB4 in Endometrial Tissue}

\subsection{Rationale and Overall Hypothesis}

HOX genes are homeodomain-containing regulatory proteins that function as transcriptional factors directing the regional identity of the embryo along the anteroposterior body axis via activating or repressing their target genes [195]. They control embryonic development and continue to regulate cellular growth and differentiation later in adulthood. Aberrant expression and function of HOX genes has been demonstrated in several gynaecologic pathologies and is implicated in malignancies such as breast, ovarian and endometrial cancers [139].

The expression and function of genes in the different HOX clusters has been thoroughly studied in the mouse and human female reproductive tract, during embryogenesis, and during adulthood [154, 196-203]. Taylor et al reported that in the human female genital tract, the posterior HOXA genes have a differential pattern of expression that controls the developmental orientation of the genital organs [154]. For instance, in the Mullerian tract, HOXA9 was found to be highly expressed in the oviducts, whereas HOXA10 was expressed during uterus organogenesis. Also, HOXA11 and HOXA12 are expressed in the cervix and vagina, respectively. The importance of these transcriptional factors is not limited to embryonic development as they continue to be expressed and function in the reproductive tract even after the commencement of the menstrual cycle and during pregnancy [200]. Moreover, the expression of HOX genes was found to be varied during the menstrual cycle; HOXA10 and HOXA11 were found to peak in the secretory phase. In the case of exogenous treatment with medroxyprogesterone acetate (MPA) or gonadotropinreleasing hormone analog $(\mathrm{GnRH})$, HOXA10 expression was significantly lower when compared to the tissue obtained in the late secretory phase [158]. This was confirmed in vivo when endometrial cells were treated with estradiol and/or progesterone as the expression of both 
HOXA10 and HOXA11 mRNA levels were upregulated in a menstrual cycle phase-dependent manner [158, 177]. In endometriosis, HOXA10 was expressed in both eutopic and ectopic endometrial tissue with lower stromal HOXA10 expression in the ectopic implants $(P=0.001)$ [191]. Browne and Taylor speculated that progesterone resistance may play a role in HOXA10 aberrant expression in the ectopic implants [191].

When compared to the above mentioned genes, group 4 HOX paralogs (i.e. HOXA4, HOXB4, HOXC4 and HOXD4) are positioned anteriorly. Redundant interaction between group 4 HOX paralogs or even other genes in other HOX groups has been described [181, 204, 205]. In the reproductive tract, analysis of total RNA from reproductive endometrial tissues showed expression of HOXB4 is only present in the endometrial glands [184]. Furthermore, this expression was shown to be regulated by estrogen and progesterone using northern blots [184]. Moreover, analysis of publicly available microarray data from the Gene Expression Omnibus (GEO) database shows a reduction in HOXB4 expression in endometrioma when compared to the normal eutopic endometrium [206, 207]. Similarly, another microarray study $(\mathrm{n}=37)$ showed HOXB4 expression may be reduced in endometriotic vs. eutopic endometrial tissues in different menstrual phases (Appendices B and C) [207, 208]. To the best of our knowledge, HOXB4 immunoreactivity in the eutopic endometrium of patients without endometriosis (EC), eutopic endometrium (EE), endometrioma (Eoma) or deep infiltrating endometriosis (DIE) of patients with endometriosis has not been reported in the literature. Therefore, I hypothesized that the expression of HOXB4 is reduced in eutopic and ectopic endometrial tissues of patients with endometriosis. 


\subsection{SAMPLE CHARACTERISTICS}

First immunohistochemical analysis using a validated monoclonal rabbit HOXB4 antibody was performed to examine the expression and localization of HOXB4 in formalin fixed paraffin embedded (FFPE) endometrial tissues from forty four women without endometriosis (EC: $n=44$ patient ). Our positive control was normal fallopian tube fimbria and the negative control was the ovary [176]. Samples from six patients were excluded by the exclusion criteria mentioned below (Figure 2.1). Of the 38 scored control slides, twenty (52.3\%) were in the proliferative phase and eighteen $(47.4 \%)$ in the secretory phase.

Then eutopic endometrium (EE) and ectopic endometrial tissues (i.e. endometrioma (Eoma) and deep infiltrating endometriosis (DIE)) of patients with endometriosis ( $\mathrm{Pt} n=46)$ were stained using the above mentioned antibody. Once the analysis was restricted to cases of EE with glandular epithelia in cyclic women, the final number of EE, Eoma, and DIE slides was 29. Of these, the number of the slides in the proliferative or secretory phase is shown in (Figure 2.1).

All of the women included in this study had a diagnostic laparoscopy due to pelvic pain and/or infertility. The excluded slides were omitted from the final analysis for the following reason: poor preservation, cauterized glands, absence of endometrial glands, section was representative of another abnormality (e.g. adenomyosis, endocervix, or mature cystic teratoma), preserved in molecular fixative or histopathological changes suggesting exogenous progesterone treatment. Moreover, whenever the eutopic endometrium was inactive ( $\mathrm{EE}=9)$, both the ectopic implants (Eoma=10 and DIE=9) and eutopic endometrium were excluded from the general location and phase analyses.

The Eoma lesions were either unilateral or bilateral and the DIE lesions were located in one or more of the pelvic locations (Zone 2: rectovaginal and vaginal area, caul-de-sac, uterosacral 
ligament, para-sacral ligament, bladder, appendix, and bowel serosa and Zone 3: side walls, fallopian tubes, and peri-uretric area).

The mean $( \pm \mathrm{SD})$ age of the endometriosis group $(\mathrm{n}=42)$ was $38.90( \pm 1.611)$ years compared with $40.90( \pm 0.9363)$ years in the controls $(\mathrm{n}=38 ; P=0.26)$.

\subsection{RESULTS}

\subsubsection{Localization of HOXB4 Expression in Patients without Endometriosis (EC) and} Patients with Endometriosis (EE, Eoma, and DIE)

In the human female reproductive tract, HOXB4 protein was expressed in the normal fallopian tube fimbria and in the normal endometrium (Figure 3.1). This expression was exclusively in the nucleus of the glandular epithelial cells with no expression observed in the cytoplasm or in the stromal cells.

Eutopic endometrium from 38 women without endometriosis (EC) showed variable HOXB4 immunoreactivity. HOXB4 expression was observed in the nuclei of glandular epithelial cells (Figure 3.2 and 3.3). In women with endometriosis, 29 eutopic (EE) and ectopic endometrium $($ Eoma $=15$ and $\mathrm{DIE}=22)$ express variable levels of HOXB4 protein. Again, this expression was found only in the nuclei of glandular epithelial cells and was absent in the cytoplasm and in the stroma (Figure 3.4 and 3.5). Although some exceptions were observed: faint cytoplasmic HOXB4 immunoreactivity was found in a few slides of EC, EE, Eoma and DIE. This could, however, be considered as an artifact background most likely caused by improper tissue cuts or fixation.

No statistical significant differences were found in HOXB4 immuno-intensity between eutopic endometrium from the control and disease groups by Histoscore analysis $(P=0.0567$; 
Figure 3.6). However, a significant decrease of HOXB4 expression was observed in the DIE group compared to the EC group $(P<0.0001)$. Among the endometriosis groups, HOXB4 expression was significantly lower in the DIE group compared to the EE group $(P<0.0001)$ and the Eoma group $(P=0.0002)$.

In the disease group, we had samples from the EE group with multiple matched ectopic sites of the disease phenotype (i.e. unilateral or bilateral Eoma or matched multiple DIE lesions) for the same patient. Inter-person variation was a potential factor in differences between ectopic and eutopic HOXB4 expression; therefore, we took advantage of having multiple sample from the same phenotype and we were able to calculate the difference of $\mathrm{H}$-score $(\Delta \mathrm{H}$-score) between the eutopic tissue and ectopic DIE on a patient to patient basis. For DIE, 9 of the 13 matched samples had a negative $\Delta \mathrm{H}$-score (i.e. reduced expression of DIE vs EE; Figure 3.8, A) In contrast, when we did the same sub analysis in the endometrioma group, there is no consistent pattern for a change in H-score in that group (Figure 3.9, A). The average of the multiple ectopic lesions of the same phenotype (i.e. Eoma or DIE) was used for the paired sub-analysis (Figures 3.8 and 3.9). In patients with unilateral or bilateral Eoma, there was no statistical significance between EE and Eoma samples $(P=0.557)$. On the other hand, in cases with paired EE and DIE, HOXB4 was significantly lower in the DIE samples $(P=0.038)$. The paired cases being analyzed separately and yielding results consistent with the general analysis of all the available samples of the Eoma and DIE lesions further supported the overall observations about the differential expression of HOXB4 in patients with or without endometriosis. 


\subsubsection{HOXB4 Protein Expression during the Menstrual Cycle}

Differential hormonal environments in proliferative and secretory phases may alter the expression of HOXB4 during the menstrual cycle. Thus, the endometrium was dated in both cases and control groups according to the Noyes criteria described earlier to be either proliferative or secretory (Figure 3.9). In general, there was a significant elevation of HOXB4 expression in proliferative phases compared to secretory phases in the eutopic endometrium from patients without endometriosis $(P=0.002)$. This difference between the phases was lost among the disease groups (i.e. EE: $P=0.0504$, Eoma: $P=0.9707$ and DIE: $P=0.1164$ ). When analysed per phase, a significant reduction in HOXB4 expression was observed, in the proliferative phase, in EE, Eoma and DIE groups when compared to EC $(P=0.004, P=0.0009$ and $P<0.0001$, respectively; Figure 3.9). This immunoreactivity variation was only detected between EC and DIE groups in the secretory phase $(P=0.033$; Figure 3.9$)$.

As reported earlier, we had to exclude the cases where the eutopic endometrium of patients with endometriosis was histopathologically described as inactive (i.e. absence of any proliferative or secretory histopathological features). Inactive endometriosis in patients with endometriosis was found in 9 eutopic endometrium, 10 Eoma, and 9 DIE (Figure 3.10). When we included these cases in our analysis, surprisingly, HOXB4 expression was significantly lower in the eutopic endometrium of inactive groups when compared to the controls $(P=0.002)$.

\subsection{DISCUSSION}

Endometriosis is defined as the presence of ectopic glands and/or endometrial stroma in conjunction with a higher hormonal response in the stroma than the glands [209]. Endometriotic tissues (as opposed to normal eutopic endometrium) are estrogen dependent and progesterone- 
resistant. Microscopically, fewer glandular cells (one or more) are found in endometriotic lesions and usually are replaced with hemosiderin residuals [210]. This made careful examination of microscope slides containing endometriotic lesions necessary in order to identify the slides with glands only.

All the tissues included in this analysis were formalin fixed paraffin embedded (FFPE) tissues. This fixation method is feasible due to its constant use as a diagnostic tool in histopathological evaluation of different pathological morphologies, lower price, and practicality. Moreover, in clinical research, many immunohistochemical (IHC) assays have been repeatedly validated using this method of tissue fixation [211]. The Endo-Onc tissue bank was established as a pilot study in 2012 to prospectively archive tissues of women suffering of endometriosis. This full scale project was approved by Clinical Research Ethics Board at the University of British Columbia in June 2015. One of the major advantages of this tissue bank is that all the tissues included in this bank are fixed using formalin and/or a molecular fixative (MF). MF is composed of methanol and polyethylene glycol and has been proven to be a better preservative method for downstream molecular diagnostic assays, such as PCR [189]. In IHC, however, the sensitivity of MF tissues to immunostaining is controversial when compared to formalin fixation, especially when it comes to nuclear antigens [189, 212-214]. In my study, I stained 27 MF lesions (EE=5, Eoma $=10$, and DIE=2) using the protocol presented in section 2.2. The HOXB4 immunoreactivity for these lesions were lower than what was observed in the FFPE ones. Given the fact that this could be a false reduction (as we don't have a matched FFPE slides for the MF ones) in addition to the delay in receiving the full scale Endo-Onc study approval, limiting the time to optimize and validate the current IHC protocol for the MF tissues, we had to exclude all the MF from the analysis. 
HOXB4 encodes for a nuclear protein with a homeobox DNA-binding domain. In the human female reproductive tract, HOXB4 RNA levels were detected in the fallopian tube and endometrial epithelial glands $[176,184]$. In the current study, HOXB4 protein immunoreactivity was found to be variable in the eutopic endometrium from disease free women during the menstrual cycle. Our results are in consistence with the Gao et al group study, which was, to the best of our knowledge, the only paper that examined HOXB4 total RNA levels in the endometrium[184]. When they purified normal human endometrial stromal and epithelial cells, HOXB4 mRNA was expressed specifically in endometrial glands. Moreover, HOXB4 total RNA levels in the endometrial glands were observed to be upregulated after the treatment of $17 \beta$ estradiol (E2) or methylprogesterone acetate (MPA) using a northern blot; however, neither the number of patients nor the menstrual cycle phase were indicated. In our general analysis of all available samples of lesions from patients with and without endometriosis, HOXB4 was highly expressed in the eutopic endometrium of patients without endometriosis. This expression was significantly higher in the proliferative phase when compared to all the other study groups. On the hormonal level, all endometriotic tissues (Eoma or DIE) express lower aromatase and decreased 17ß-Hydroxysteroid dehydrogenases type 2, leading to higher E2 bioavailability in these endometriotic lesions due to the deficient metabolism of E2 in endometriosis [215, 216]. As mentioned earlier, PR expression in the ectopic implants is reduced due to the decreased ER $\alpha$ :ER $\beta$ ratio, leading to an inhibitory E2 effect on PRs [217]. HOX genes were found to function differently in different tissues based on their interaction with different cofactors and collaborators in regulating their downstream targets [218]. Although HOXB4 in adult tissue was found to promote proliferation in hematopoietic stem cells $[219,220]$, HOXB4 was not an effective promoter of proliferation in four ovarian cancer cell lines [176]. 
The expression of HOXB4 was significantly lower in the deep infiltrating lesions when compared to the eutopic endometrium of both control and diseased groups. The lower expression of HOXB4 in the DIE group could be due to the nature of the disease as deep infiltrating endometriosis have higher mixed and undifferentiated glandular patterns when compared to the other groups [221, 222]. To further confirm the specificity of HOXB4 expression reduction in the DIE group, a matched sub analysis of HOXB4 immunoreactivity in all the samples that have paired DIE or Eoma and EE was performed (Figures 3.7 and 3.8). The aim of this analysis was to confirm the immunoreactivity in the same patient with more than one ectopic lesion when paired with the eutopic endometrium. This gave us the advantage to further explore the direct relationship between the lesion HOXB4 expression and the eutopic endometrium expression in every patient. As expected, HOXB4 expression was significantly lower in the DIE lesions $(P=0.038)$ when compared to the Eoma lesions $(P=0.557)$.

As mentioned earlier, some of the EE samples were histologically described as inactive EE $(n=9)$. Histologically, these samples did not show proliferation or secretions, no stratifications, and usually were composed of a single layer of flattened epithelium. Moreover, mitotic figures were not present, the nucleus to cytoplasmic ratio was high, and there was no specific cytoplasmic differentiation, although cilia may be present with inactive glands and spindled stroma [223, 224]. These histological observations may reflect a peripubertal or perimenopausal hypoestrogenic weakly proliferative endometrium. Moreover, women receiving hormonal replacement therapies or oral contraception may also have an inactive endometrium which could be a reflection of the small doses of exogenous estrogen or the mixed hormonal status [224]. This is why excluding these samples and their paired ectopic lesions from the general analysis was a must. Surprisingly, the inactive EE had lower expression when compared to EC ( $P=0.002)$; however, no significant 
reduction was observed when compared to the active EE samples $(P=0.1301)$. We were unable to know the exact reason of the inactivity of these samples and therefore speculated that a mixed hormonal status may be behind this kind of reduction. On the other hand, the ectopic lesions do not show any differences when compared to any of the other groups (i.e. EC, EE, Eoma, or DIE). On the whole, HOXB4 expression does not appear to differ between normal endometrium and eutopic endometrium in women with endometriosis. However, its expression is reduced in DIE, but not endometrioma, and may be dysregulated in ectopic implants. During the menstrual cycle, the expression of HOXB4 in endometrial glandular epithelial cells, from normal eutopic endometrium, is higher in the proliferative phase than in the secretory phase. This difference is lost in the lesions from the endometriosis group. 

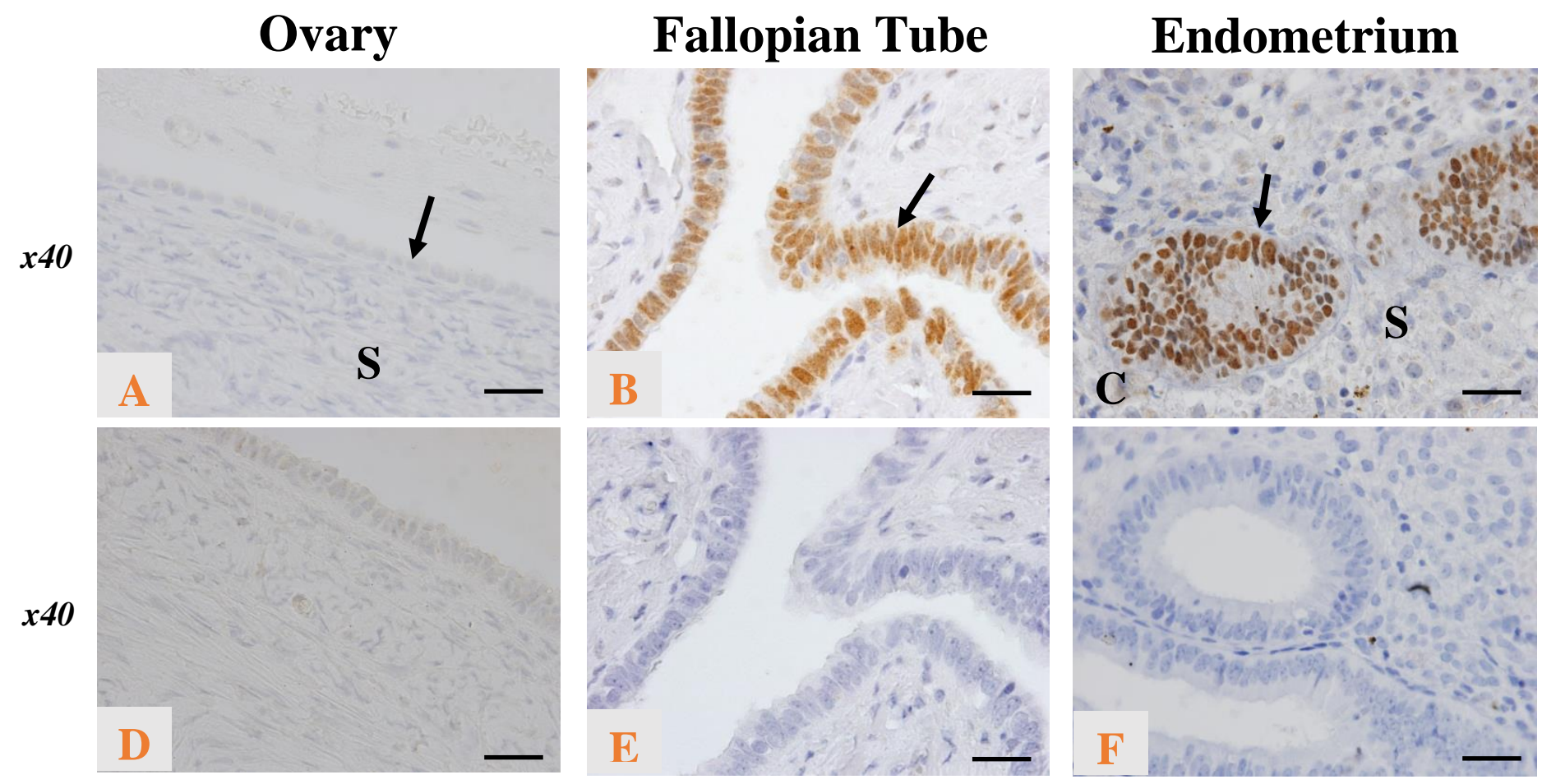

HOXB4

NIS

Figure 3.1: Immunohistochemical localization of HOXB4 in the female genital tract:

A. Section through normal human ovary stained with HOXB4 antibody at 1:800 dilutions: no staining in the stromal tissue (S) and ovarian surface epithelium (arrow). B. Section through normal human fallopian tube fimbria stained with HOXB4 antibody at 1:800 dilutions: high staining in fimbrial epithelium, especially secretory cells (arrow). C. Section through the human endometrium in the proliferative phase stained with HOXB4 antibody at 1:800 dilutions: HOXB4 is expressed in the epithelial glands only (arrow). No staining is detected in the cytoplasm of the glands nor the stroma (S). D. Section through normal human ovary stained with non-immune rabbit immunoglobulin. E. Section through normal human fallopian tube fimbria with non-immune rabbit immunoglobulin. F. Section through normal human endometrium in the proliferative phase stained with non-immune rabbit immunoglobulin. NIS indicates staining with non-immune rabbit immunoglobulin ( $\operatorname{IgG})$ 1:800 dilution. (x40, scale bar: $25 \mu \mathrm{m}$ ). 

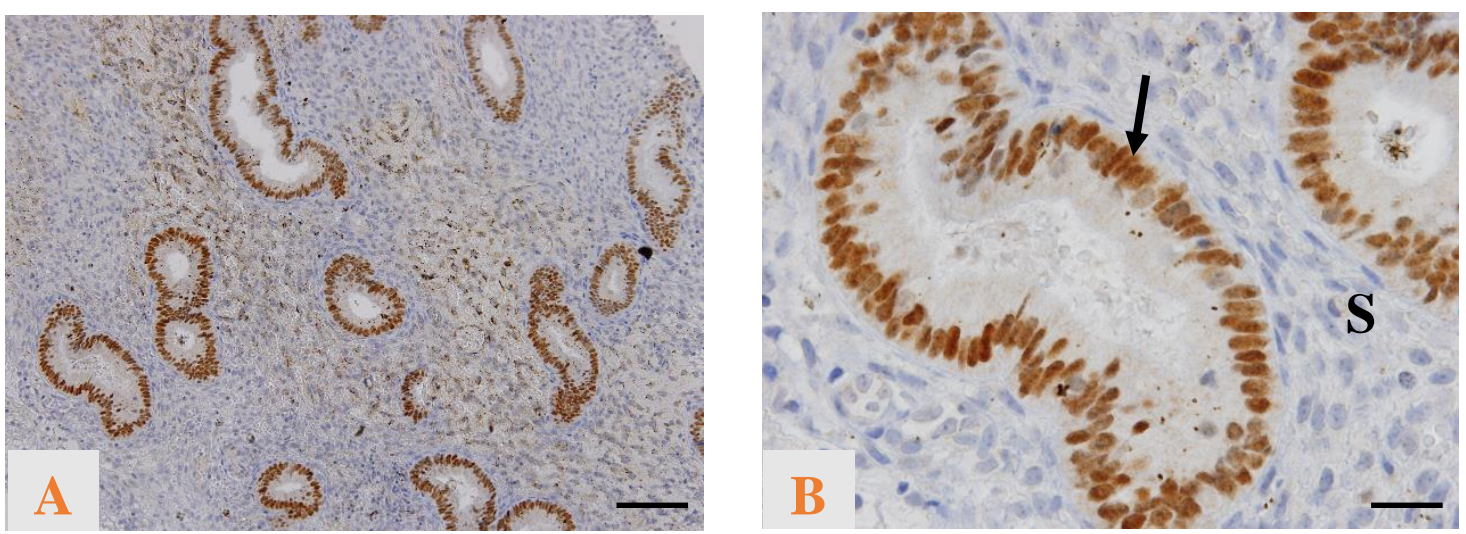

HOXB4
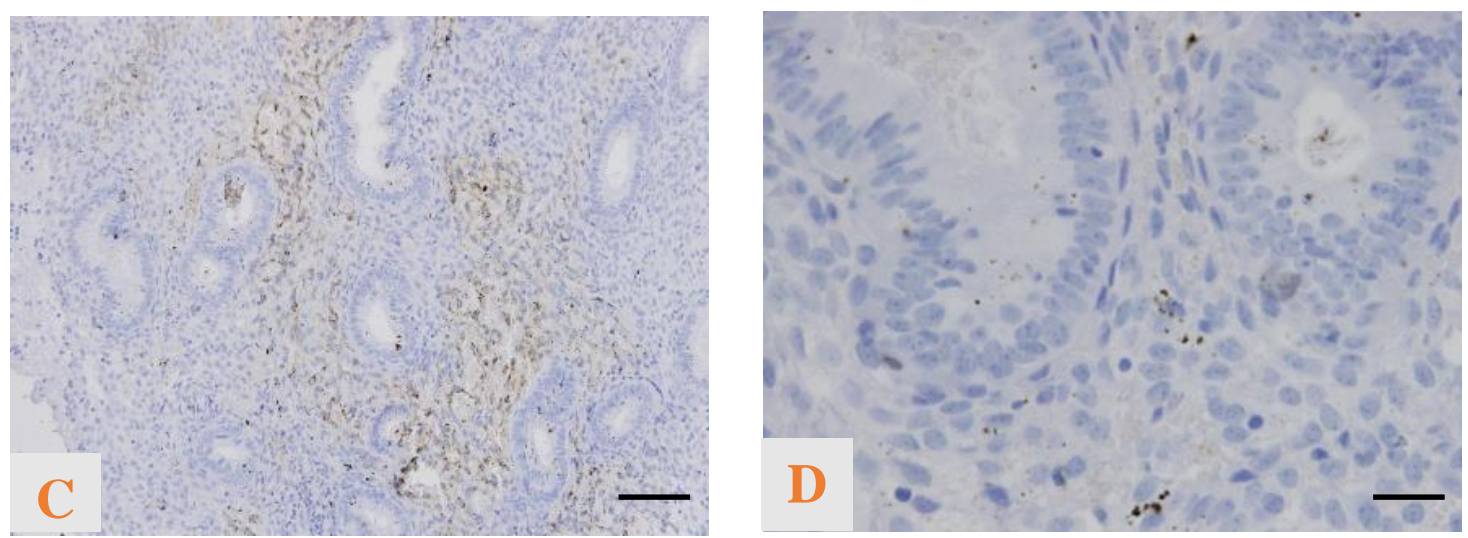

NIS

Figure 3.2: Immunohistochemical localization of HOXB4 in Normal Eutopic Endometrium from women without endometriosis in the proliferative phase:

A. Section through human endometrium in the proliferative phase stained with HOXB4 at x10. HOXB4 expression is high in the glandular epithelial. The stroma is not stained for HOXB4.

B. The same section stained with HOXB4 at x40: Strong HOXB4 immunoreactivity in the nucleus of the epithelial glands only (arrow). No staining is detected in the cytoplasm of the glands nor in the stroma (S). C and D. The same section stained with non-immune rabbit immunoglobulin. HOXB4 dilution is 1:800. NIS indicates staining with non-immune rabbit immunoglobulin (IgG) 1:800 dilution. $(\times 10$, scale bar: $100 \mu \mathrm{m} \times 40$, scale bar: $25 \mu \mathrm{m})$. 
$X 10$
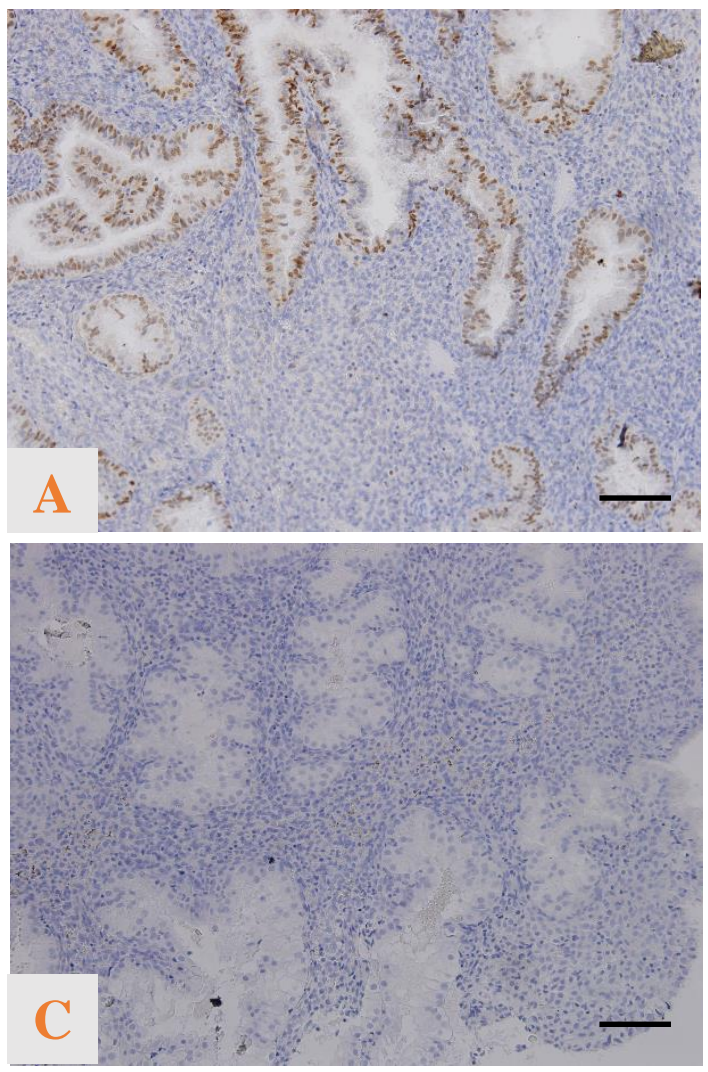

$X 40$

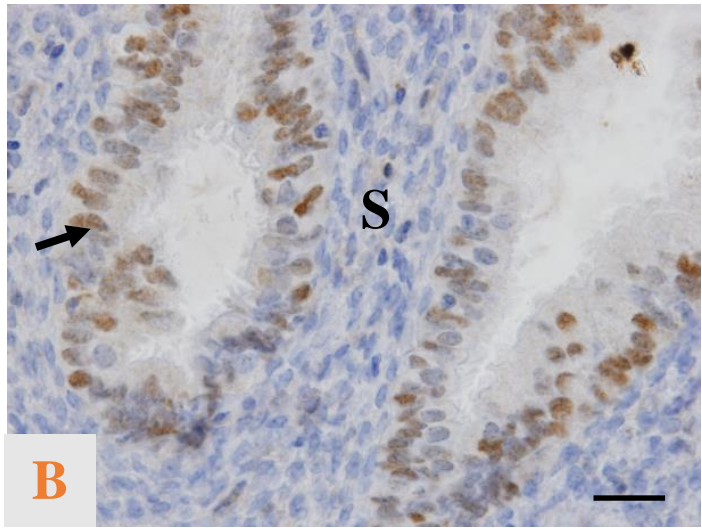

HOXB4

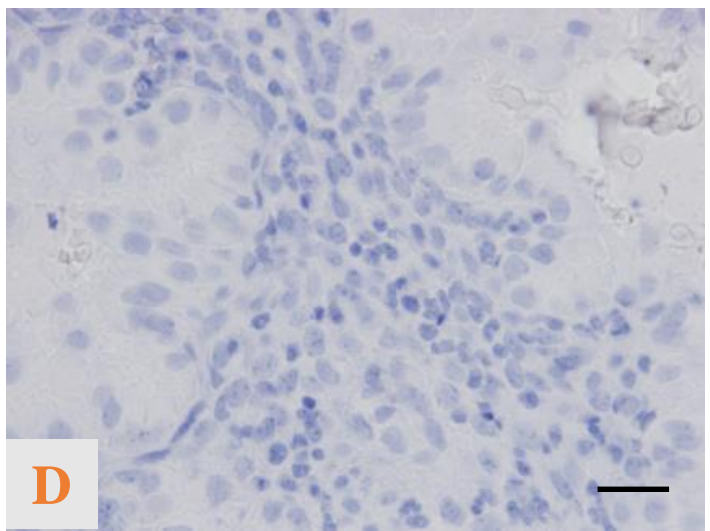

NIS

Figure 3.3: Immunohistochemical localization of HOXB4 in Normal Eutopic Endometrium from women without endometriosis in the secretory phase:

A. Section through human endometrium in the secretory phase stained with HOXB4 at x10. HOXB4 expression is in the glandular epithelial. The stroma is not stained for HOXB4.

B. The same section stained with HOXB4 at x40: mild to moderate HOXB4 immunoreactivity in the nucleus of the epithelial glands only (arrow). No staining is detected in the cytoplasm of the glands nor in the stroma (S). C and D. The same section stained with non-immune rabbit immunoglobulin.HOXB4 dilution is 1:800. NIS indicates staining with non-immune rabbit immunoglobulin (IgG) 1:800 dilution. (x10, scale bar: $100 \mu \mathrm{m}$ x40, scale bar: $25 \mu \mathrm{m}$ ). 

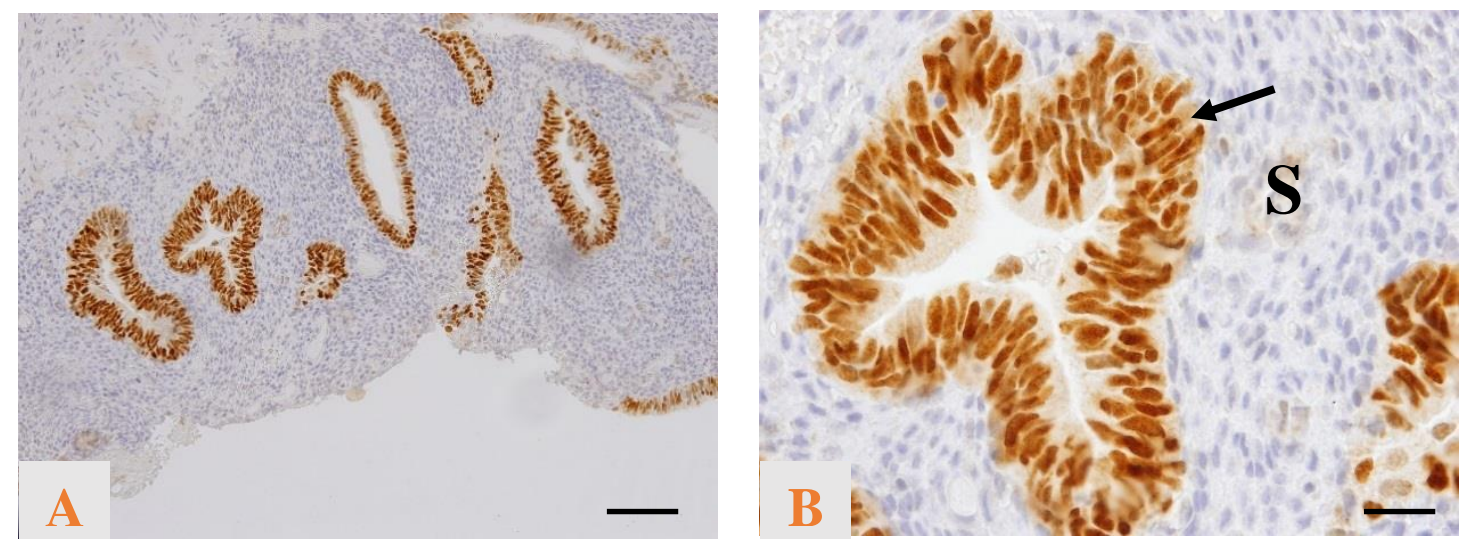

HOXB4
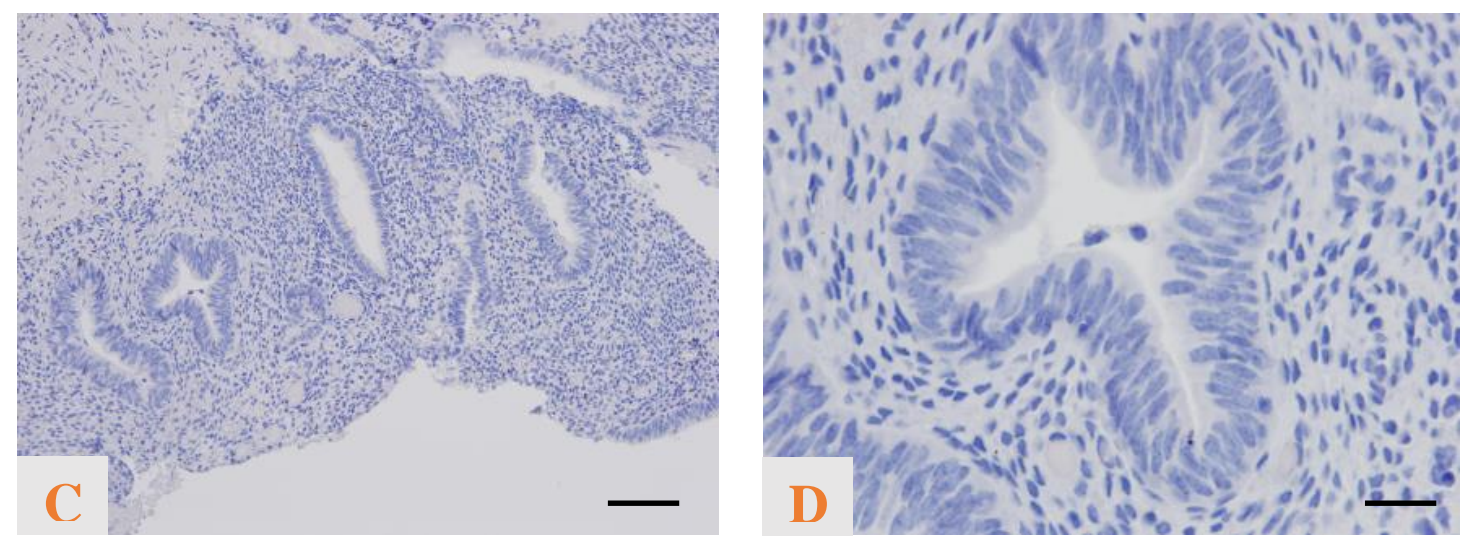

NIS

Figure 3.4: Immunohistochemical localization of HOXB4 in ovarian endometrioma:

A. Section through human left ovarian endometrioma stained with HOXB4 at x10. B. The same section stained with HOXB4 at x40. High staining in the glandular epithelium (arrows) with no staining endometrial stroma (S). C and D. The same section stained with non-immune rabbit immunoglobulin. HOXB4 dilution is 1:800. NIS indicates staining with non-immune rabbit immunoglobulin (IgG) 1:800 dilution. (x10, scale bar: $100 \mu \mathrm{m} x 40$, scale bar: $25 \mu \mathrm{m})$. 

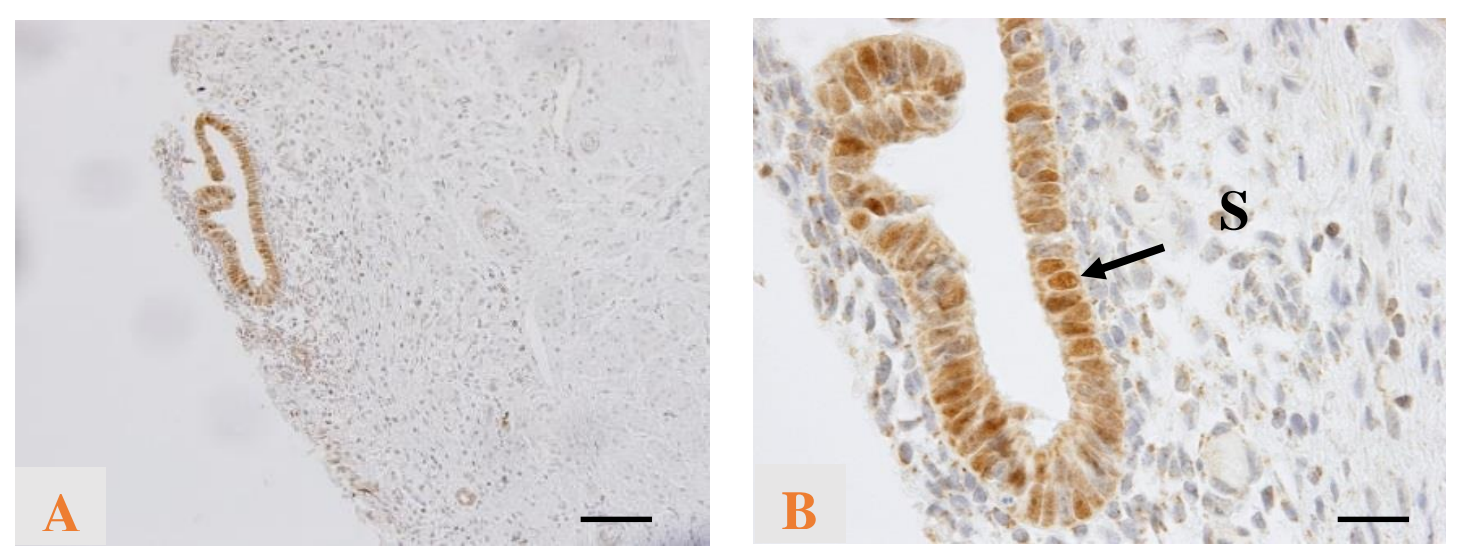

HOXB4
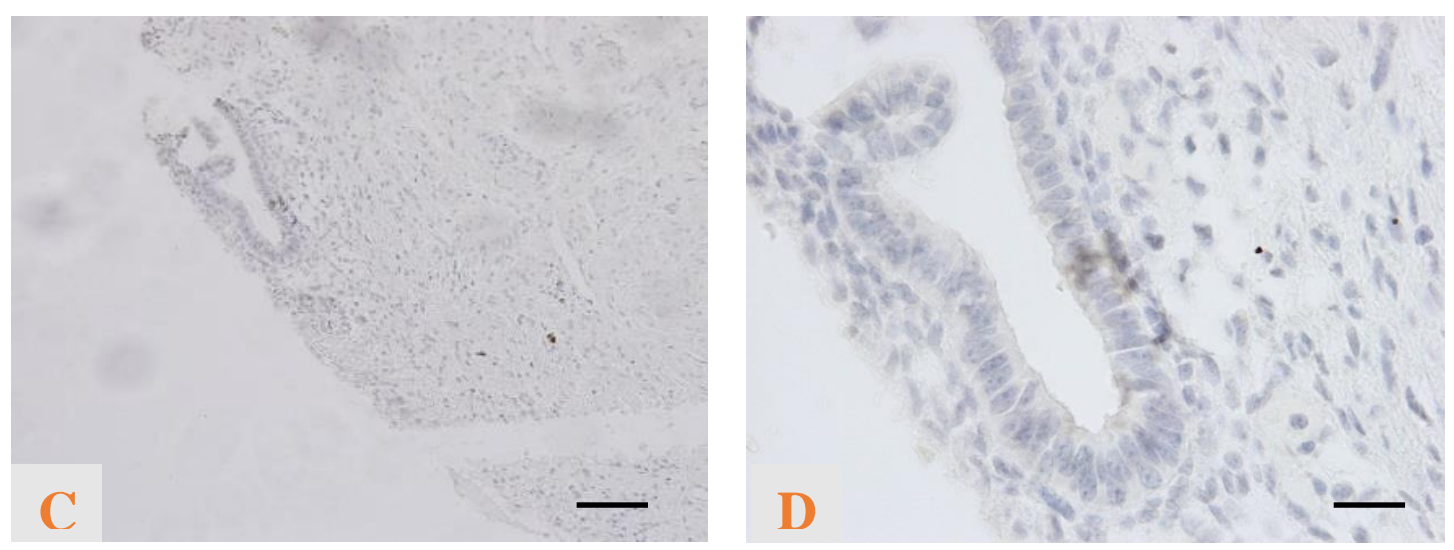

NIS

Figure 3.5: Immunohistochemical localization of HOXB4 in deep infiltrating endometriosis:

A. Section through human deep infiltrating endometriosis in the left uterosacral ligament stained with HOXB4: high staining in the glandular epithelium (arrows) with no staining in endometrial stroma (S). HOXB4 dilution is 1:800. NIS indicates staining with non-immune rabbit immunoglobulin (IgG) 1:800 dilution. (x10, scale bar: $100 \mu \mathrm{m} \times 40$, scale bar: $25 \mu \mathrm{m}$ ). 


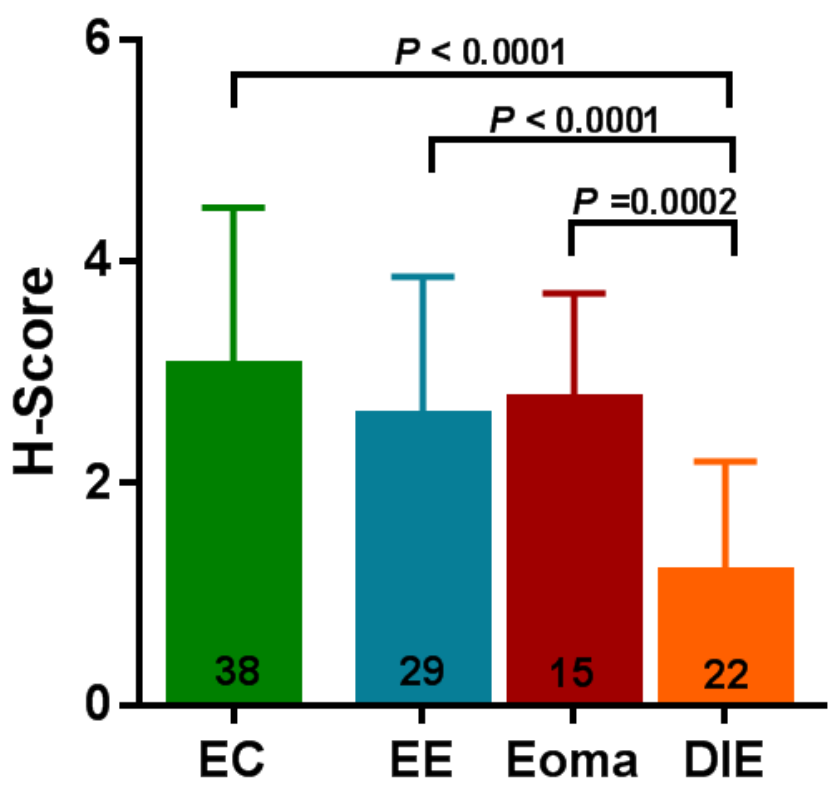

Figure 3.6: Analysis of HOXB4 immunoreactivity in all available samples of lesions from patients without endometriosis (EC) and patients with endometriosis (EE, Eoma, and DIE) using the Histoscore (H-score):

Mean $\mathrm{H}$ scores ( \pm standard deviation $[\mathrm{SD}]$ ) for the staining intensity of glandular HOXB4 protein expression in both eutopic endometrium (EE) and ectopic implants (Eoma and DIE) in patents with endometriosis compared to normal endometrium (EC). A statistically significant difference was noted in HOXB4 expression between EC and DIE $(P<0.0001)$. When compared to EC, no statistically significant difference was observed in EE and Eoma groups $(P=0.057$ and 0.101 , respectively). EC: normal endometrium in the women without endometriosis, EE: eutopic endometrium in women with endometriosis, Eoma: endometrioma lesions, DIE: deep infiltrating endometriosis lesions. 


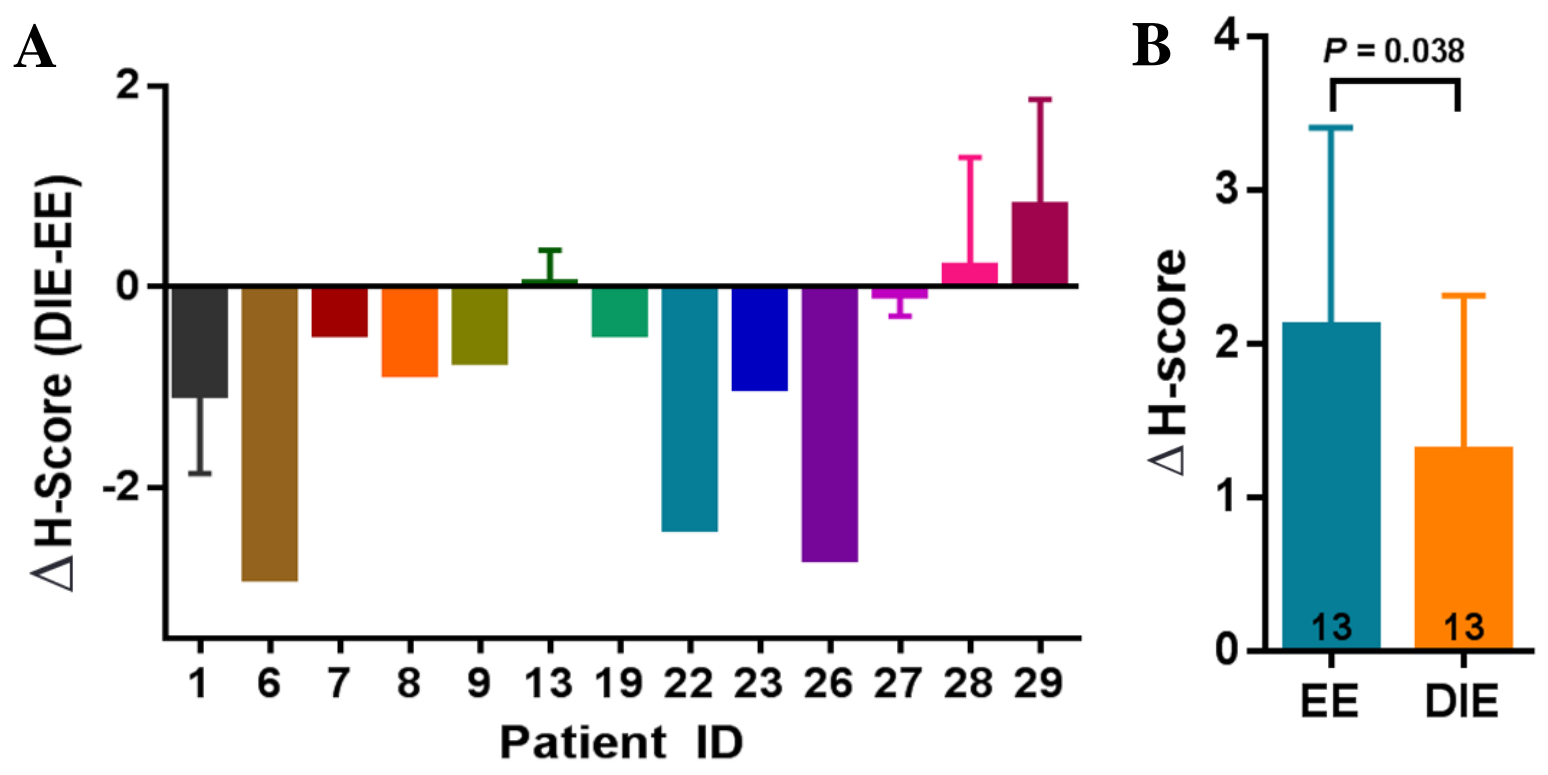

Figure 3.7: Matched sub-analysis of HOXB4 immunoreactivity in patients with endometriosis (EE and DIE) using the Histoscore (H-score):

In the case of sampling patients with one or more deep infiltrating endometriosis (DIE) locations ( $\mathrm{Pt} n=13$, Lesions $\mathrm{n}=22$ ), a paired sub-analysis of HOXB4 H-score change was done to evaluate the pattern of score variation in each of these patients to evaluate the expression of HOXB4 in these cases. For patients with more than one endometrioma, the average of the lesions was used for the paired sub-analysis. A. HOXB4 expression variation when different DIE locations were paired with the patient's eutopic endometrium (EE). B. Paired analysis of the H-score when matching the eutopic endometrium in women with endometriosis (EE) with their own DIE lesions. In these paired lesions, HOXB4 expression was significantly reduced in the DIE lesions. 

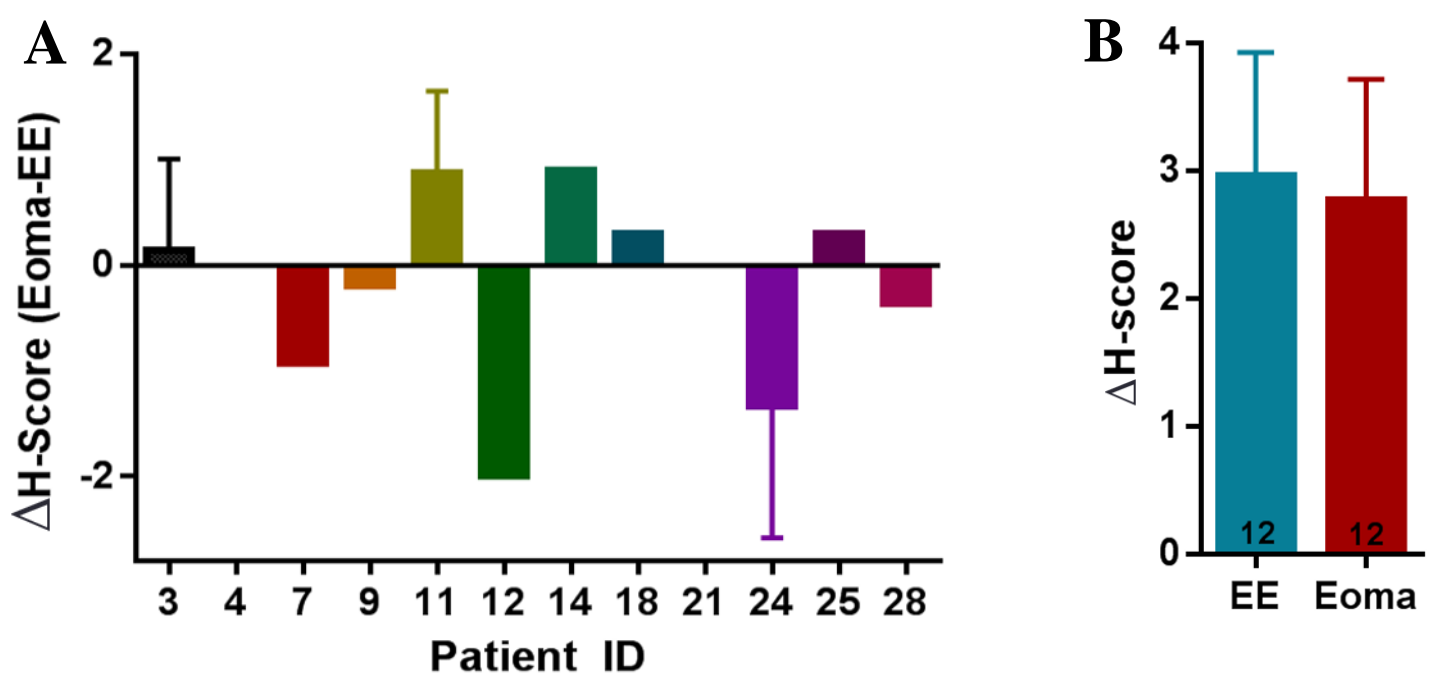

Figure 3.8: Matched sub-analysis of HOXB4 immunoreactivity in patients with endometriosis (EE and Eoma) using the Histoscore (H-score):

In the case of sampling patients with one or two endometrioma (Eoma) locations (Pt $\mathrm{n}=12$, Lesions $\mathrm{n}=15$ ), a paired sub-analysis of HOXB4 H-score change was done to evaluate the pattern of score variation in every patient with one or two endometrioma in order to evaluate the expression of HOXB4 in these cases. For patients with more than one endometrioma, the average of the lesions was used for the paired sub-analysis. A. HOXB4 expression variation when different endometrioma (Eoma) sites were paired with the patient's eutopic endometrium (EE). B. Paired analysis of the H-score when matching the eutopic endometrium in women with endometriosis (EE) with their own Eoma lesions. In these paired lesions, HOXB4 expression didn't change between the eutopic and ectopic endometrium. 


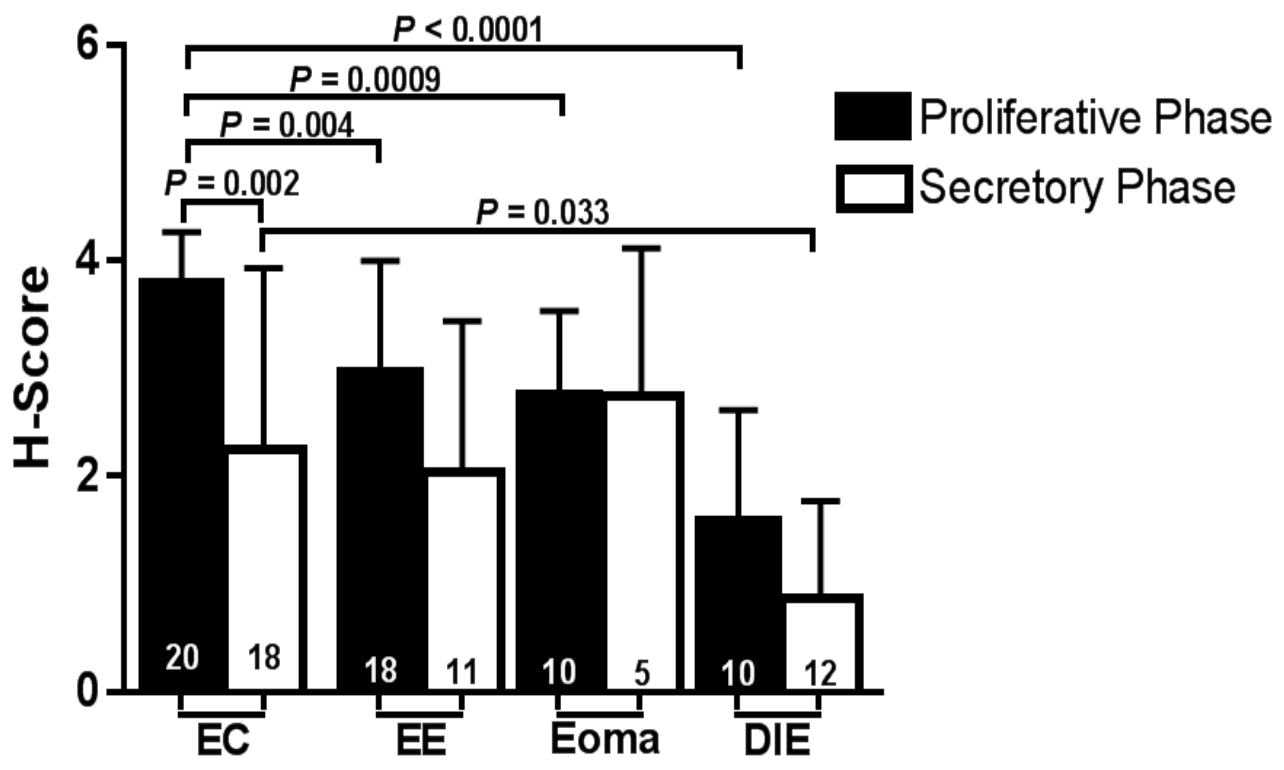

Figure 3.9: Analysis of HOXB4 immunoreactivity in all available samples of lesions from patients without endometriosis (EC) and patients with endometriosis (EE, Eoma, and DIE) during the menstrual phases using the Histoscore (H-score):

Mean $\mathrm{H}$ scores $( \pm \mathrm{SD})$ for the staining intensity of glandular HOXB4 protein expression in different tissue types during the menstrual cycle. A statistically significant difference was noted in HOXB4 expression between EC in the proliferative and secretory phase $(P=0.002)$. This significant difference in the expression between the phases was lost in all the disease tissue types ( $P=0.050, P=0.971$, and $P=0.116$ in EE, Eoma and DIE, respectively). When the proliferative phase lesion groups were analysed, HOXB4 expression was lower in EE, Eoma and DIE when compared to EC controls $(P=0.004, P=0.0009$, and $P=<0.0001$, respectively). The only significant difference in secretory phase HOXB4 expression in lesions was found in EC and DIE groups $(P=0.033)$. EC: normal endometrium in the women without endometriosis, EE: eutopic endometrium in women with endometriosis, Eoma: endometrioma lesions, DIE: deep infiltrating endometriosis lesions. 


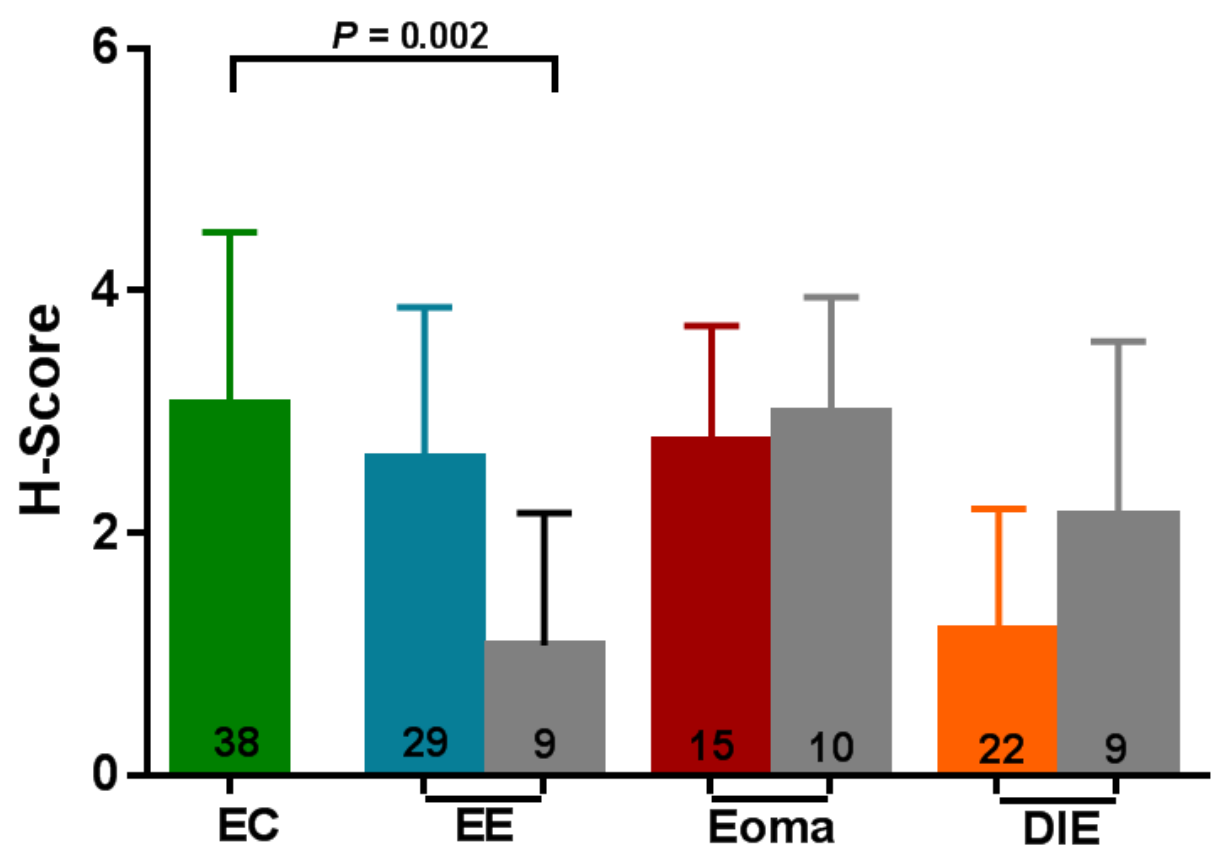

Figure 3.10: Analysis of the crude HOXB4 immunoreactivity in all available samples of lesions from patients without endometriosis (EC) and with endometriosis (EE, Eoma, and DIE) compared to inactive endometrium using the Histoscore (H-score):

Mean $\mathrm{H}$ scores ( \pm standard deviation $[\mathrm{SD}]$ ) for the staining intensity of glandular HOXB4 protein expression in both eutopic endometrium (EE) and ectopic implants (Eoma and DIE) in patents with endometriosis compared to normal endometrium (EC). The expression of HOXB4 in the inactive eutopic endometrium of women with endometriosis was lower than normal eutopic endometrium ( $P=0.0021)$. A lower HOXB4 expression was found in the inactive EE when compared to the inactive Eoma ( $P=0.0019)$; however no difference was found between inactive EE and inactive DIE $(P=0.1822)$. There was no significant difference when HOXB4 expression was compared between: eutopic endometrium in both the cycling and inactive groups $(P=0.1301)$. 


\section{Chapter 4: The Expression of HOXB4 mRNA in Eutopic and Ectopic Endometrial Tissue from Women with or without Endometriosis}

\subsection{Rationale and Overall Hypothesis}

My immunohistochemistry studies in Chapter 3 have shown that significant lower levels of HOXB4 protein are expressed in endometriotic tissues from women with deep infiltrating endometriosis (DIE) compared to eutopic and ectopic endometrial tissues from control women (EC) and women diagnosed with endometrioma (Eoma). However, a known drawback of immunohistochemistry studies is their relative inability to quantitate changes over a large dynamic range. Multiple studies have utilized quantitative microarray approaches to study the differences of gene expression between eutopic and ectopic endometrial tissues from women with endometriosis $[225,226]$. Interestingly, several reports suggested that HOXB4 may be among many genes that have distinct expression patterns between eutopic and ectopic endometrial tissues [206, 208]. However, additional studies are needed to further validate their brief suggestion. Thus, the aim of my study in this chapter is to investigate the expression of HOXB4 mRNA in eutopic and ectopic endometrial tissue from women with or without endometriosis.

Based on my previous immunohistochemistry findings listed in Chapter 3, HOXB4 is expressed at lower levels in ectopic tissues from women with DIE compared to eutopic and ectopic endometrium from control women and women with endometrioma.

\subsection{SAMPLE CHARACTERISTICS}

As a complement to the immunohistochemical approach, HOXB4 mRNA levels were examined in eutopic endometrium from women without endometriosis (EC) and lesions from 
eutopic (EE) and ectopic implants (Eoma and DIE) from women with endometriosis (Figure 2.2). Briefly, total RNA was extracted from formalin fixed paraffin embedded (FFPE) tissues as mentioned in section 2.4. Commercially available RNA extraction kits were used to maximize the RNA quality as formalin fixation may result in a reduction of RNA yield by inducing cross-links between nucleic acids and proteins. Specific TaqMan quantitative PCR assays were used to amplify HOXB4, GAPDH and Cytokeratin 7 cDNAs. From the protein data presented in section 3.3, HOXB4 levels are expressed exclusively in the epithelial glands. Thus, we included cytokeratin 7 (epithelial marker) as a putative means of normalizing HOXB4 mRNA levels based on epithelial content. To ensure consistancy between different plates of assays, a particular sample in the EE group was included in all plates and the HOXB4 cycle threshold for that sample was equalized for all plates.

\subsection{RESULTS}

\subsubsection{The Expression of HOXB4 mRNA in Eutopic and Ectopic Endometrial Tissue}

The proper use of housekeeping genes as internal control is critically important when evaluating target gene expression from tissue biopsies using real-time qPCR method. Glyceraldehyde-3-phosphate dehydrogenase (GAPDH), 18s ribosomal RNA (18S rRNA), and beta actin (ACTB) are the most widely used housekeeping gene in gynaecological tissue gene expression analyses in primates and human studies [208, 227-229]. Thus, I sought to use GAPDH as a reference gene to evaluate the expression of HOXB4 in eutopic and ectopic endometrial biopsies. When HOXB4 mRNA levels were normalised to GAPDH mRNA levels in lesions from patients without endometriosis (EC) and patients with endometriosis (EE, Eoma, and DIE), a significant reduction in HOXB4 mRNA levels was observed in Eoma group when compared to 
EC, EE and DIE groups $(P=0.008, P=0.007$, and $P=0.035$, respectively) (Figure 4.1). No significance of HOXB4 mRNA levels was observed between EC, EE and DIE groups $(P>0.05)$.

Decreased HOXB4 protein levels were observed in ectopic endometrial tissue biopsies from DIE groups according to my immunohistochemistry results, contrasting with my qPCR results. According to my immunohistochemistry results, HOXB4 protein was exclusively expressed in glandular epithelial cells; therefore, variations in epithelial content between eutopic and ectopic tissue biopsies may affect the accuracy of using the universally expressed GAPDH as a reference gene (i.e. GAPDH expressed both in epithelial and stromal cells). Thus, I sought to use an epithelial exclusive reference gene, such as cytokeratin 7, to reassess my data. After normalisation of HOXB4 mRNA levels with the epithelial marker CK7, surprisingly, no significant differences in HOXB4 expression were found among any of the study groups (Figure 4.2, $P>0.05)$.

The epithelial content of individual tissue biopsies can be estimated histologically by a pathologist. This estimated epithelial content has previously been reported to help in quantifying protein levels in the epithelial cells exclusively, such as the level of epithelial cell adhesion molecule (EpCAM) in prostate cancer [230]. Similarly, the epithelial content of tissue biopsies used for RNA extraction was estimated to determine mRNA levels exclusive to epithelial cells. In order to maintain consistency in the epithelial content of the sections cut for mRNA extraction and epithelial content estimation, serial sections that were cut no more than 15 micron away from each other were used in these respective analyses. A negative correlation between CK7 CT values and the epithelial content percentage was observed, as expected (Figure 4.3), suggesting a negative correlation between the CK7 mRNA levels and epithelial content in these tissue biopsies. 
Furthermore, after normalization with epithelial content as a reference, HOXB4 mRNA levels were significantly lower in the DIE and Eoma groups when compared to the eutopic endometrium of women without endometriosis (EC) $(P=0.0001, P=0.001$, respectively). Additionally, significantly lower HOXB4 mRNA levels were detected in DIE group when compared to the Eoma group $(P=0.018$; Figure 4.4).

\subsubsection{The Expression of HOXB4 mRNA in Different Pelvic Zones from Women with}

\section{Endometriosis}

As mentioned in section 1.1.5.1, there is a standardised system to report pelvic anomalies during a laparoscopic pelvic examinations based on the anatomical landmarks [123]. The variation of HOXB4 mRNA levels according to the pelvic zones in the DIE group was conducted. Only two zones were represented in our samples: zone 2 which represents medially located structures $(n=8)$ and zone 3 which represents lateral anatomical structures $(n=3)$. Medial structures (Zone 2$)$ were found to have significantly higher HOXB4 mRNA levels when normalized to the epithelial content percentage (Figure 4.5).

\subsection{DISCUSSION}

With the advancement of molecular assays, FFPE tissues are considered an invaluable resource in research. FFPE is considered an excellent approach to preserve antigens and proteins as it minimizes degradation that would usually happen over time and has been validated for different immunohistochemical assays [211, 231]. Nevertheless, many reports have proven that nucleic acid degradation in FFPE tissues is unavoidable. This could be due to suboptimal tissue processing, fixation or storage which will lead to significant RNA fragmentation and subsequently lower levels [211, 232, 233]. 
As discussed in section 3.4, the Endo-Onc tissue bank implemented a new approach to prevent DNA and RNA degradation with prolonged storage using a molecular fixative. It is considered a better fixative as it enables better downstream molecular applications like gene expression [189]. However, due to time limitation, extracting RNA from FFPE tissues was more feasible in our case.

One of the major challenges of extracting RNA from the FFPE blocks was the low RNA yields when using the RecoverAll ${ }^{\mathrm{TM}}$ Kit and a success rate of only $51.7 \%$ (see section 2.4). This was improved when we changed and modified the extraction method with the other AllPrep DNA/RNA FFPE Kit. However, we were extracting the RNA from the whole scroll which affected yields as HOXB4 is only expressed in the glandular epithelium.

Endometriotic tissue (as opposed to normal endometrium) is considered progesteroneresistant. Microscopically, fewer glandular cells (one or more) are found in endometriotic lesions and usually are replaced with hemosiderin residuals [210]. It becomes really challenging to find endometrial glands in ovarian endometrioma due to the replacement with stromal cells and fibrotic tissue. As a result, many sections from the same lesion should be examined in order to confirm the absence of these glands [234]. In the normal cycling endometrium the regular gland:stroma ratio is 1:1. The observation of fewer glands than stroma, resulting in a ratio less than $1: 1$, may be an indication of atrophy, decidua, hyperplastic or neoplastic lesions[235]. Unfortunately, the exact gland:stroma ratio in endometriotic lesions is not reported in the literature.

Although, to my knowledge, no study has been conducted to evaluate the putative housekeeping genes for endometriosis, a report suggested that GAPDH may be suitable as a reference gene for cyclic and early pregnant equine endometrium [227] and in other gynecological diseases in human $[208,228,229]$. However, in the present study when HOXB4 mRNA levels 
were normalised to the housekeeping gene GAPDH, a significant reduction in the fold change of Eoma compared to the other groups EC $(P=0.008)$, EE $(P=0.007)$, and DIE $(P=0.035)$ was observed. It has been reported that gene expression in the endometrium could be regulated by environmental, cyclical or pathological conditions. For instance, Milne et al demonstrated a cyclical change in the expression of prostaglandin $\mathrm{E}_{2}$ gene [236]. Moreover, in the placenta, GAPDH has been reported to be expressed at different levels in 20 placental samples and this is why GAPDH is not commonly used as a housekeeping gene in placenta studies [237]. In normal ovarian tissue and serous or mucinous ovarian cancer FFPE samples, Cai et al demonstrated that GAPDH is not a suitable stable housekeeping gene and the use of a multiple-reference approach is advisable [238]. Moreover, Sadek et al recommended using at least two housekeeping genes when comparing gene expression variation between endometrium in normal and polycystic ovarian syndrome (PCOS) women [229]. As a result, speculations about GAPDH specificity as an internal stable reference were made and the option of using other reference genes was advised.

As demonstrated in section 3.3, HOXB4 is expressed only in the glandular epithelial cells. Because there were no readily available methods to verify the accuracy of the glandular epithelial extraction, an epithelial marker cytokeratin7 (CK7) assay, in addition to the housekeeping gene GAPDH and the target gene HOXB4, was evaluated in plate. To the best of my knowledge, CK7 was never reported to be used as a RT-PCR endometrial epithelial marker. Few cytokeratins are expressed in the simple epithelia that lines internal organ cavities, however CK7 and CK20 are the two most frequently used cytokeratins that are known to be expressed exclusively in glandular epithelial tissues and neoplasms [239-241]. In more than 400 neoplastic samples, all the ovarian and uterine cancer samples expressed positive immunoreactivity to CK7 when compared to CK20 [242]. In RT-PCR, CK7 was used as an epithelial marker for circulating tumor cell detection in 
non-small cell lung cancer [243, 244]. To insure consistency among different 96-well PCR plates, all the cycle thresholds (CTs) were pegged to one particular sample in the EE group. Unfortunately, this approach didn't reveal any significant difference (Figure 4.2). This could be due to poor RNA yield and concentrations after extraction from FFPEs. Moreover, speculation about the heterogeneity of cellular content found in a scroll (i.e. epithelial, endothelial, stroma, myoepithelial cells, and adipocytes) combined with the lack of evidence of both the housekeeping and the epithelial marker genes specificity and sensitivity in endometrial cells reduced the possibility of consistency in fractional cycle number at which the amplification of any of the genes were detected.

Subsequently, we took another approach to analyse the data by evaluating the percentage of the epithelial content in all the blocks used for RNA extraction. There are many approaches to evaluate the epithelial content. A traditional approach was to count the epithelial nuclei in a hematoxylin and eosin (H\&E) stained slide. Another approach is to evaluate the epithelial content digitally using histophotometrical methods [230]. However, results from the digital estimation approach were found to be similar to those obtained visually by a pathologist [230]. Due to feasibility issues, the former approach was used to evaluate the percentage of glandular epithelial content in every block. Consecutive sliced scrolls (adjacent to each other) were used for the IHC and RNA analyses respectively and epithelial content was measured in both in order to minimize variations in tissue and facilitate comparisons between the two methods. The estimation of the epithelial percentage was done by evaluating the hematoxylin and eosin (H\&E) stained slides that represent each block included in the analysis. The epithelial content values ranged from zero to one. When no epithelial glands were found in the slide, the epithelial content was designated a value of zero. The slides with the highest epithelial content were scored with a value of 1 . This 
allowed us to evaluate the accuracy of using the CK7 assay as an indicator for epithelial content (Figure 4.3). When we evaluated the correlation between cycle thresholds (CTs) of CK7 paired to the epithelial content percentage in each sample, an expected, though not convincing, negative correlation was found $(P=0.01)$. Taking into account that higher $\mathrm{CT}$ value means lower mRNA level is in any given sample, many samples with higher epithelial content had lower CK7 mRNA levels (i.e. higher CT value). However, there were a number of samples with extremely divergent epithelial content (i.e. 0 or 1.0) that have identical CT values, which means CK7 mRNA levels may not directly reflect the content of epithelial cells in a given sample. This may due to the following: first of all, other non-epithelial cell types such as endothelial cells existing in our sample also express CK7 [245]; second, little is known about whether the mRNA expression of CK7 is consistent in the endometrial epithelial cells between the phases of the menstrual cycle, or between individual patients; finally, differences in the quality and purity of the extracted RNA from the FFPE scrolls may affect the accuracy of quantifying CK7 mRNA levels in our samples.

The epithelial content estimation approach allowed us to address the qPCR data from a different angle, one that used HOXB4 CT values normalised directly to the epithelial content percentage (Figure 4.4). By using this approach the mRNA data was in parallel to the protein data presented in section 3.3.

Although we didn't have a large sample size for the PCR analysis, we analysed the DIE group data and normalized HOXB4 mRNA levels using the three different approaches mentioned above in reference to the pelvic zones system [185]. This is a novel system to describe important pelvic structure locations in order to improve laparoscopic pelvic examination and diagnostic accuracy. There was only a significant reduction in HOXB4 mRNA levels in samples obtained 
from zone 2, which includes uterosacral and medial structure disease, when compared to zone 3, pelvic side wall and abdominal wall disease.

As a whole, procurement of homogeneous cells for gene expression profiles is essential in cases were mixed cells are available, as is the case for tissues in endometriosis. Moreover, validating housekeeping genes in both normal and endometrial pathologies coupled with specific epithelial markers will provide more precise evaluation of the genetic alterations or gene expression profiles. In order to avoid the heterogeneity encountered in the current RNA extraction method, laser capture microdissection will be one of the future directions to warrant the accuracy and consistency of the results. 


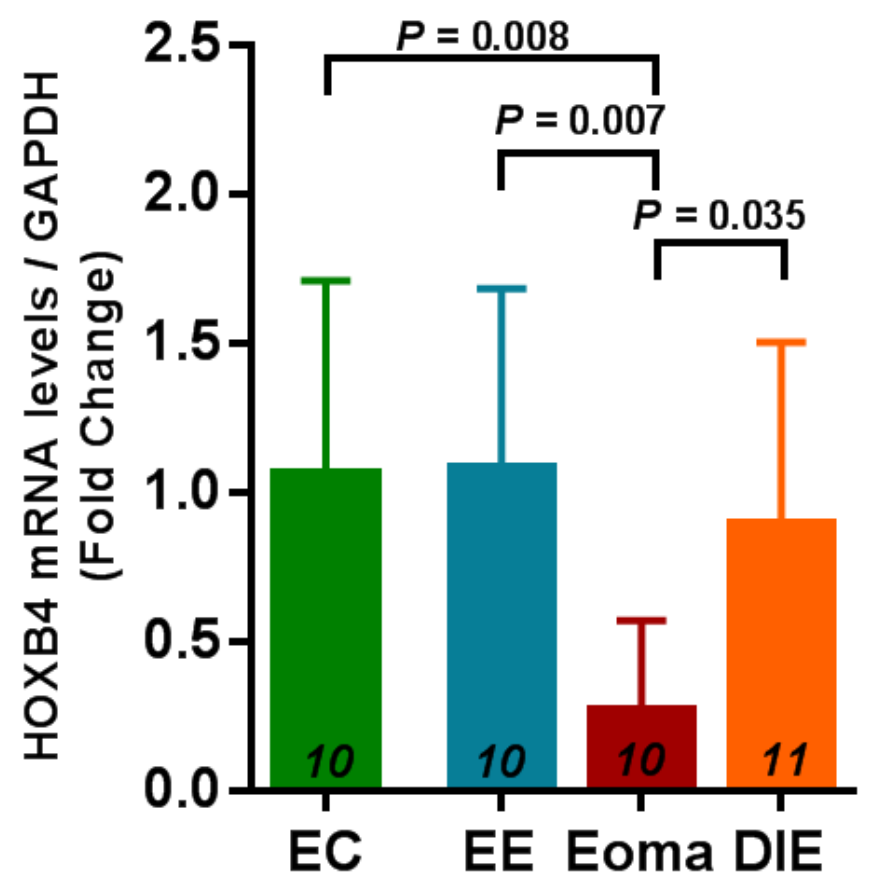

Figure 4.1: HOXB4 mRNA levels normalised to the reference gene GAPDH in lesions from patients without endometriosis (EC) and patients with endometriosis (EE, Eoma, and DIE).

Total RNA was extracted from FFPE blocks using the methods described in section 2.4. qPCR was performed using HOXB4 TaqMan assay after reverse transcription. All the cycle thresholds (CTs) were pegged to one particular sample in the EE group in order to insure the consistancy between different batch of assays. The mRNA levels of HOXB4 were normalised to GAPDH. The results are presented as mean \pm standard deviation $[\mathrm{SD}]$ in the bargraph above. 


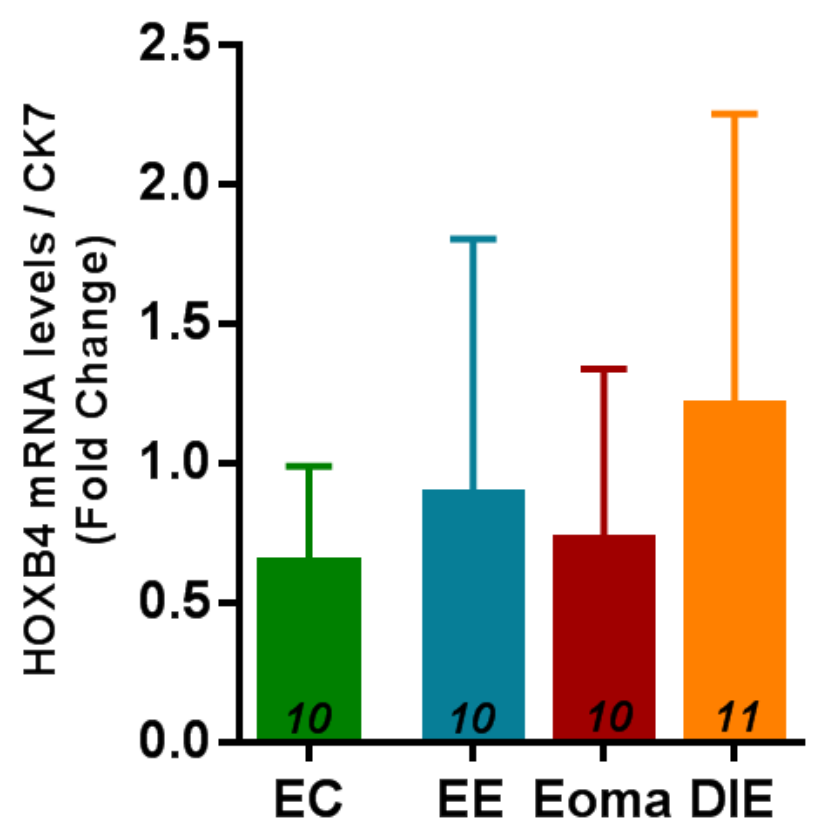

Figure 4.2: HOXB4 mRNA levels normalised to the epithelial marker Cytokeratin 7 in lesions from patients without endometriosis (EC) and patients with endometriosis (EE, Eoma, and DIE).

Total RNA was extracted from FFPE blocks using the methods described in section 2.4. qPCR was performed using HOXB4 TaqMan assay after reverse transcription. All the cycle thresholds (CTs) were pegged to one particular sample in the EE group in order to insure the consistancy between different batch of assays. The mRNA levels of HOXB4 were normalised to Cytokeratine 7. The results are presented as mean \pm standard deviation $[\mathrm{SD}]$ in the bargraph above. 


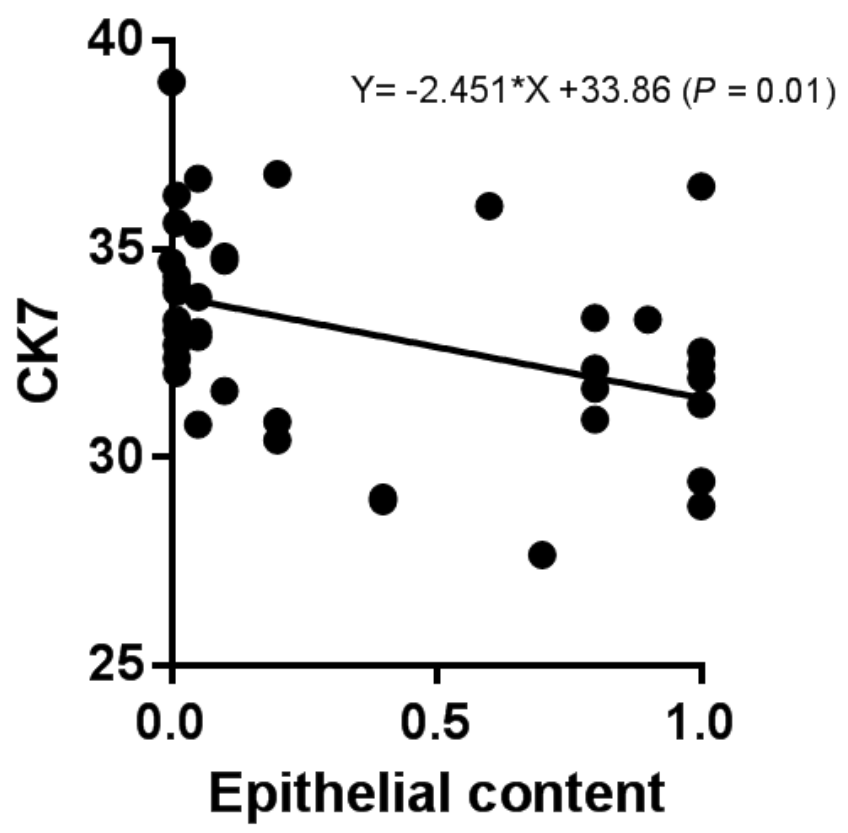

Figure 4.3: Correlation between the epithelial content and Cytokeratin7.

Total RNA was extracted from FFPE blocks using the methods described in section 2.4. qPCR was performed using Cytokeratine 7 (CK7) TaqMan assay after reverse transcription. All the cycle thresholds (CTs) were pegged to one particular sample in the EE group in order to insure the consistancy between different batch of assays. High CT value indicates lower CK7 mRNA level and vice versa. To quantify the epithelial conent, glandular epithelial nuclie percentage was estimated from the hematoxylin and eosin (H\&E) stained histology slides. The epithelial content was indicated as zero if no glands were found in the H\&E slide. The epithelial content from the H\&E stained slides with highest glandular percentage were given as 1 . The correlation between CK7 CTs paired with the epithelial content percentage are ploted in the scatter plot above. The linear regression was performed and the formula is presented above the scatter plot. 


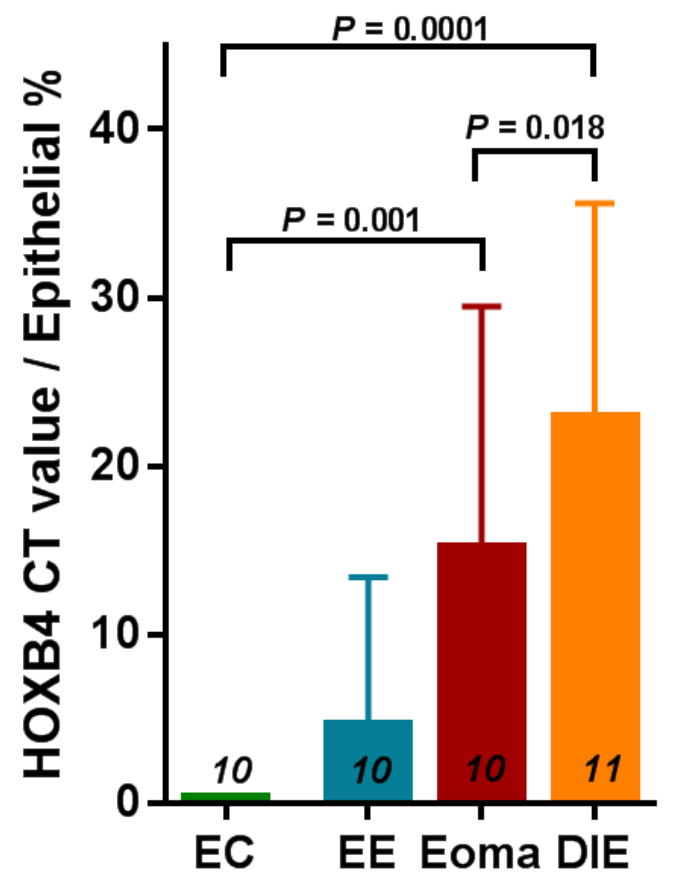

Figure 4.4: HOXB4 mRNA levels normalised to the epithelial content in lesions from patients without endometriosis (EC) and patients with endometriosis (EE, Eoma, and DIE).

Total RNA was extracted from FFPE blocks using the methods described in section 2.4. qPCR was performed using HOXB4 TaqMan assay after reverse transcription. All the cycle thresholds (CTs) were pegged to one particular sample in the EE group in order to insure the consistancy between different batch of assays. High CT value indicates lower HOXB4 mRNA level and vice versa. The mRNA levels of HOXB4 were normalised to epithelial content percentage. The results are presented as mean \pm standard deviation [SD] in the bargraph above. 

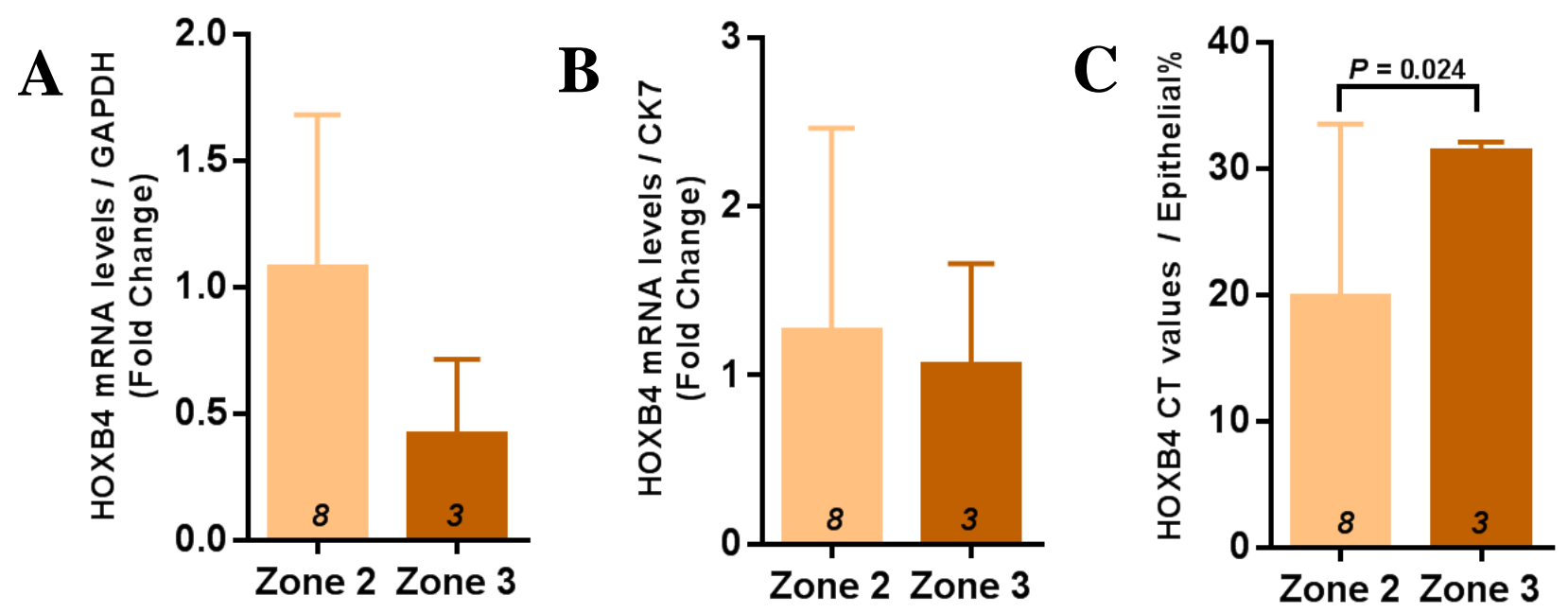

Figure 4.5: HOXB4 mRNA levels in deep infiltrating endometriosis lesions (DIE) in different pelvic zones.

Total RNA was extracted from FFPE blocks using the methods described in section 2.4. qPCR was performed using HOXB4 TaqMan assay after reverse transcription. All the cycle thresholds (CTs) were pegged to one particular sample in the EE group in order to insure the consistancy between different batch of assays. A. HOXB4 mRNA levels were normalised to GAPDH. B. HOXB4 mRNA levels were normalised to CK7. C. HOXB4 mRNA were normalised to epithelial content percentage. High CT value indicates lower HOXB4 mRNA level and vice versa. The results are presented as mean \pm standard deviation [SD] in the bargraph above. 


\section{Chapter 5: Conclusion and Future Directions}

HOX genes play a functional role in the endometrium. They are essential for endometrial proliferation, differentiation, and receptivity [246]. In human primary glandular epithelial cells, HOXB4 total mRNA levels were abundant and upregulated by estrogen and progesterone [184]. However, no publication has demonstrated HOXB4 protein immunoreactivity in eutopic endometrium of normal premenopausal women. Moreover, the localization and immunoreactivity of HOXB4 in eutopic and ectopic endometrium from women with endometriosis has not been proven. For these reasons, the experiments described in this dissertation aimed to establish not only the expression and localization of HOXB4 in normal eutopic endometrial tissue, but also to examine the expression in both eutopic and ectopic endometrial tissues in women with endometriosis during the menstrual cycle. Moreover, we intended to quantify the expression of HOXB4 in normal eutopic endometrial tissue and eutopic and ectopic endometrial tissues from patients with endometriosis.

First, we have demonstrated that HOXB4 protein expression was immunolocalized in the nuclei of glandular epithelial cells in normal eutopic endometrium, eutopic endometrium and ectopic endometrial implants from women with endometriosis. HOXB4 immunoreactivity was absent from endometrial stromal cells in all tissues examined. Second, this expression was higher in the proliferative phase in the eutopic endometrium from women without endometriosis when compared to the secretory phase. This difference was lost among the diseased groups. Third, HOXB4 immunoreactivity was significantly reduced in ectopic deep infiltrating endometriosis when compared to eutopic endometrium from women without endometriosis as well as eutopic endometrium and endometrioma tissues from women with endometriosis. Finally, HOXB4 mRNA levels were significantly lower in the deep infiltrating endometriosis and endometrioma groups 
comapred to the eutopic endometrium of women without endometriosis when normalised with epithelial content as a reference.

We will continue to evaluate the expression of the other three group 4 HOX genes and their roles in regulating the pathogenesis of endometriotic tissue which may correlate to the prognosis of endometriosis. Also, reducing heterogeneity in extracting epithelial endometrial glands by laser capture micro-dissection and finding multiple suitable reference genes will improve the accuracy of the results described in section 4.3 .

Many reports have established a link between endometriosis and ovarian cancer, specifically clear cell and endometrioid ovarian cancer [134, 247], with endometriosis-associated ovarian carcinomas having a more favourable prognosis [248, 249]. As there appears to be an association between endometriosis and these ovarian carcinomas, we used the Cheryl Brown Ovarian Cancer Outcomes Unit array (an array consisting of 612 ovarian cancer tumour cores from British Columbia, $42 \%$ of which are from women with endometrioid and clear cell ovarian cancer) to measure the expression of HOXB4 in tissue derived from these carcinomas and compare them to tissues from endometrial implants. I also was interested in investigating differences in HOXB4 expression in endometrial cancer compared to normal endometrium. Therefore, with the help of the Department of Anatomical Pathology at Vancouver General Hospital, we gained access to the endometrial cancer (09-004) Tissue Microarrays (TMA), comprised of 172 cases of endometrial carcinoma, and analyzed HOXB4 expression. The majority of these arrays were from endometrioid endometrial cancer. Both the ovarian and endometrial TMAs were stained and scored with HOXB4 using the method described in section 2.3 and 2.4, respectively. The H-score analysis of both TMAs will be then compared to the endometriosis H-score results described in section 3.3. With the understanding of the differences in HOXB4 expression in normal 
endometrium, different ectopic implants, and ovarian carcinomas, we hope to contribute towards the development of novel biomarkers for endometriosis and, ultimately, more accurate diagnostic tools for this disease. 


\section{References}

1. Vigano P, Parazzini F, Somigliana E, Vercellini P: Endometriosis: epidemiology and aetiological factors. Best practice \& research Clinical obstetrics \& gynaecology 2004, 18(2): 177-200.

2. Crosignani P, Olive D, Bergqvist A, Luciano A: Advances in the management of endometriosis: an update for clinicians. Human reproduction update 2006, 12(2):179189.

3. Leyland N, Casper R, Laberge P, Singh SS, Sogc: Endometriosis: diagnosis and management. Journal of obstetrics and gynaecology Canada $:$ JOGC = Journal d'obstetrique et gynecologie du Canada : JOGC 2010, 32(7 Suppl 2):S1-32.

4. De Graaff AA, D'Hooghe TM, Dunselman GA, Dirksen CD, Hummelshoj L, Consortium WE, Simoens S: The significant effect of endometriosis on physical, mental and social wellbeing: results from an international cross-sectional survey. Hum Reprod 2013, 28(10):2677-2685.

5. $\quad$ Sinaii N, Plumb K, Cotton L, Lambert A, Kennedy S, Zondervan K, Stratton P: Differences in characteristics among 1,000 women with endometriosis based on extent of disease. Fertility and sterility 2008, 89(3):538-545.

6. Sampson JA: Metastatic or Embolic Endometriosis, due to the Menstrual Dissemination of Endometrial Tissue into the Venous Circulation. The American journal of pathology 1927, 3(2):93-110 143.

7. Hughesdon PE: The structure of endometrial cysts of the ovary. J Obstet Gynaecol Br Emp 1957, 64(4):481-487.

8. Treloar SA, Bell TA, Nagle CM, Purdie DM, Green AC: Early menstrual characteristics associated with subsequent diagnosis of endometriosis. American journal of obstetrics and gynecology 2010, 202(6):534 e531-536.

9. Sangi-Haghpeykar H, Poindexter AN, 3rd: Epidemiology of endometriosis among parous women. Obstetrics and gynecology 1995, 85(6):983-992.

10. Chatman DL, Ward AB: Endometriosis in adolescents. J Reprod Med 1982, 27(3):156160.

11. Missmer SA, Hankinson SE, Spiegelman D, Barbieri RL, Marshall LM, Hunter DJ: Incidence of laparoscopically confirmed endometriosis by demographic, anthropometric, and lifestyle factors. American journal of epidemiology 2004, 160(8):784-796.

12. Koninckx PR: Epidemiology of Endometriosis. In: Endometriosis Advances and Controversies. edn. Edited by David B. Redwine TT. New York: Marcel Dekker; 2004 : 16.

13. Nnoaham KE, Hummelshoj L, Webster P, d'Hooghe T, de Cicco Nardone F, de Cicco Nardone C, Jenkinson C, Kennedy SH, Zondervan KT, World Endometriosis Research Foundation Global Study of Women's Health c: Impact of endometriosis on quality of life and work productivity: a multicenter study across ten countries. Fertility and sterility 2011, 96(2):366-373 e368.

14. Holt VL, Weiss NS: Recommendations for the design of epidemiologic studies of endometriosis. Epidemiology 2000, 11(6):654-659. 
15. Fritz MA, Speroff L: Clinical gynecologic endocrinology and infertility. In., 8th edn. Philadelphia: Wolters Kluwer Health/Lippincott Williams \& Wilkins,; 2011: x, 1439 p.

16. Hediger ML, Hartnett HJ, Louis GM: Association of endometriosis with body size and figure. Fertility and sterility 2005, 84(5):1366-1374.

17. d'Hooghe TM: Endometriosis. In: Berek \& Novak’s Gynecology. edn. Edited by Berek JS: Lippincott Williams \& Wilkinson; 2012: 505-557.

18. Harris HR, Chavarro JE, Malspeis S, Willett WC, Missmer SA: Dairy-food, calcium, magnesium, and vitamin $D$ intake and endometriosis: a prospective cohort study. American journal of epidemiology 2013, 177(5):420-430.

19. Levy AR, Osenenko KM, Lozano-Ortega G, Sambrook R, Jeddi M, Belisle S, Reid RL: Economic burden of surgically confirmed endometriosis in Canada. Journal of obstetrics and gynaecology Canada $: J O G C=$ Journal d'obstetrique et gynecologie du Canada : JOGC 2011, 33(8):830-837.

20. Whelan E: 'No one agrees except for those of us who have it': endometriosis patients as an epistemological community. Sociology of Health \& Illness 2007, 29(7).

21. Simoens S, Dunselman G, Dirksen C, Hummelshoj L, Bokor A, Brandes I, Brodszky V, Canis M, Colombo GL, DeLeire T et al: The burden of endometriosis: costs and quality of life of women with endometriosis and treated in referral centres. Hum Reprod 2012, 27(5):1292-1299.

22. Burney RO, Giudice LC: Pathogenesis and pathophysiology of endometriosis. Fertility and sterility 2012, 98(3):511-519.

23. Sourial S, Tempest N, Hapangama DK: Theories on the pathogenesis of endometriosis. Int J Reprod Med 2014, 2014:179515.

24. Corwin EJ: Endometriosis: pathophysiology, diagnosis, and treatment. The Nurse practitioner 1997, 22(10):35-38, 40-32, 45-36, passim; quiz 56-37.

25. Bulun SE: Endometriosis. The New England journal of medicine 2009, 360(3):268-279.

26. Patel VC, Samuels H, Abeles E, Hirjibehedin PF: Endometriosis at the knee. A case report. Clinical orthopaedics and related research 1982(171):140-144.

27. Das Gupta S, Pal SK, Saha PK, Dawn CS: Endometriosis in the thumb. J Indian Med Assoc 1985, 83(4):122-123.

28. Gitelis S, Petasnick JP, Turner DA, Ghiselli RW, Miller AW, 3rd: Endometriosis simulating a soft tissue tumor of the thigh: CT and MR evaluation. J Comput Assist Tomogr 1985, 9(3):573-576.

29. Jabr FI, Mani V: An unusual cause of abdominal pain in a male patient: Endometriosis. Avicenna J Med 2014, 4(4):99-101.

30. L. OD: Endometriosis in clinical practice. London ; New York Taylor \& Francis, 2005.; 2004.

31. Park SY, Jameson JL: Minireview: transcriptional regulation of gonadal development and differentiation. Endocrinology 2005, 146(3):1035-1042.

32. Giudice L: Endometriosis : science and practice. In: Endometriosis: Science and Practice. edn. Edited by Giudice LC, Evers JLH, Healy DL: Wiley-Blackwell; 2012: 4253.

33. Benagiano G, Brosens I, Lippi D: The history of endometriosis. Gynecologic and obstetric investigation 2014, 78(1):1-9.

34. Redwine DB: Was Sampson wrong? Fertility and sterility 2002, 78(4):686-693. 
35. Dehoux JP, Defrere S, Squifflet J, Donnez O, Polet R, Mestdagt M, Foidart JM, Van Langendonckt A, Donnez J: Is the baboon model appropriate for endometriosis studies? Fertility and sterility 2011, 96(3):728-733 e723.

36. D'Hooghe TM, Bambra CS, Raeymaekers BM, De Jonge I, Lauweryns JM, Koninckx PR: Intrapelvic injection of menstrual endometrium causes endometriosis in baboons (Papio cynocephalus and Papio anubis). American journal of obstetrics and gynecology 1995, 173(1):125-134.

37. Olive DL, Henderson DY: Endometriosis and mullerian anomalies. Obstetrics and gynecology 1987, 69(3 Pt 1):412-415.

38. Kruitwagen RF, Poels LG, Willemsen WN, de Ronde IJ, Jap PH, Rolland R: Endometrial epithelial cells in peritoneal fluid during the early follicular phase. Fertility and sterility 1991, 55(2):297-303.

39. Witz CA, Monotoya-Rodriguez IA, Schenken RS: Whole explants of peritoneum and endometrium: a novel model of the early endometriosis lesion. Fertility and sterility 1999, 71(1):56-60.

40. Maas JW, Groothuis PG, Dunselman GA, de Goeij AF, Struijker-Boudier HA, Evers JL: Development of endometriosis-like lesions after transplantation of human endometrial fragments onto the chick embryo chorioallantoic membrane. Hum Reprod 2001, 16(4):627-631.

41. Halme J, Hammond MG, Hulka JF, Raj SG, Talbert LM: Retrograde menstruation in healthy women and in patients with endometriosis. Obstetrics and gynecology 1984, 64(2):151-154.

42. Liu DT, Hitchcock A: Endometriosis: its association with retrograde menstruation, dysmenorrhoea and tubal pathology. British journal of obstetrics and gynaecology 1986, 93(8):859-862.

43. Blumenkrantz MJ, Gallagher N, Bashore RA, Tenckhoff H: Retrograde menstruation in women undergoing chronic peritoneal dialysis. Obstetrics and gynecology 1981, 57(5):667-670.

44. R M: Uber den staude der frage der adenomyosites adenomyoma in allgemeinen und adenomyometritis sarcomastosa. Zentralb Gynakol 1919, 36(745).

45. Sundheimer LW, Alford CE, Taylor RN, DeCherney AH: Endometriosis. In: Endotext. edn. Edited by De Groot LJ, Beck-Peccoz P, Chrousos G, Dungan K, Grossman A, Hershman JM, Koch C, McLachlan R, New M, Rebar R et al. South Dartmouth (MA); 2000.

46. P G: Origin of endometriosis from the mesenchyme of the celomic walls. American journal of obstetrics and gynecology 1942, 44(3):470-474.

47. Matsuura K, Ohtake H, Katabuchi H, Okamura H: Coelomic metaplasia theory of endometriosis: evidence from in vivo studies and an in vitro experimental model. Gynecologic and obstetric investigation 1999, 47 Suppl 1:18-20; discussion 20-12.

48. Sundheimer LW, Alford CE, Taylor RN, DeCherney AH: Endometriosis. In: Endometriosis. edn. Edited by De Groot LJ B-PP, Chrousos G, et al., editors. . Endotext [Internet], South Dartmouth (MA): MDText.com, Inc.; 2000-[Updated 2014 Nov 1].

49. Frey GH: The familial occurrence of endometriosis; report of five instances and review of the literature. American journal of obstetrics and gynecology 1957, 73(2):418-421. 
50. Nash F, Heffernan RJ: Familial endometriosis; report of mother and three daughters. Obstetrics and gynecology 1959, 13(4):485-486.

51. Moen MH, Magnus P: The familial risk of endometriosis. Acta obstetricia et gynecologica Scandinavica 1993, 72(7):560-564.

52. Hadfield RM, Mardon HJ, Barlow DH, Kennedy SH: Endometriosis in monozygotic twins. Fertility and sterility 1997, 68(5):941-942.

53. Albertsen HM, Chettier R, Farrington P, Ward K: Genome-wide association study link novel loci to endometriosis. PloS one 2013, 8(3):e58257.

54. Lebovic DI, Mueller MD, Taylor RN: Immunobiology of endometriosis. Fertility and sterility 2001, 75(1):1-10.

55. Eisenberg VH, Zolti M, Soriano D: Is there an association between autoimmunity and endometriosis? Autoimmun Rev 2012, 11(11):806-814.

56. Koch AE, Polverini PJ, Kunkel SL, Harlow LA, DiPietro LA, Elner VM, Elner SG, Strieter RM: Interleukin-8 as a macrophage-derived mediator of angiogenesis. Science 1992, 258(5089):1798-1801.

57. Beste MT, Pfaffle-Doyle N, Prentice EA, Morris SN, Lauffenburger DA, Isaacson KB, Griffith LG: Molecular network analysis of endometriosis reveals a role for c-Junregulated macrophage activation. Sci Transl Med 2014, 6(222):222ra216.

58. Osuga Y, Koga K, Hirota Y, Hirata T, Yoshino O, Taketani Y: Lymphocytes in endometriosis. American journal of reproductive immunology : AJRI : official journal of the American Society for the Immunology of Reproduction and the International Coordination Committee for Immunology of Reproduction 2011, 65(1):1-10.

59. Barbieri RL, Niloff JM, Bast RC, Jr., Scaetzl E, Kistner RW, Knapp RC: Elevated serum concentrations of CA-125 in patients with advanced endometriosis. Fertility and sterility 1986, 45(5):630-634.

60. Helvacioglu A, Aksel S, Peterson RD: Endometriosis and autologous lymphocyte activation by endometrial cells. Are lymphocytes or endometrial cell defects responsible? J Reprod Med 1997, 42(2):71-75.

61. Dmowski WP, Steele RW, Baker GF: Deficient cellular immunity in endometriosis. American journal of obstetrics and gynecology 1981, 141(4):377-383.

62. Valko M, Leibfritz D, Moncol J, Cronin MT, Mazur M, Telser J: Free radicals and antioxidants in normal physiological functions and human disease. The international journal of biochemistry \& cell biology 2007, 39(1):44-84.

63. Murphy AA, Palinski W, Rankin S, Morales AJ, Parthasarathy S: Evidence for oxidatively modified lipid-protein complexes in endometrium and endometriosis. Fertility and sterility 1998, 69(6):1092-1094.

64. Murphy AA, Santanam N, Parthasarathy S: Endometriosis: a disease of oxidative stress? Semin Reprod Endocrinol 1998, 16(4):263-273.

65. Alpay Z, Saed GM, Diamond MP: Female infertility and free radicals: potential role in adhesions and endometriosis. J Soc Gynecol Investig 2006, 13(6):390-398.

66. Agarwal A, Gupta S, Sharma RK: Role of oxidative stress in female reproduction. Reproductive biology and endocrinology : RB\&E 2005, 3:28.

67. Augoulea A, Alexandrou A, Creatsa M, Vrachnis N, Lambrinoudaki I: Pathogenesis of endometriosis: the role of genetics, inflammation and oxidative stress. Archives of gynecology and obstetrics 2012, 286(1):99-103. 
68. Wang Y, Sharma RK, Falcone T, Goldberg J, Agarwal A: Importance of reactive oxygen species in the peritoneal fluid of women with endometriosis or idiopathic infertility. Fertility and sterility 1997, 68(5):826-830.

69. Defrere S, Lousse JC, Gonzalez-Ramos R, Colette S, Donnez J, Van Langendonckt A: Potential involvement of iron in the pathogenesis of peritoneal endometriosis. Molecular human reproduction 2008, 14(7):377-385.

70. Verit FF, Erel O, Celik N: Serum paraoxonase-1 activity in women with endometriosis and its relationship with the stage of the disease. Hum Reprod 2008, 23(1):100-104.

71. Mier-Cabrera J, Aburto-Soto T, Burrola-Mendez S, Jimenez-Zamudio L, Tolentino MC, Casanueva E, Hernandez-Guerrero C: Women with endometriosis improved their peripheral antioxidant markers after the application of a high antioxidant diet. Reproductive biology and endocrinology : RB\&E 2009, 7:54.

72. Parazzini F, Vigano P, Candiani M, Fedele L: Diet and endometriosis risk: a literature review. Reproductive biomedicine online 2013, 26(4):323-336.

73. Hays SM, Aylward LL: Dioxin risks in perspective: past, present, and future. Regul Toxicol Pharmacol 2003, 37(2):202-217.

74. Bellelis P, Podgaec S, Abrao MS: Environmental factors and endometriosis. Rev Assoc Med Bras 2011, 57(4):448-452.

75. White SS, Birnbaum LS: An overview of the effects of dioxins and dioxin-like compounds on vertebrates, as documented in human and ecological epidemiology. $J$ Environ Sci Health C Environ Carcinog Ecotoxicol Rev 2009, 27(4):197-211.

76. Bruner-Tran KL, Ding T, Osteen KG: Dioxin and endometrial progesterone resistance. Seminars in reproductive medicine 2010, 28(1):59-68.

77. Resuehr D, Glore DR, Taylor HS, Bruner-Tran KL, Osteen KG: Progesteronedependent regulation of endometrial cannabinoid receptor type 1 (CB1-R) expression is disrupted in women with endometriosis and in isolated stromal cells exposed to 2,3,7,8-tetrachlorodibenzo-p-dioxin (TCDD). Fertility and sterility 2012, 98(4):948-956 e941.

78. Igarashi TM, Bruner-Tran KL, Yeaman GR, Lessey BA, Edwards DP, Eisenberg E, Osteen KG: Reduced expression of progesterone receptor- $B$ in the endometrium of women with endometriosis and in cocultures of endometrial cells exposed to $2,3,7,8$ tetrachlorodibenzo-p-dioxin. Fertility and sterility 2005, 84(1):67-74.

79. Mutter GL, Prat JD, ClinicalKey Flex: Pathology of the female reproductive tract. In., Third edition. edn. Edinburgh: Churchill Livingstone/Elsevier,; 2014: 1 online resource.

80. Markham SM, Carpenter SE, Rock JA: Extrapelvic endometriosis. Obstetrics and gynecology clinics of North America 1989, 16(1):193-219.

81. Honore GM: Extrapelvic endometriosis. Clinical obstetrics and gynecology 1999, 42(3):699-711.

82. Jenkins S, Olive DL, Haney AF: Endometriosis: pathogenetic implications of the anatomic distribution. Obstetrics and gynecology 1986, 67(3):335-338.

83. Bouquet De Joliniere J, Ayoubi JM, Gianaroli L, Dubuisson JB, Gogusev J, Feki A: Endometriosis: a new cellular and molecular genetic approach for understanding the pathogenesis and evolutivity. Frontiers in surgery 2014, 1:16. 
84. Gustofson RL, Kim N, Liu S, Stratton P: Endometriosis and the appendix: a case series and comprehensive review of the literature. Fertility and sterility 2006, 86(2):298-303.

85. Howard FM: Endometriosis and mechanisms of pelvic pain. Journal of minimally invasive gynecology 2009, 16(5):540-550.

86. Hoffman B, Schorge J, Schaffer J, Halvorson L, Bradshaw K, Cunningham F: Williams Gynecology. 2012:1401

87. Becker CM, Laufer MR, Stratton P, Hummelshoj L, Missmer SA, Zondervan KT, Adamson GD, Group WEW: World Endometriosis Research Foundation Endometriosis Phenome and Biobanking Harmonisation Project: I. Surgical phenotype data collection in endometriosis research. Fertility and sterility 2014, 102(5):1213-1222.

88. Adamson GD, Frison L, Lamb EJ: Endometriosis: studies of a method for the design of a surgical staging system. Fertility and sterility 1982, 38(6):659-666.

89. Koninckx PR, Martin DC: Deep endometriosis: a consequence of infiltration or retraction or possibly adenomyosis externa? Fertility and sterility 1992, 58(5):924928.

90. van der Linden PJ: Theories on the pathogenesis of endometriosis. Hum Reprod 1996, 11 Suppl 3:53-65.

91. Jansen RP, Russell P: Nonpigmented endometriosis: clinical, laparoscopic, and pathologic definition. American journal of obstetrics and gynecology 1986, 155(6):1154-1159.

92. Tulandi T, Redwine D: Endometriosis Advances and Contraversies: Marcel Dekker; 2004.

93. Nisolle M, Donnez J: Peritoneal endometriosis, ovarian endometriosis, and adenomyotic nodules of the rectovaginal septum are three different entities. Fertility and sterility 1997, 68(4):585-596.

94. Nisolle M, Casanas-Roux F, Anaf V, Mine JM, Donnez J: Morphometric study of the stromal vascularization in peritoneal endometriosis. Fertility and sterility 1993, 59(3):681-684.

95. Nisolle M, Casanas-Roux F, Donnez J: Immunohistochemical analysis of proliferative activity and steroid receptor expression in peritoneal and ovarian endometriosis. Fertility and sterility 1997, 68(5):912-919.

96. Vercellini P, Aimi G, De Giorgi O, Maddalena S, Carinelli S, Crosignani PG: Is cystic ovarian endometriosis an asymmetric disease? British journal of obstetrics and gynaecology 1998, 105(9):1018-1021.

97. Fauconnier A, Chapron C, Dubuisson JB, Vieira M, Dousset B, Breart G: Relation between pain symptoms and the anatomic location of deep infiltrating endometriosis. Fertility and sterility 2002, 78(4):719-726.

98. Koninckx PR, Meuleman C, Demeyere S, Lesaffre E, Cornillie FJ: Suggestive evidence that pelvic endometriosis is a progressive disease, whereas deeply infiltrating endometriosis is associated with pelvic pain. Fertility and sterility 1991, 55(4):759765 . 
99. Kinkel K, Chapron C, Balleyguier C, Fritel X, Dubuisson JB, Moreau JF: Magnetic resonance imaging characteristics of deep endometriosis. Hum Reprod 1999, 14(4):1080-1086.

100. Brook CG: Mechanism of puberty. Hormone research 1999, 51 Suppl 3:52-54.

101. Silverthorn DU: Human Physiology: An Integrated Approach.

102. Losos JB, Raven PH, Johnson GB, Singer SR: Biology. New York: McGraw-Hill; 2002.

103. All About Menstruation [http://teens.webmd.com/girls/all-about-menstruation]; Access date $8 / 8 / 2015$.

104. Edenics [http://www.edenics.net/english-word-origins.aspx?word=ESTROGEN]; Access date $9 \backslash 8 \backslash 2015$.

105. Ryan KJ: Biochemistry of aromatase: significance to female reproductive physiology. Cancer research 1982, 42(8 Suppl):3342s-3344s.

106. Ahn SH, Monsanto SP, Miller C, Singh SS, Thomas R, Tayade C: Pathophysiology and Immune Dysfunction in Endometriosis. BioMed research international 2015, 2015:795976.

107. Jacob J, Sebastian KS, Devassy S, Priyadarsini L, Farook MF, Shameem A, Mathew D, Sreeja S, Thampan RV: Membrane estrogen receptors: genomic actions and post transcriptional regulation. Molecular and cellular endocrinology 2006, 246(1-2):34-41.

108. Kumar R, Zakharov MN, Khan SH, Miki R, Jang H, Toraldo G, Singh R, Bhasin S, Jasuja R: The dynamic structure of the estrogen receptor. J Amino Acids 2011, 2011:812540.

109. Soltysik K, Czekaj P: Membrane estrogen receptors - is it an alternative way of estrogen action? J Physiol Pharmacol 2013, 64(2):129-142.

110. Prossnitz ER, Arterburn JB, Sklar LA: GPR30: A G protein-coupled receptor for estrogen. Molecular and cellular endocrinology 2007, 265-266:138-142.

111. Bulun SE, Lin Z, Imir G, Amin S, Demura M, Yilmaz B, Martin R, Utsunomiya H, Thung S, Gurates B et al: Regulation of aromatase expression in estrogen-responsive breast and uterine disease: from bench to treatment. Pharmacol Rev 2005, 57(3):359383.

112. Attar E, Bulun SE: Aromatase and other steroidogenic genes in endometriosis: translational aspects. Human reproduction update 2006, 12(1):49-56.

113. Fortier MA, Krishnaswamy K, Danyod G, Boucher-Kovalik S, Chapdalaine P: A postgenomic integrated view of prostaglandins in reproduction: implications for other body systems. J Physiol Pharmacol 2008, 59 Suppl 1:65-89.

114. Bulun SE, Utsunomiya H, Lin Z, Yin P, Cheng YH, Pavone ME, Tokunaga H, Trukhacheva E, Attar E, Gurates B et al: Steroidogenic factor-1 and endometriosis. Molecular and cellular endocrinology 2009, 300(1-2):104-108.

115. Allen WM: Progesterone: how did the name originate? Southern medical journal 1970, 63(10):1151-1155.

116. Stevenson A: Oxford Dictionary of English: New York, NY : Oxford University Press, 2010.; 2010.

117. Kastner P, Krust A, Turcotte B, Stropp U, Tora L, Gronemeyer H, Chambon P: Two distinct estrogen-regulated promoters generate transcripts encoding the two functionally different human progesterone receptor forms $\mathbf{A}$ and $\mathbf{B}$. The $E M B O$ journal 1990, 9(5):1603-1614. 
118. Gene: PGR (ENSG00000082175)

[http://may2009.archive.ensembl.org/Homo_sapiens/Gene/Summary?g=ENSG00000082 175]; Access date 7/6/2015.

119. Richer JK, Jacobsen BM, Manning NG, Abel MG, Wolf DM, Horwitz KB: Differential gene regulation by the two progesterone receptor isoforms in human breast cancer cells. The Journal of biological chemistry 2002, 277(7):5209-5218.

120. Bedaiwy MA, Dahoud W, Skomorovska-Prokvolit Y, Yi L, Liu JH, Falcone T, Hurd WW, Mesiano S: Abundance and Localization of Progesterone Receptor Isoforms in Endometrium in Women With and Without Endometriosis and in Peritoneal and Ovarian Endometriotic Implants. Reproductive sciences 2015, 22(9):1153-1161.

121. Taylor AH, McParland PC, Taylor DJ, Bell SC: The cytoplasmic 60 kDa progesterone receptor isoform predominates in the human amniochorion and placenta at term. Reproductive biology and endocrinology : RB\&E 2009, 7:22.

122. Vegeto E, Cocciolo MG, Raspagliesi F, Piffanelli A, Fontanelli R, Maggi A: Regulation of progesterone receptor gene expression. Cancer research 1990, 50(17):5291-5295.

123. Bedaiwy MA, Henry D, Liu J, Falcone T: Standardization of laparoscopic pelvic examination. Fertility and sterility 2013, 99(5):e11.

124. Practice Committee of the American Society for Reproductive M: Endometriosis and infertility: a committee opinion. Fertility and sterility 2012, 98(3):591-598.

125. Yeung P, Jr.: The laparoscopic management of endometriosis in patients with pelvic pain. Obstetrics and gynecology clinics of North America 2014, 41(3):371-383.

126. Revised American Society for Reproductive Medicine classification of endometriosis: 1996. Fertility and sterility 1997, 67(5):817-821.

127. Tuttlies F, Keckstein J, Ulrich U, Possover M, Schweppe KW, Wustlich M, Buchweitz $\mathrm{O}$, Greb R, Kandolf $\mathrm{O}$, Mangold R et al: [ENZIAN-score, a classification of deep infiltrating endometriosis]. Zentralbl Gynakol 2005, 127(5):275-281.

128. Haas D, Chvatal R, Habelsberger A, Wurm P, Schimetta W, Oppelt P: Comparison of revised American Fertility Society and ENZIAN staging: a critical evaluation of classifications of endometriosis on the basis of our patient population. Fertility and sterility 2011, 95(5):1574-1578.

129. Adamson GD, Pasta DJ: Endometriosis fertility index: the new, validated endometriosis staging system. Fertility and sterility 2010, 94(5):1609-1615.

130. Nezhat FR, Kalir T: Comparative immunohistochemical studies of endometriosis lesions and endometriotic cysts. Fertility and sterility 2002, 78(4):820-824.

131. Prowse AH, Manek S, Varma R, Liu J, Godwin AK, Maher ER, Tomlinson IP, Kennedy $\mathrm{SH}$ : Molecular genetic evidence that endometriosis is a precursor of ovarian cancer. International journal of cancer Journal international du cancer 2006, 119(3):556-562.

132. Banz C, Chalvatzas N, Kelling K, Beyer D, Hornemann A, Diedrich K, Kavallaris A: Laparoscopic management of ectopic pregnancy during a 9-year period. Fertility and sterility 2010, 94(7):2780-2782.

133. Pollacco J, Sacco K, Portelli M, Schembri-Wismayer P, Calleja-Agius J: Molecular links between endometriosis and cancer. Gynecological endocrinology : the official journal of the International Society of Gynecological Endocrinology 2012, 28(8):577581. 
134. Somigliana E, Vigano P, Parazzini F, Stoppelli S, Giambattista E, Vercellini P: Association between endometriosis and cancer: a comprehensive review and a critical analysis of clinical and epidemiological evidence. Gynecologic oncology 2006, 101(2):331-341.

135. Somigliana E, Infantino M, Benedetti F, Arnoldi M, Calanna G, Ragni G: The presence of ovarian endometriomas is associated with a reduced responsiveness to gonadotropins. Fertility and sterility 2006, 86(1):192-196.

136. Kim HS, Kim TH, Chung HH, Song YS: Risk and prognosis of ovarian cancer in women with endometriosis: a meta-analysis. British journal of cancer 2014, 110(7):1878-1890.

137. Bridges CB: Current Maps of the Location of the Mutant Genes of Drosophila Melanogaster. Proceedings of the National Academy of Sciences of the United States of America 1921, 7(4):127-132.

138. McGinnis W, Krumlauf R: Homeobox genes and axial patterning. Cell 1992, 68(2):283-302.

139. Shah N, Sukumar S: The Hox genes and their roles in oncogenesis. Nature reviews Cancer 2010, 10(5):361-371.

140. McGinnis W, Hart CP, Gehring WJ, Ruddle FH: Molecular cloning and chromosome mapping of a mouse DNA sequence homologous to homeotic genes of Drosophila. Cell 1984, 38(3):675-680.

141. McGinnis W, Levine MS, Hafen E, Kuroiwa A, Gehring WJ: A conserved DNA sequence in homoeotic genes of the Drosophila Antennapedia and bithorax complexes. Nature 1984, 308(5958):428-433.

142. McGinnis W, Garber RL, Wirz J, Kuroiwa A, Gehring WJ: A homologous proteincoding sequence in Drosophila homeotic genes and its conservation in other metazoans. Cell 1984, 37(2):403-408.

143. Lewis EB: A gene complex controlling segmentation in Drosophila. Nature 1978, 276(5688):565-570.

144. Magli MC, Barba P, Celetti A, De Vita G, Cillo C, Boncinelli E: Coordinate regulation of HOX genes in human hematopoietic cells. Proceedings of the National Academy of Sciences of the United States of America 1991, 88(14):6348-6352.

145. Belotti D, Clausse N, Flagiello D, Alami Y, Daukandt M, Deroanne C, Malfoy B, Boncinelli E, Faiella A, Castronovo V: Expression and modulation of homeobox genes from cluster B in endothelial cells. Laboratory investigation; a journal of technical methods and pathology 1998, 78(10):1291-1299.

146. Scott MP, Tamkun JW, Hartzell GW, 3rd: The structure and function of the homeodomain. Biochimica et biophysica acta 1989, 989(1):25-48.

147. Taniguchi Y: Hox transcription factors: modulators of cell-cell and cell-extracellular matrix adhesion. BioMed research international 2014, 2014:591374.

148. Bhatlekar S, Fields JZ, Boman BM: HOX genes and their role in the development of human cancers. Journal of molecular medicine 2014, 92(8):811-823.

149. Abate-Shen C: Deregulated homeobox gene expression in cancer: cause or consequence? Nature reviews Cancer 2002, 2(10):777-785.

150. Economides $\mathrm{KD}$, Capecchi MR: Hoxb13 is required for normal differentiation and secretory function of the ventral prostate. Development 2003, 130(10):2061-2069. 
151. Jung C, Kim RS, Zhang HJ, Lee SJ, Jeng MH: HOXB13 induces growth suppression of prostate cancer cells as a repressor of hormone-activated androgen receptor signaling. Cancer research 2004, 64(24):9185-9192.

152. Wang Z, Dahiya S, Provencher H, Muir B, Carney E, Coser K, Shioda T, Ma XJ, Sgroi DC: The prognostic biomarkers HOXB13, IL17BR, and CHDH are regulated by estrogen in breast cancer. Clinical cancer research : an official journal of the American Association for Cancer Research 2007, 13(21):6327-6334.

153. Daftary GS, Taylor HS: Endocrine regulation of HOX genes. Endocrine reviews 2006, 27(4):331-355.

154. Taylor HS, Vanden Heuvel GB, Igarashi P: A conserved Hox axis in the mouse and human female reproductive system: late establishment and persistent adult expression of the Hoxa cluster genes. Biology of reproduction 1997, 57(6):1338-1345.

155. Chau YM, Pando S, Taylor HS: HOXA11 silencing and endogenous HOXA11 antisense ribonucleic acid in the uterine endometrium. The Journal of clinical endocrinology and metabolism 2002, 87(6):2674-2680.

156. Block K, Kardana A, Igarashi P, Taylor HS: In utero diethylstilbestrol (DES) exposure alters Hox gene expression in the developing mullerian system. FASEB $J$ 2000, 14(9):1101-1108.

157. Dupont S, Krust A, Gansmuller A, Dierich A, Chambon P, Mark M: Effect of single and compound knockouts of estrogen receptors alpha (ERalpha) and beta (ERbeta) on mouse reproductive phenotypes. Development 2000, 127(19):4277-4291.

158. Taylor HS, Arici A, Olive D, Igarashi P: HOXA10 is expressed in response to sex steroids at the time of implantation in the human endometrium. The Journal of clinical investigation 1998, 101(7):1379-1384.

159. Duester G: Retinoic acid synthesis and signaling during early organogenesis. Cell 2008, 134(6):921-931.

160. Marshall H, Morrison A, Studer M, Popperl H, Krumlauf R: Retinoids and Hox genes. FASEB J 1996, 10(9):969-978.

161. Langston AW, Gudas LJ: Retinoic acid and homeobox gene regulation. Curr Opin Genet Dev 1994, 4(4):550-555.

162. Langston AW, Gudas LJ: Identification of a retinoic acid responsive enhancer 3' of the murine homeobox gene Hox-1.6. Mech Dev 1992, 38(3):217-227.

163. Marshall H, Studer M, Popperl H, Aparicio S, Kuroiwa A, Brenner S, Krumlauf R: A conserved retinoic acid response element required for early expression of the homeobox gene Hoxb-1. Nature 1994, 370(6490):567-571.

164. Conlon RA, Rossant J: Exogenous retinoic acid rapidly induces anterior ectopic expression of murine Hox-2 genes in vivo. Development 1992, 116(2):357-368.

165. Du H, Daftary GS, Lalwani SI, Taylor HS: Direct regulation of HOXA10 by 1,25$(\mathrm{OH}) 2 \mathrm{D} 3$ in human myelomonocytic cells and human endometrial stromal cells. Molecular endocrinology 2005, 19(9):2222-2233.

166. Vigano P, Somigliana E, Chiodo I, Abbiati A, Vercellini P: Molecular mechanisms and biological plausibility underlying the malignant transformation of endometriosis: a critical analysis. Human reproduction update 2006, 12(1):77-89. 
167. Worley MJ, Welch WR, Berkowitz RS, Ng SW: Endometriosis-associated ovarian cancer: a review of pathogenesis. International journal of molecular sciences 2013, 14(3):5367-5379.

168. Hennessy BT, Coleman RL, Markman M: Ovarian cancer. Lancet 2009, 374(9698):1371-1382.

169. Cheng W, Liu J, Yoshida H, Rosen D, Naora H: Lineage infidelity of epithelial ovarian cancers is controlled by HOX genes that specify regional identity in the reproductive tract. Nature medicine 2005, 11(5):531-537.

170. Roby KF, Taylor CC, Sweetwood JP, Cheng Y, Pace JL, Tawfik O, Persons DL, Smith PG, Terranova PF: Development of a syngeneic mouse model for events related to ovarian cancer. Carcinogenesis 2000, 21(4):585-591.

171. Jiang Y, Chu Y, Tang W, Wan Y, Zhang L, Cheng W: Transcription factor WT1 and promoter CpG hypomethylation coactivate HOXA10 expression in ovarian cancer. Current pharmaceutical design 2014, 20(11):1647-1654.

172. Yamashita T, Tazawa S, Yawei Z, Katayama H, Kato Y, Nishiwaki K, Yokohama Y, Ishikawa M: Suppression of invasive characteristics by antisense introduction of overexpressed HOX genes in ovarian cancer cells. International journal of oncology 2006, 28(4):931-938.

173. Goode EL, Chenevix-Trench G, Song H, Ramus SJ, Notaridou M, Lawrenson K, Widschwendter M, Vierkant RA, Larson MC, Kjaer SK et al: A genome-wide association study identifies susceptibility loci for ovarian cancer at 2 q31 and 8q24. Nature genetics 2010, 42(10):874-879.

174. Ota T, Klausen C, Salamanca MC, Woo HL, Leung PC, Auersperg N: Expression and function of HOXA genes in normal and neoplastic ovarian epithelial cells.

Differentiation; research in biological diversity 2009, 77(2):162-171.

175. Klausen C, Leung PC, Auersperg N: Cell motility and spreading are suppressed by HOXA4 in ovarian cancer cells: possible involvement of beta1 integrin. Molecular cancer research : MCR 2009, 7(9):1425-1437.

176. Zhang X: THE EXPRESSION AND INVASION-SUPPRESSIVE FUNCTION OF HOXB4 IN EPITHELIAL OVARIAN CANCER. Vancouver, Canada: University of British Columbia; 2014.

177. Taylor HS, Igarashi P, Olive DL, Arici A: Sex steroids mediate HOXA11 expression in the human peri-implantation endometrium. The Journal of clinical endocrinology and metabolism 1999, 84(3):1129-1135.

178. Wu Y, Halverson G, Basir Z, Strawn E, Yan P, Guo SW: Aberrant methylation at HOXA10 may be responsible for its aberrant expression in the endometrium of patients with endometriosis. American journal of obstetrics and gynecology 2005, 193(2):371-380.

179. Zanatta A, Rocha AM, Carvalho FM, Pereira RM, Taylor HS, Motta EL, Baracat EC, Serafini PC: The role of the Hoxa10/HOXA10 gene in the etiology of endometriosis and its related infertility: a review. Journal of assisted reproduction and genetics 2010, 27(12):701-710.

180. Gaunt SJ, Krumlauf R, Duboule D: Mouse homeo-genes within a subfamily, Hox-1.4, $\mathbf{2 . 6}$ and $\mathbf{- 5 . 1}$, display similar anteroposterior domains of expression in the embryo, 
but show stage- and tissue-dependent differences in their regulation. Development 1989, 107(1):131-141.

181. Iacovino M, Hernandez C, Xu Z, Bajwa G, Prather M, Kyba M: A conserved role for Hox paralog group 4 in regulation of hematopoietic progenitors. Stem cells and development 2009, 18(5):783-792.

182. Jackson M, Axton RA, Taylor AH, Wilson JA, Gordon-Keylock SA, Kokkaliaris KD, Brickman JM, Schulz H, Hummel O, Hubner N et al: HOXB4 can enhance the differentiation of embryonic stem cells by modulating the hematopoietic niche. Stem cells 2012, 30(2):150-160.

183. Zhang XB, Beard BC, Trobridge GD, Wood BL, Sale GE, Sud R, Humphries RK, Kiem HP: High incidence of leukemia in large animals after stem cell gene therapy with a HOXB4-expressing retroviral vector. The Journal of clinical investigation 2008, 118(4):1502-1510.

184. Gao J, Mazella J, Tseng L: Hox proteins activate the IGFBP-1 promoter and suppress the function of hPR in human endometrial cells. DNA and cell biology 2002, 21(11):819-825.

185. Bedaiwy MA, Pope R, Henry D, Zanotti K, Mahajan S, Hurd W, Falcone T, Liu J: Standardization of laparoscopic pelvic examination: a proposal of a novel system. Minimally invasive surgery 2013, 2013:153235.

186. Noyes RW, Hertig AT, Rock J: Dating the Endometrial Biopsy. Fertility and sterility 1950, 1(1):3-25.

187. Fadare O, Zheng W: Histologic dating of the endometrium: accuracy, reproducibility, and practical value. Advances in anatomic pathology 2005, 12(2):3946.

188. Peng B, Zhu H, Leung PC: Gonadotropin-Releasing Hormone Regulates Human Trophoblastic Cell Invasion via TWIST-Induced N-cadherin Expression. The Journal of clinical endocrinology and metabolism 2015, 100(1):E19-29.

189. Turashvili G, Yang W, McKinney S, Kalloger S, Gale N, Ng Y, Chow K, Bell L, Lorette $\mathrm{J}$, Carrier $\mathrm{M}$ et al: Nucleic acid quantity and quality from paraffin blocks: defining optimal fixation, processing and DNA/RNA extraction techniques. Experimental and molecular pathology 2012, 92(1):33-43.

190. Sharpe-Timms KL, Ricke EA, Piva M, Horowitz GM: Differential expression and localization of de-novo synthesized endometriotic haptoglobin in endometrium and endometriotic lesions. Hum Reprod 2000, 15(10):2180-2185.

191. Browne H, Taylor H: HOXA10 expression in ectopic endometrial tissue. Fertility and sterility 2006, 85(5):1386-1390.

192. Horne AW, Lalani EN, Margara RA, White JO: The effects of sex steroid hormones and interleukin-1-beta on MUC1 expression in endometrial epithelial cell lines. Reproduction 2006, 131(4):733-742.

193. Tamm K, Room M, Salumets A, Metsis M: Genes targeted by the estrogen and progesterone receptors in the human endometrial cell lines HEC1A and RL95-2. Reproductive biology and endocrinology : $R B \& E$ 2009, 7:150.

194. Livak KJ, Schmittgen TD: Analysis of relative gene expression data using real-time quantitative PCR and the 2(-Delta Delta C(T)) Method. Methods 2001, 25(4):402408. 
195. Chariot A, Gielen J, Merville MP, Bours V: The homeodomain-containing proteins: an update on their interacting partners. Biochemical pharmacology 1999 , 58(12):1851-1857.

196. Davis AP, Capecchi MR: Axial homeosis and appendicular skeleton defects in mice with a targeted disruption of hoxd-11. Development 1994, 120(8):2187-2198.

197. Benson GV, Lim H, Paria BC, Satokata I, Dey SK, Maas RL: Mechanisms of reduced fertility in Hoxa-10 mutant mice: uterine homeosis and loss of maternal Hoxa-10 expression. Development 1996, 122(9):2687-2696.

198. Lim H, Ma L, Ma WG, Maas RL, Dey SK: Hoxa-10 regulates uterine stromal cell responsiveness to progesterone during implantation and decidualization in the mouse. Molecular endocrinology 1999, 13(6):1005-1017.

199. Taylor HS, Bagot $\mathrm{C}$, Kardana A, Olive $\mathrm{D}$, Arici A: HOX gene expression is altered in the endometrium of women with endometriosis. Hum Reprod 1999, 14(5):1328-1331.

200. Taylor HS: The role of HOX genes in human implantation. Human reproduction update 2000, 6(1):75-79.

201. Taylor HS: The role of HOX genes in the development and function of the female reproductive tract. Seminars in reproductive medicine 2000, 18(1):81-89.

202. Taylor HS: Transcriptional regulation of implantation by HOX genes. Reviews in endocrine \& metabolic disorders 2002, 3(2):127-132.

203. Taylor HS: Endocrine disruptors affect developmental programming of HOX gene expression. Fertility and sterility 2008, 89(2 Suppl):e57-58.

204. Horan GS, Kovacs EN, Behringer RR, Featherstone MS: Mutations in paralogous Hox genes result in overlapping homeotic transformations of the axial skeleton: evidence for unique and redundant function. Dev Biol 1995, 169(1):359-372.

205. Chen F, Capecchi MR: Paralogous mouse Hox genes, Hoxa9, Hoxb9, and Hoxd9, function together to control development of the mammary gland in response to pregnancy. Proceedings of the National Academy of Sciences of the United States of America 1999, 96(2):541-546.

206. Hever A, Roth RB, Hevezi P, Marin ME, Acosta JA, Acosta H, Rojas J, Herrera R, Grigoriadis D, White $\mathrm{E}$ et al: Human endometriosis is associated with plasma cells and overexpression of B lymphocyte stimulator. Proceedings of the National Academy of Sciences of the United States of America 2007, 104(30):12451-12456.

207. Barrett T, Wilhite SE, Ledoux P, Evangelista C, Kim IF, Tomashevsky M, Marshall KA, Phillippy KH, Sherman PM, Holko M et al: NCBI GEO: archive for functional genomics data sets--update. Nucleic acids research 2013, 41(Database issue):D991995.

208. Burney RO, Talbi S, Hamilton AE, Vo KC, Nyegaard M, Nezhat CR, Lessey BA, Giudice LC: Gene expression analysis of endometrium reveals progesterone resistance and candidate susceptibility genes in women with endometriosis. Endocrinology 2007, 148(8):3814-3826.

209. Mai KT, Yazdi HM, Perkins DG, Parks W: Pathogenetic role of the stromal cells in endometriosis and adenomyosis. Histopathology 1997, 30(5):430-442.

210. Clement PB: The pathology of endometriosis: a survey of the many faces of a common disease emphasizing diagnostic pitfalls and unusual and newly appreciated aspects. Advances in anatomic pathology 2007, 14(4):241-260. 
211. Coleman WB, Tsongalis GJ: Molecular Diagnostics: For the Clinical Laboratorian vol. 1, 2nd edn: Humana Press; 2012

212. Nadji M, Nassiri M, Vincek V, Kanhoush R, Morales AR: Immunohistochemistry of tissue prepared by a molecular-friendly fixation and processing system. Appl Immunohistochem Mol Morphol 2005, 13(3):277-282.

213. Nassiri M, Ramos S, Zohourian H, Vincek V, Morales AR, Nadji M: Preservation of biomolecules in breast cancer tissue by a formalin-free histology system. BMC Clin Pathol 2008, 8:1.

214. Howat WJ, Wilson BA: Tissue fixation and the effect of molecular fixatives on downstream staining procedures. Methods 2014, 70(1):12-19.

215. Dassen H, Punyadeera C, Kamps R, Delvoux B, Van Langendonckt A, Donnez J, Husen B, Thole H, Dunselman G, Groothuis P: Estrogen metabolizing enzymes in endometrium and endometriosis. Hum Reprod 2007, 22(12):3148-3158.

216. Bulun SE, Cheng YH, Pavone ME, Yin P, Imir G, Utsunomiya H, Thung S, Xue Q, Marsh EE, Tokunaga $\mathrm{H}$ et al: 17Beta-hydroxysteroid dehydrogenase-2 deficiency and progesterone resistance in endometriosis. Seminars in reproductive medicine 2010, 28(1):44-50.

217. Bulun SE, Cheng YH, Pavone ME, Xue Q, Attar E, Trukhacheva E, Tokunaga H, Utsunomiya $\mathrm{H}$, Yin $\mathrm{P}$, Luo X et al: Estrogen receptor-beta, estrogen receptor-alpha, and progesterone resistance in endometriosis. Seminars in reproductive medicine 2010, 28(1):36-43.

218. Mann RS, Lelli KM, Joshi R: Hox specificity unique roles for cofactors and collaborators. Current topics in developmental biology 2009, 88:63-101.

219. Sauvageau G, Thorsteinsdottir U, Eaves CJ, Lawrence HJ, Largman C, Lansdorp PM, Humphries RK: Overexpression of HOXB4 in hematopoietic cells causes the selective expansion of more primitive populations in vitro and in vivo. Genes \& development 1995, 9(14):1753-1765.

220. Lee J, Shieh JH, Zhang J, Liu L, Zhang Y, Eom JY, Morrone G, Moore MA, Zhou P: Improved ex vivo expansion of adult hematopoietic stem cells by overcoming CUL4mediated degradation of HOXB4. Blood 2013, 121(20):4082-4089.

221. Abrao MS, Neme RM, Carvalho FM, Aldrighi JM, Pinotti JA: Histological classification of endometriosis as a predictor of response to treatment. International journal of gynaecology and obstetrics: the official organ of the International Federation of Gynaecology and Obstetrics 2003, 82(1):31-40.

222. Kamergorodsky G, Ribeiro PA, Galvao MA, Abrao MS, Donadio N, Lemos NL, Aoki T: Histologic classification of specimens from women affected by superficial endometriosis, deeply infiltrating endometriosis, and ovarian endometriomas. Fertility and sterility 2009, 92(6):2074-2077.

223. Mills SE: Histology for Pathologists vol. 1, 4 edn: Wolters Kluwer; 2012.

224. Deligdisch L: Hormonal pathology of the endometrium. Modern pathology : an official journal of the United States and Canadian Academy of Pathology, Inc 2000, 13(3):285-294.

225. Eyster KM, Boles AL, Brannian JD, Hansen KA: DNA microarray analysis of gene expression markers of endometriosis. Fertility and sterility 2002, 77(1):38-42. 
226. Arimoto T, Katagiri T, Oda K, Tsunoda T, Yasugi T, Osuga Y, Yoshikawa H, Nishii O, Yano T, Taketani Y et al: Genome-wide cDNA microarray analysis of geneexpression profiles involved in ovarian endometriosis. International journal of oncology 2003, 22(3):551-560.

227. Kayis SA, Atli MO, Kurar E, Bozkaya F, Semacan A, Aslan S, Guzeloglu A: Rating of putative housekeeping genes for quantitative gene expression analysis in cyclic and early pregnant equine endometrium. Anim Reprod Sci 2011, 125(1-4):124-132.

228. Riesewijk A, Martin J, van Os R, Horcajadas JA, Polman J, Pellicer A, Mosselman S, Simon C: Gene expression profiling of human endometrial receptivity on days $\mathbf{L H}+2$ versus LH+7 by microarray technology. Molecular human reproduction 2003, 9(5):253-264.

229. Sadek KH, Cagampang FR, Bruce KD, Shreeve N, Macklon N, Cheong Y: Variation in stability of housekeeping genes in endometrium of healthy and polycystic ovarian syndrome women. Hum Reprod 2012, 27(1):251-256.

230. Chen J, Toghi Eshghi S, Bova GS, Li QK, Li X, Zhang H: Epithelium percentage estimation facilitates epithelial quantitative protein measurement in tissue specimens. Clin Proteomics 2013, 10(1):18.

231. Werner M, Chott A, Fabiano A, Battifora $\mathrm{H}$ : Effect of formalin tissue fixation and processing on immunohistochemistry. Am J Surg Pathol 2000, 24(7):1016-1019.

232. Masuda N, Ohnishi T, Kawamoto S, Monden M, Okubo K: Analysis of chemical modification of RNA from formalin-fixed samples and optimization of molecular biology applications for such samples. Nucleic acids research 1999, 27(22):4436-4443.

233. Macabeo-Ong M, Ginzinger DG, Dekker N, McMillan A, Regezi JA, Wong DT, Jordan $\mathrm{RC}$ : Effect of duration of fixation on quantitative reverse transcription polymerase chain reaction analyses. Modern pathology : an official journal of the United States and Canadian Academy of Pathology, Inc 2002, 15(9):979-987.

234. Kondi-Pafitis A: Pathological Aspects of Endometriosis. In: Endometriosis - Basic Concepts and Current Research Trends. edn. Edited by Chaudhury PK: InTech; 2012.

235. Sternberg SS, Mills SE, Carter D: Sternberg's diagnostic surgical pathology, 5th edn. Philadelphia: Wolters Kluwer Health/Lippincott Williams \& Wilkins; 2010.

236. Milne SA, Perchick GB, Boddy SC, Jabbour HN: Expression, localization, and signaling of PGE(2) and EP2/EP4 receptors in human nonpregnant endometrium across the menstrual cycle. The Journal of clinical endocrinology and metabolism 2001, 86(9):4453-4459.

237. Meller M, Vadachkoria S, Luthy DA, Williams MA: Evaluation of housekeeping genes in placental comparative expression studies. Placenta 2005, 26(8-9):601-607.

238. Cai J, Li T, Huang B, Cheng H, Ding H, Dong W, Xiao M, Liu L, Wang Z: The use of laser microdissection in the identification of suitable reference genes for normalization of quantitative real-time PCR in human FFPE epithelial ovarian tissue samples. PloS one 2014, 9(4):e95974.

239. Melfi FM, Lucchi M, Davini F, Viti A, Fontanini G, Boldrini L, Boni G, Mussi A: Intraoperative sentinel lymph node mapping in stage $I$ non-small cell lung cancer: detection of micrometastases by polymerase chain reaction. Eur J Cardiothorac Surg 2008, 34(1):181-186. 
240. Loy TS, Calaluce RD: Utility of cytokeratin immunostaining in separating pulmonary adenocarcinomas from colonic adenocarcinomas. Am J Clin Pathol 1994, 102(6):764-767.

241. Benlloch S, Galbis-Caravajal JM, Alenda C, Peiro FM, Sanchez-Ronco M, RodriguezPaniagua JM, Baschwitz B, Rojas E, Massuti B: Expression of molecular markers in mediastinal nodes from resected stage I non-small-cell lung cancer (NSCLC): prognostic impact and potential role as markers of occult micrometastases. Ann Oncol 2009, 20(1):91-97.

242. Chu P, Wu E, Weiss LM: Cytokeratin 7 and cytokeratin 20 expression in epithelial neoplasms: a survey of $\mathbf{4 3 5}$ cases. Modern pathology : an official journal of the United States and Canadian Academy of Pathology, Inc 2000, 13(9):962-972.

243. Xi L, Nicastri DG, El-Hefnawy T, Hughes SJ, Luketich JD, Godfrey TE: Optimal markers for real-time quantitative reverse transcription PCR detection of circulating tumor cells from melanoma, breast, colon, esophageal, head and neck, and lung cancers. Clinical chemistry 2007, 53(7):1206-1215.

244. Devriese LA, Bosma AJ, van de Heuvel MM, Heemsbergen W, Voest EE, Schellens JH: Circulating tumor cell detection in advanced non-small cell lung cancer patients by multi-marker QPCR analysis. Lung cancer 2012, 75(2):242-247.

245. Miettinen M FJ: Keratin 7 reactivity in endothelial cell. Appl Immunohistochem Mol Morphol 1997, 5:229-233.

246. Cakmak H, Taylor HS: Molecular mechanisms of treatment resistance in endometriosis: the role of progesterone-hox gene interactions. Seminars in reproductive medicine 2010, 28(1):69-74.

247. Brinton LA, Gridley G, Persson I, Baron J, Bergqvist A: Cancer risk after a hospital discharge diagnosis of endometriosis. American journal of obstetrics and gynecology 1997, 176(3):572-579.

248. McMeekin DS, Burger RA, Manetta A, DiSaia P, Berman ML: Endometrioid adenocarcinoma of the ovary and its relationship to endometriosis. Gynecologic oncology 1995, 59(1):81-86.

249. Orezzoli JP, Russell AH, Oliva E, Del Carmen MG, Eichhorn J, Fuller AF: Prognostic implication of endometriosis in clear cell carcinoma of the ovary. Gynecologic oncology 2008, 110(3):336-344.

250. Jemal A, Bray F, Center MM, Ferlay J, Ward E, Forman D: Global cancer statistics. $C A$ Cancer J Clin 2011, 61(2):69-90.

251. Chiang S, Soslow RA: Updates in diagnostic immunohistochemistry in endometrial carcinoma. Semin Diagn Pathol 2014, 31(3):205-215.

252. Hecht JL, Mutter GL: Molecular and pathologic aspects of endometrial carcinogenesis. Journal of clinical oncology : official journal of the American Society of Clinical Oncology 2006, 24(29):4783-4791.

253. Yoshida H, Broaddus R, Cheng W, Xie S, Naora H: Deregulation of the HOXA10 homeobox gene in endometrial carcinoma: role in epithelial-mesenchymal transition. Cancer research 2006, 66(2):889-897.

254. Whitcomb BP, Mutch DG, Herzog TJ, Rader JS, Gibb RK, Goodfellow PJ: Frequent HOXA11 and THBS2 promoter methylation, and a methylator phenotype in 
endometrial adenocarcinoma. Clinical cancer research : an official journal of the American Association for Cancer Research 2003, 9(6):2277-2287.

255. Zhao Y, Yamashita T, Ishikawa M: Regulation of tumor invasion by HOXB13 gene overexpressed in human endometrial cancer. Oncology reports 2005, 13(4):721-726.

256. Hannan NJ, Paiva P, Dimitriadis E, Salamonsen LA: Models for study of human embryo implantation: choice of cell lines? Biology of reproduction 2010, 82(2):235245.

257. Theisen ER, Gajiwala S, Bearss J, Sorna V, Sharma S, Janat-Amsbury M: Reversible inhibition of lysine specific demethylase 1 is a novel anti-tumor strategy for poorly differentiated endometrial carcinoma. BMC cancer 2014, 14:752.

258. Weigelt B, Warne PH, Lambros MB, Reis-Filho JS, Downward J: PI3K pathway dependencies in endometrioid endometrial cancer cell lines. Clinical cancer research : an official journal of the American Association for Cancer Research 2013, 19(13):3533-3544. 


\section{Appendices}

\section{APPENDIX A: HOXB4 Expression and Function in Endometrial Cancer Cell Lines}

\section{A.1 Rationale}

Endometrial cancer is the most common gynecologic malignancy in the developed countries [250]. In the last few years, the overall incident and mortality rate has increased the incidence rate has increased. The most common subtype is estrogen-related endometrioid uterine cancer (up to $80 \%$ ) with the most favorable prognosis. Other uncommon subtypes with poor prognosis are mucinous, clear cell, serous, squamous, and undifferentiated. Women suffering from this malignancy may present with abnormal uterine bleeding.

Endometrioid endometrial carcinomas are usually well-differentiated. They form new glands. Histopathologic staining panels are used to distinguish the different morphologies among endometrial cancer subtypes. Chiang et all demonstrated the loss of phosphatase and tensin homolog (PTEN) and AT-rich interactive domain-containing protein 1A (ARID $1 \mathrm{~A})$ proteins expression in endometrioid subtype [251]. Grading these tumours is based on the combination of nuclear availability grade percent and gland formation. Multiple mutations has been identified in endometrioid endometrial cancer tissues as PTEN, K-RAS, and beta-catenin genes has been characterised in this subtype [252].

Members of HOX genes were found to be regulating motility and endometrial cancer cell invasion. Most HOX genes were found to play a suppressive effect in endometrial cancer cells. HOXA10 expression correlated negatively to the invasiveness of endometrial cancer [253]. Moreover, in early stages of endometrial cancer, HOXA11 hypermethilation correlated to poor outcome [254]. On the other hand, Zhao et al. found that HOXB13 was overexpressed in 
endometrial cancer cells. The invasiveness of these cells was induced by the 17 beta-estradiol and responded in both time- and dose-dependent manner [255].

Geo et al showed by northern blot that glandular endometrial epithelial cells HOXB4 mRNA levels were sensitive to treatment with 17 $\beta$-estradiol (E2) and methylprogesterone acetate (MPA) [184]. Although not a perfect model, an alternative is to use endometrioid endometrial cancer cell lines as a model for normal glandular epithelia since these tumors are of endometrial epithelial origin. To this end, I performed western blot for HOXB4 with protein lysates from six different endometrial cancer cell lines generously provided by Dr. Peter Leung's lab (HEC1A and HEC1B, human endometrioid endometrial cancer of endometrial glandular cell origin; HEC50, poorly differentiated human endometrial glandular cell representative of type II endometrioid endometrial cancer; and KLE, poorly differentiated human endometrial glandular cell representative of type II endometrioid endometrial cancer; RL952, moderately differentiated human adenosquamous; AN3CA, poorly differentiated human endometrial glandular cell representative of type II endometrioid endometrial cancer [256-258].

\section{A.2 Expression of Hoxb4 in Endometrial Cancer Cells}

Western blot preliminary analysis showed high HOXB4 protein levels in HEC1B, HEC50 and AN3CA cells, moderate levels in RL952 cells, and reduced levels in HEC1A and KLE cells (Figure A.1). Both HEC1B HEC50 cells show relatively higher HOXB4 expression when compared to the other 4 cells. 


\section{A.3 Effect of Estrogen Treatment on Hoxb4 Expression in Endometrial Cancer Cells}

To further identify the effect of estrogen (E2) on the expression of HOXB4 in endometrioid endometrial cancer cells, HEC1A and HEC1B cells were treated with estrogen as described in section 2.5. E2 does not stimulate HOXB4 expression in HEC1A (Figure A.2) and HEC1B (Figure A.3). Moreover, when both cell lines were treated with E2 and/or its antagonist (Fulvestrant), HOXB4 expression was not affected in both HEC1A and HEC1B (Figure A.4). 

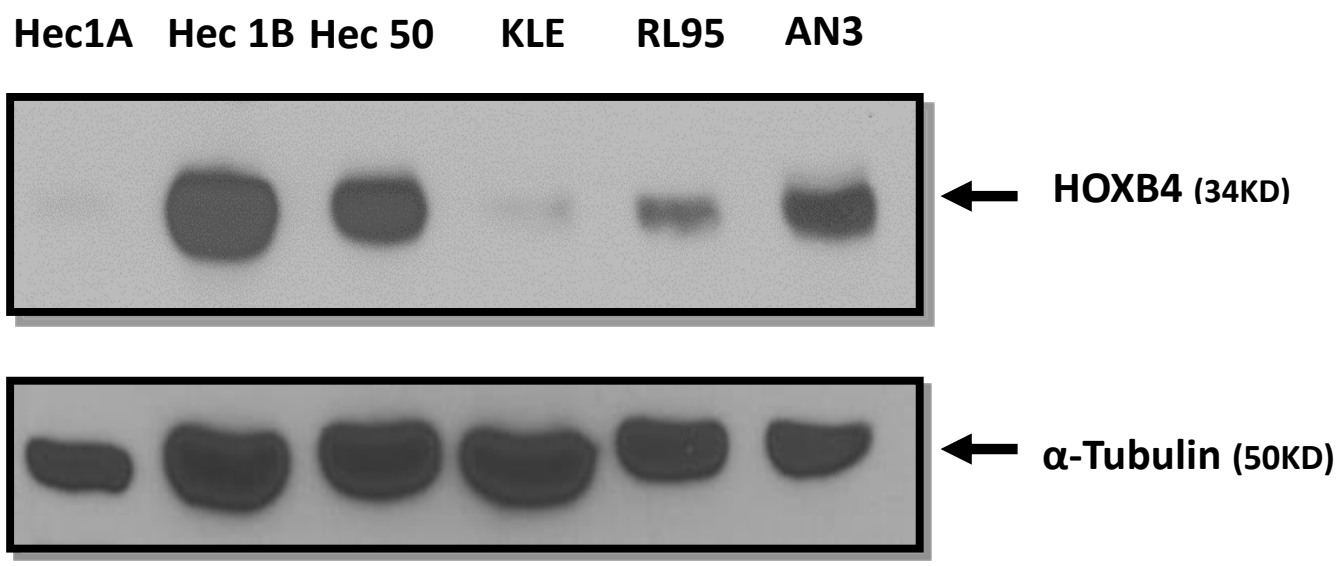

Figure A.1: The expression of HOXB4 in endometrial cancer cells

Western blot analysis showed HOXB4 protein levels endometrial cancer cell lines (Hec1B, Hec50 and AN3). 

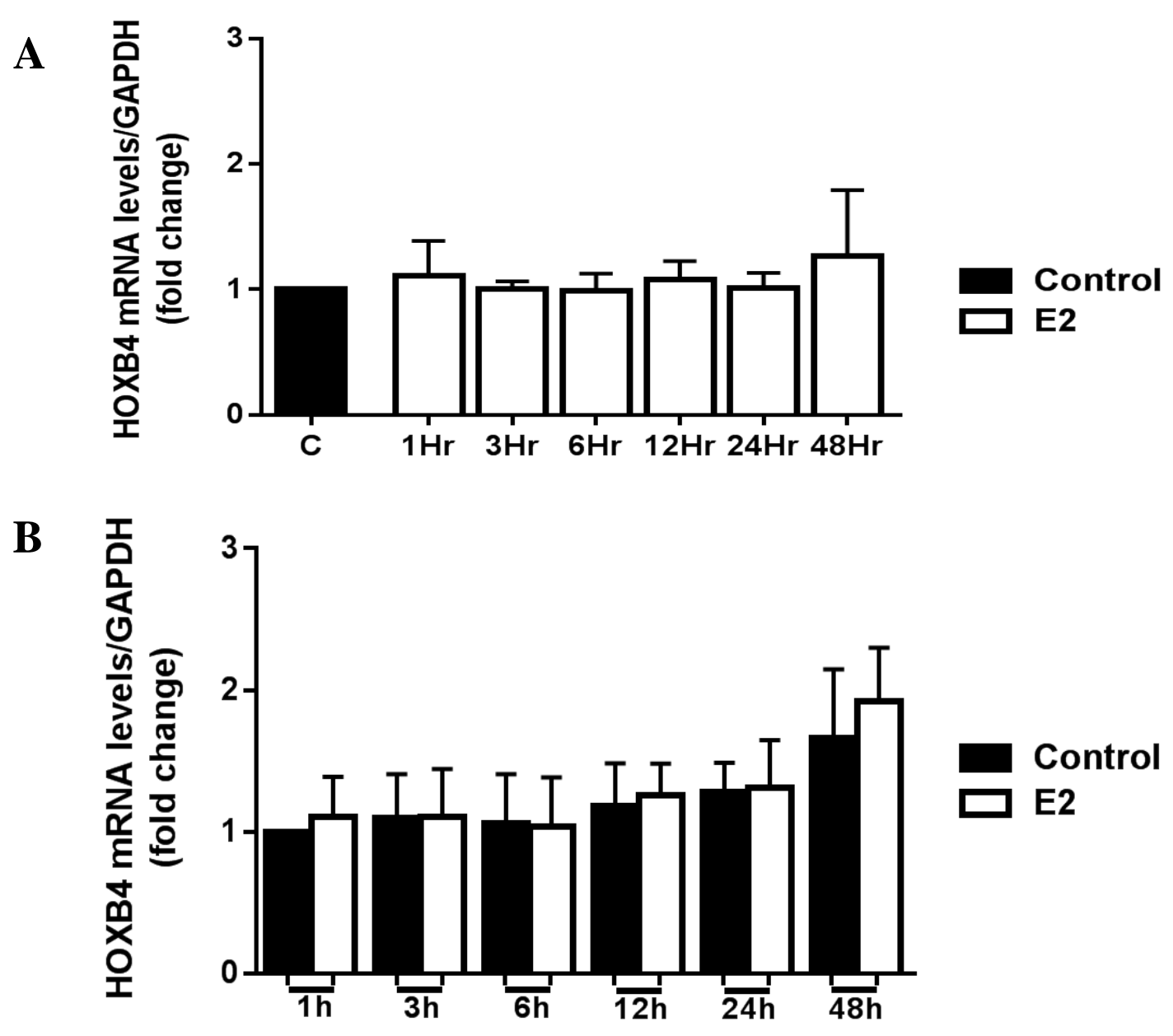

Figure A.2: E2 does not stimulate HOXB4 expression in HEC1A cells with different incubation periods

HEC1A cells were incubated in charcoal filtered FBS and treated with $10^{-8} \mathrm{M}$ estradiol and cells were collected $1 \mathrm{~h}, 3 \mathrm{~h}, 6 \mathrm{~h}, 12 \mathrm{~h}, 24 \mathrm{~h}, 48 \mathrm{~h}$ after treatment The HOXB4 mRNA levels were normalized to GAPDH and compared to either $(\mathbf{A})$ each time point control or $(\mathbf{B}) 1 \mathrm{~h}$ control. This experiment was repeated 4 times. 

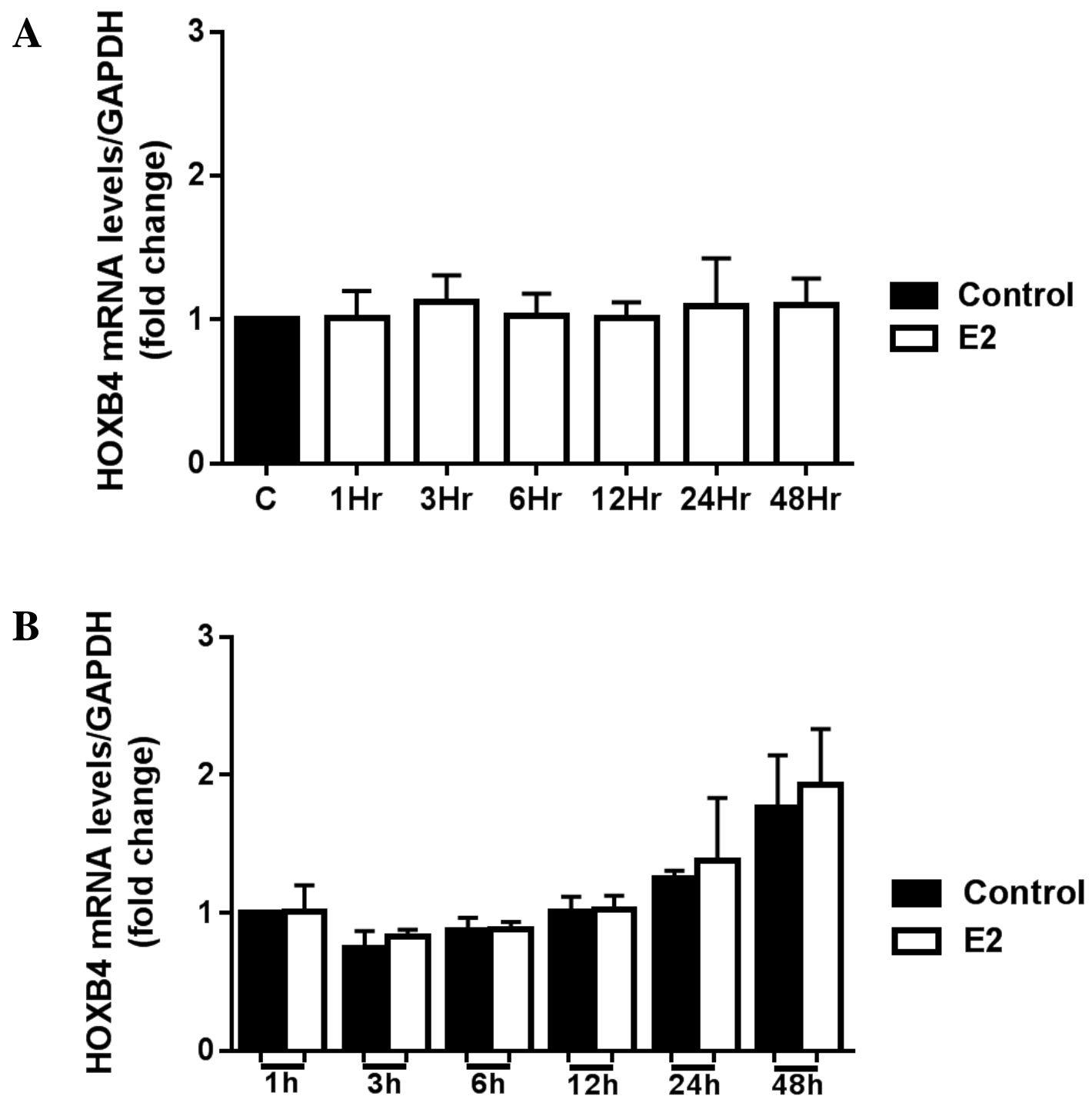

Figure A.3: E2 does not stimulate HOXB4 expression in HEC1B cells with different incubation periods

HEC1B cells were incubated in charcoal filtered FBS and treated with $10^{-8} \mathrm{M}$ estradiol and cells were collected $1 \mathrm{~h}, 3 \mathrm{~h}, 6 \mathrm{~h}, 12 \mathrm{~h}, 24 \mathrm{~h}, 48 \mathrm{~h}$ after treatment The HOXB4 mRNA levels were normalized to GAPDH and compared to either (A) each time point control or (B) $1 \mathrm{~h}$ control. This experiment was repeated 4 times. 

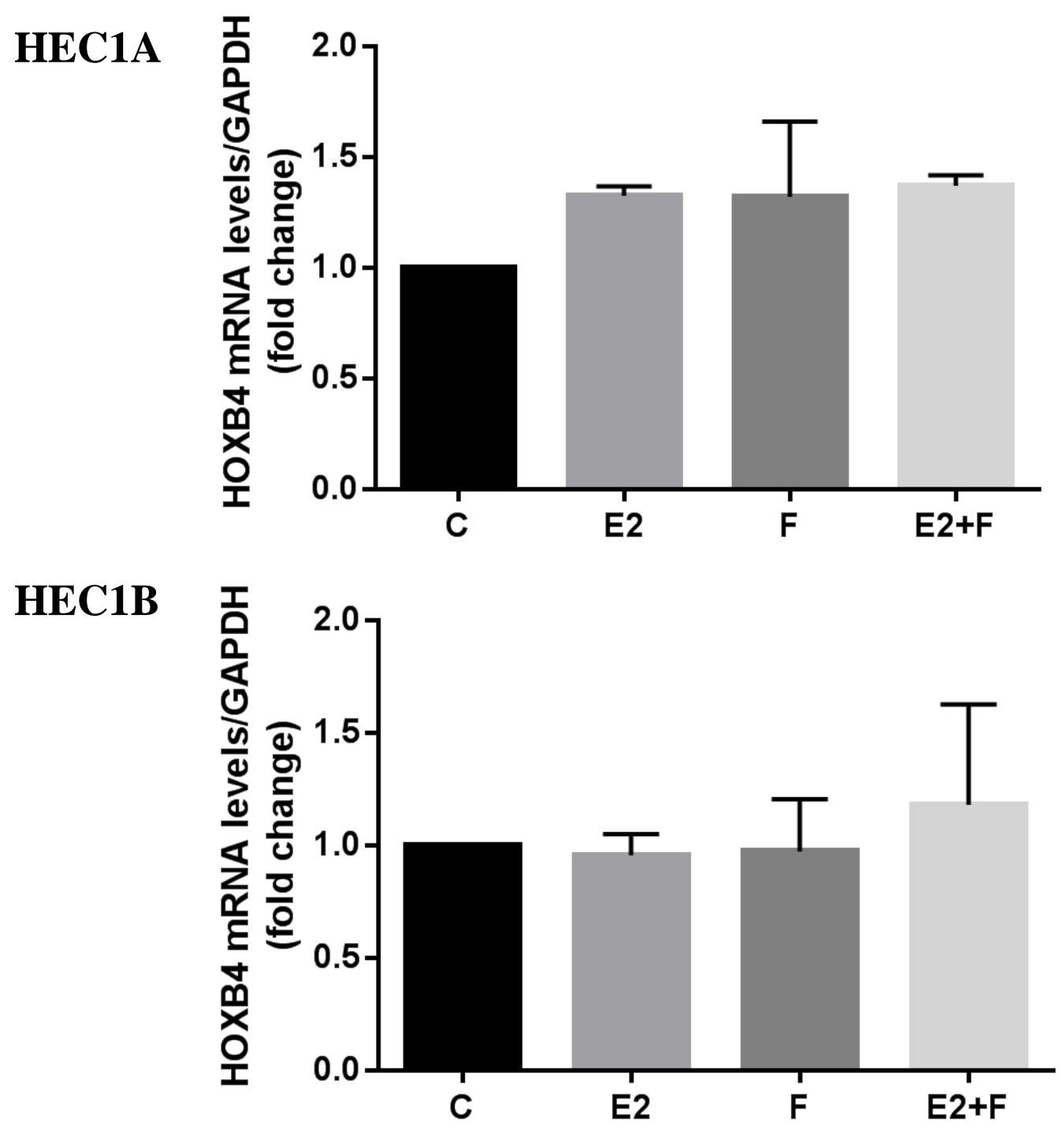

Figure A.4: E2 and its antagonist don't have an effect on HOXB4 expression in both HEC1A and HEC1B

HEC1A and B cells were incubated in charcoal filtered FBS and treated with $0.01 \mu \mathrm{M}$ of Estradiol and $0.1 \mu \mathrm{M}$ Fulvestrant for (A) $48 \mathrm{~h}$ in HEC1A and (B) 24h in HEC1B. The HOXB4 mRNA levels were normalized to GAPDH. This experiment was repeated 2 times. No significant effect was seen in either cell lines. 


\section{Appendix B: Hoxb4 Expression in Normal Endometrium and Endometrioma from the Gene}

\section{Expression Omnibus (Geo) Microarray Database}

Profile GDS2835/231767_at / HOXB4

Title Ovarian endometriosis

Organism Homo sapiens

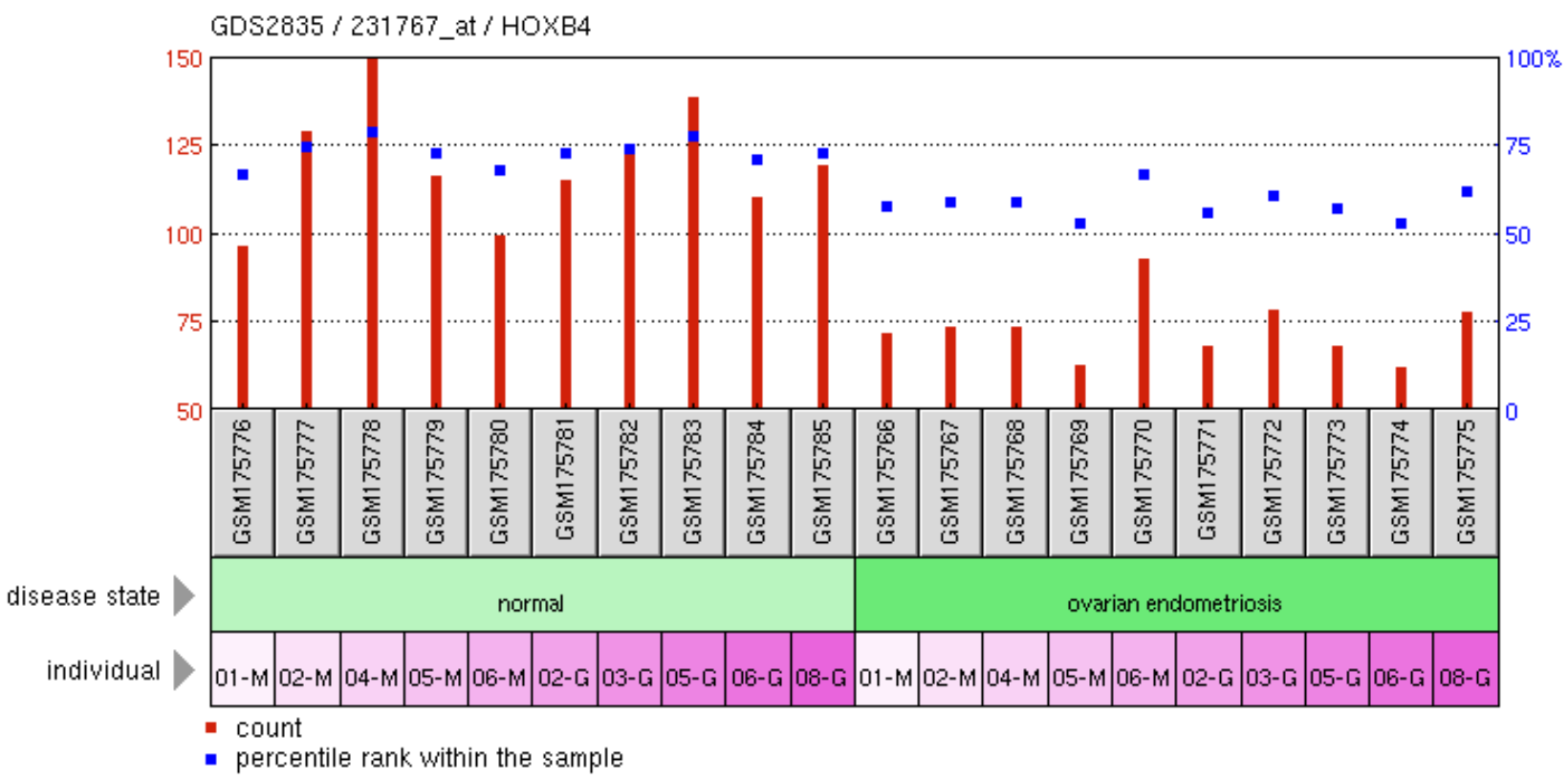

Figure B.1: HOXB4 expression in normal endometrium and endometrioma from the Gene Expression Omnibus (GEO) microarray database.

Comparison of endometriosis lesions $(n=10)$ to normal endometrial tissues $(n=10)$ obtained from the same patient at the same time by HOXB4 expression profiling array.

Platform: GPL570 Series: GSE730520 Samples

Download data: GEO (CEL)

DataSetAccession: GDS2835ID: 2835 [206]. 


\section{Appendix C: Hoxb4 Expression in Normal Endometrium and Endometriosis from the Gene Expression Omnibus (Geo) Microarray Database}

Profile GDS2737 / 231767_at / HOXB4

Title Endometriosis

Organism Homo sapiens

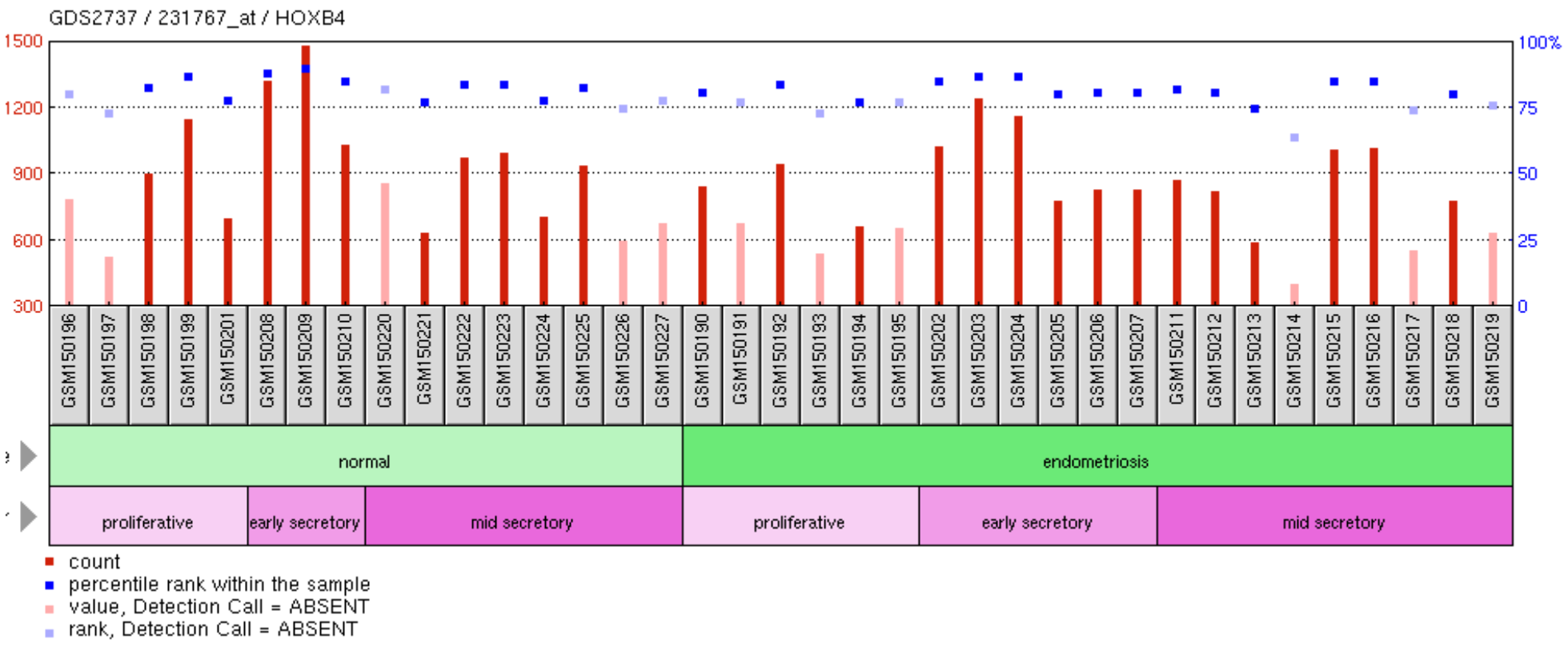

Figure C.1: HOXB4 expression in normal endometrium and endometriosis from the Gene Expression Omnibus (GEO) microarray database:

Analysis of endometrial specimens from women with endometriosis $(n=21)$ compared with normal endometrium $(\mathrm{n}=16)$. Endometrial gene expression examined at various phases of the menstrual cycle.

Results provide insight into the molecular pathogenesis of endometriosis.

Platform: GPL570 Series: GSE636437 Samples

Download data: GEO (CEL)

DataSetAccession: GDS2737ID: 2737 [208]. 